
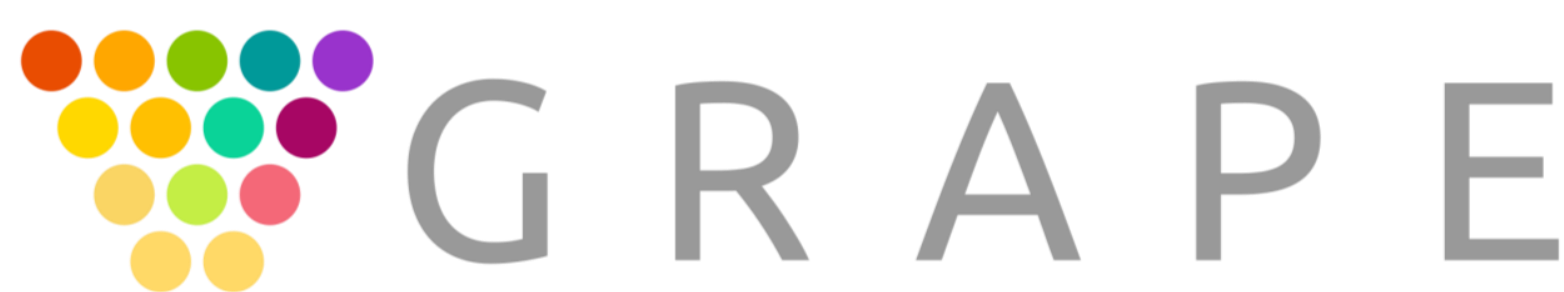

Group for Research in APplied Economics

GRAPE Working Paper \# 16

Striking a balance: optimal tax policy with labor market duality

Gilbert Mbara, Ryszard Kokoszczynski, Joanna Tyrowicz

Foundation of Admirers and Mavens of Economics

Group for Research in Applied Economics 


\title{
Striking a balance: optimal tax policy with labor market duality
}

\author{
Gilbert Mbara \\ FAME|GRAPE
}

\author{
Ryszard Kokoszczynski \\ University of Warsaw \\ National Bank of Poland
}

\author{
Joanna Tyrowicz \\ FAME|GRAPE \\ University of Warsaw
}

\begin{abstract}
We develop a dynamic general equilibrium model in which firms may evade the employer contribution component of social security taxes by offering some workers "secondary contracts". When calibrated, the model yields estimates of secondary labor market participation consistent with empirical evidence for the EU14 countries and the US. We investigate the optimal mix of the avoidable and unavoidable components of labor taxes and analyze the fiscal and macroeconomic effects of bringing the composition to the welfare optimum. We find that partial labor tax evasion makes tax revenues more elastic, but full tax compliance need not be a welfare enhancing policy mix.
\end{abstract}

Keywords:

Laffer curve, tax evasion, labor market duality

JEL Classification

H2, H26, H3, E13, E26, J81

Corresponding author

Jan Hagemejer, j.hagemejer@uw.edu.pl

\section{Acknowledgements}

Authors are grateful for comments to Jakub Growiec, Marcin Kacperczyk, Anna Orlik, Carlos Serrano, Karsten Staehr, Harald Uhlig, Jan Werner, Krzysztof Makarski, Jan Hagemejer, Pawel Zabczyk and participants of NBP Summer Macroeconomic Workshop 2016, Warsaw International Economic Meeting 2016. The support of National Science Centre grant UMO2014/13/B/HS4/00394 is gratefully acknowledged. All opinions expressed are those of the authors and have not been endorsed by NSC nor NBP. The remaining errors are ours.

Published by: $\quad$ FAME | GRAPE

ISSN: 2544-2473

(c) with the authors, 2017 


\section{Introduction and motivation}

Economies differ substantially in how they finance social benefits. Some countries rely on general taxes, others on universal labor taxes with little or no earmarking for social benefits. However, in many countries dedicated social security contributions constitute a large share in the overall taxes levied on labor income. Many countries also define labor market duality in terms of the social security and job protection benefits received by workers. When jobs are differentiated on the basis of whether the work is fully taxed (receiving full social security and job protection benefits) or if it "enjoys" exemption from some labor taxes (but at the cost of weak or non-existent social and employment protection), the labor market is dual (see Merz and Wolff 1993, Bergolo and Cruces 2014, Di Caro and Nicotra 2015, Flórez and Perales 2015).

The optimal labor tax has traditionally been at the core of both theoretical and policy motivated public economics (e.g. Diamond and Mirrlees 1971a,b, Mirrlees 1971, Atkinson and Stiglitz 1976). ${ }^{1}$ The scope for potential tax evasion makes the question of the optimal tax mix even more pertinent. If some components of the labor tax wedge are more susceptible to evasion, the question for a policy maker changes from the deciding about the absolute level of labor taxes to deciding about the proportion of avoidable and unavoidable taxes in total labor tax wedge. Indeed, facing economic entities with an incentive to evade part of the tax obligation, policy-makers need to decide, for each overall tax level, what is the optimal tax mix. While the literature has mostly focused on the optimal level of taxation in the presence of tax avoidance - cf. overview by Slemrod and Yitzhaki (2002) - our objective is to shed some light on the role of the form or structure in which labor is taxed. ${ }^{2}$

Even among developed economies - fairly similar in income levels, employment structure and tax auditing technology - there are striking differences in how labor is taxed, see Figure 1. In addition to the extensively analyzed tax wedge, these economies also differ in how the total wedge is split between the labor tax and social security contributions. Notably, in many countries the social security contributions borne by the employer substantially exceed the labor income tax. This suggests that the incentives to avoid social security contributions are actually strong - and possibly stronger on the side of employers than workers in those countries.

While the separation of social security contributions and labor taxes is of fundamental relevance to labor market duality and unregistered employment, it has so far remained rarely analyzed in public economics. Depending on a variety of institutional factors as well as bargaining power, employers may reduce social security coverage of some workers. Depending on the legal framework in a given country, this phenomenon may be manifested in forced self-employment, unregistered employment or atypical contracts (e.g. contracts outside labor legislation). Empirical research on these secondary contracts is typically constrained by the lack of adequate data and disparate definitions of what constitutes "secondary" across countries. Consequently, the empirical research in the field has focused to some degree on other related issues, such as the effects of benefits and insurance on registered employment (e.g. Krueger and Meyer 2002, Bergolo and Cruces 2014),

\footnotetext{
${ }^{1}$ See Piketty and Saez (2013) of a recent review of the theoretical insights and relevant empirical contributions.

${ }^{2}$ On the choice between reporting income and concealing it see literature started by Allingham and Sandmo (1972) and the recent review by Sandmo (2005).
} 
Figure 1: Labor taxes and social security contributions in the OECD

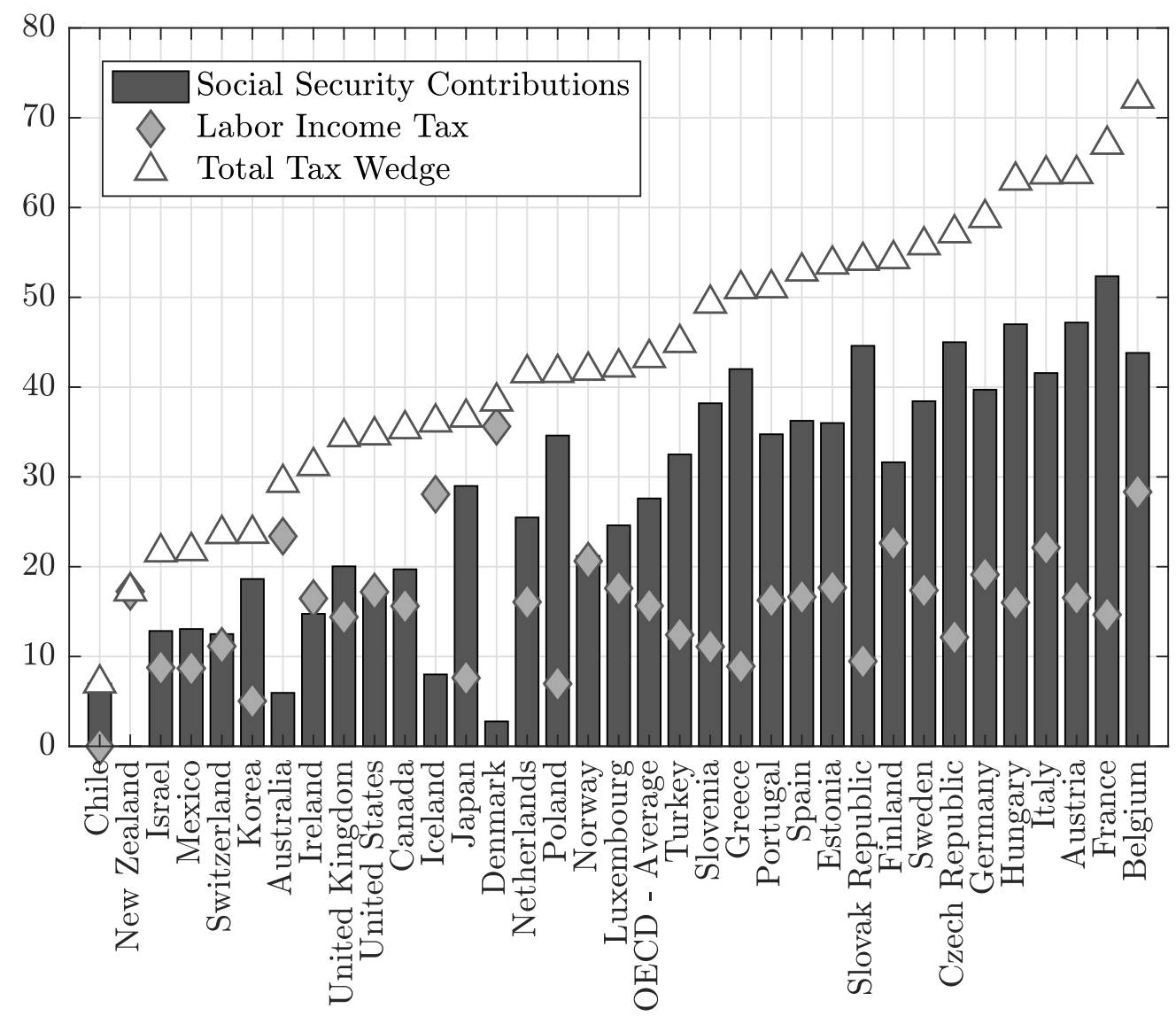

Data source: OECD. Figures for 2014, single earner households, no children at $100 \%$ of average earnings.

reported earned income (e.g. Stavrunova and Yerokhin 2014) or other work incentives (e.g. Tonin 2011, Pickhardt and Prinz 2014, Hilton et al. 2014). The analysis of actual secondary contracts remains rare and conditional on the availability of exceptional measures (cf. Slemrod and Weber 2012).

The problem of secondary contracts is closely linked to what the labor economics literature refers to as labor market duality. For example, in some countries "non-employment" contracts may be more frequent due to higher incidence of tax evasion by firms, while in some others a relatively high incidence of "non-standard" employment may reflect features of the production or industrial structure (Cappariello and Zizza 2010). Adequate measures are a problem here as well because not all non-standard employment implies labor market duality - for the labor market to be dual, atypical employment needs to be involuntary on the part of workers, which generally remains unobservable within and across countries. ${ }^{3}$ Despite being unobservable, this issue is at the heart of

\footnotetext{
${ }^{3}$ OECD reports statistics for involuntary part-time employment, but this refers to a standard employment contract only in reduced hours rather than atypical forms of employment contracts.
} 
the contemporaneous tripartite dialog between the employers (in search for flexibility) employees (expecting equality and social insurance) and the government in most of the advanced economies.

Given the constraints of data unavailability and the paramount policy relevance, the literature has grown in roughly three directions. First, there is a variety of measures for the size of informal economy and unregistered employment. Following Schneider and Enste (2000), in addition to selfreported questionnaires, a number of approaches have been developed to obtain internationally comparable objective estimates of the incidence of the undeclared work (e.g. Schneider 2011, Williams 2013). Second, a strand of the literature employs time-series or a natural experiment to estimate the size of the informal sector in one or a selected group of countries. In addition to the usually large literature on the United States, these studies are also common for Latin America (e.g. Rakowski 1994, Loayza 1996, Loayza et al. 2005, Alanon and Gomez-Antonio 2005, Castillo and Montoro 2010, Schneider and Hametner 2014), Italy (e.g. Castellucci and Bovi 1999, Dell'Anno 2003, Ardizzi et al. 2014, Di Caro and Nicotra 2015) and Germany (e.g. Merz and Wolff 1993, Pickhardt and Sardà Pons 2006). ${ }^{4}$ The third strand of the literature usually develops general equilibrium models, carefully calibrated to the case of a given country, to provide insights on the available policy alternatives. Again in this case, literature on Italy is especially rich (e.g. Busato et al. 2011, 2012, Busato and Chiarini 2013, Orsi et al. 2014, Bernasconi et al. 2015, Pappa et al. 2015).

Micro-founded studies have an important advantage, particularity in their ability to deliver insights on the probable outcomes of counter-factual scenarios. General equilibrium macroeconomic models have already been used to demonstrate that tax rates in the EU are closer to the peak of maximum tax revenue in comparison to the United States (Trabandt and Uhlig 2011) and that reducing tax rates while increasing tax auditing is likely to bring increase in fiscal revenues in Italy (Orsi et al. 2014). Our paper falls into this category of micro-founded general equilibrium models but is different in three important ways. First, we allow for both avoidable and unavoidable components of labor income taxation. The avoidable part is firms' social security contributions. Firms decide whether to evade social security contributions through the contracts they offer to their workers. The decision on how much social security taxes to pay is analogous to the choice of labor (worker types). Second, our model is a generalized version of Trabandt and Uhlig (2011) as it yields exactly the same results when there is no tax evasion. Consequently, it may inform policy debate about the effective revenue effects of fiscal consolidation actions, such as changing tax rates or tax compositions. Finally, our model yields as equilibrium outcomes implied levels of tax evasion and unregistered employment, conditional on the calibrated efficiency of tax avoidance detection and tax structure. Thus, we are able to identify changes in unregistered employment that arise purely from the structure of labor income taxation.

We contribute to the literature in three ways. First, we provide a set of theory-driven reference estimates for the size of dual labor markets. To this end, we design a dynamic general equilibrium model, in the spirit of Trabandt and Uhlig (2011) and Busato and Chiarini (2013). We calibrate our model to replicate the features of 14 European Union countries and the United States and

\footnotetext{
${ }^{4}$ Schneider (2014) provides an extensive characterization of the literature in this field. See also Breusch (2005) for a critique on Schneider's method of estimating the shadow economy.
} 
solve it for the implied size of unregistered employment. Our second contribution is to explicitly address the differences in the scope for tax avoidance between the workers and employers. In our economy, employers may avoid paying social security contributions, but workers cannot avoid paying labor income tax. This innovation in the model economy is enough to generate plausible estimates of the incidence of social security tax evasion by employers and the share of workers under atypical contracts. We also compute model implied measures of the labor market duality. In comparison to empirical estimates for the available countries, our estimates are smaller, because in our setting only taxes levied on labor may be avoided. Yet, this is enough to generate substantially more elasticity between the tax rate and the tax revenues than in a standard framework. Third, we inquire the optimal policy mix, topping fiscal considerations with analyzing the welfare effects along the transition from the status quo.

We find that most advanced economies are characterized by suboptimal proportion between avoidable and unavoidable labor taxes. Our general finding is that welfare could be improved with increasing tax revenues. We also find that under tax evasion, Laffer curves tend to be more elastic with respect to the overall tax rate and peak at a higher tax rate that commonly found in the literature. Insights from our model also show that the composition effects in terms of avoidable and unavoidable taxes have a non-negligible magnitude from both a fiscal and a welfare perspective.

There are two important policy implications of our study. First, we show that there is room for improving welfare and increasing tax revenue by changing the composition between avoidable and unavoidable labor taxes in most advanced economies. Second, we show that the transition from the status quo to the optimal structure of labor taxes is not likely to be costly in terms of transitory loss in tax revenue. Our results are obtained in a dynamic general equilibrium framework, but do not account for the fact that in some countries part of the social security contributions may be considered an implicit subsidy for old-age consumption. Although this is clearly a limitation of our approach, empirical evidence favoring such perception of social security contributions is in many cases rather weak (Lusardi and Mitchell 2011).

The remainder of the paper is structured as follows. The next section presents our theoretical model. In section 3 we discuss in detail how the model is solved and calibrated to replicate the steady-state features of the EU-14 and United States economies. We present results in section 4. Conclusions and policy implications are presented in the final section.

\section{The model}

We consider a standard neoclassical model of an economy that produces a single good used for both consumption and investment. The economy consists of many firms who combine capital and labor. The good is sold by firms to a continuum of measure 1 identical households. Households own the economy's stock of capital which they rent to firms and also supply labor services. There is a government that levies taxes on households' income and consumption to finance its expenditure on goods and lump-sum transfers. Taxes levied by the government include a proportional tax on labor income to be paid by households and a social security contribution to be made by firms.

We assume labor market to be dual: there is primary market, where workers receive full coverage 
by the social security and a secondary market, where social security protection is not provided by the employer. The government may identify such cases, but faces limited enforcement capacity in the collection of social security contributions, that is, firms have an incentive to employing in both markets. Firms do not conceal output. For avoiding social security contributions firms face a non-negligible probability of detection and a penalty.

\subsection{Production}

Time is discrete and is omitted for brevity. The economy has a representative, perfectly competitive enterprise sector. Firms combine capital $(k)$ and labor $(n)$ to produce output using the production function:

$$
\begin{aligned}
& y=A k^{\alpha} n^{1-\alpha}, \\
& n=\left((1-\omega) n_{P}^{\rho}+\omega n_{S}^{\rho}\right)^{\frac{1}{\rho}},
\end{aligned}
$$

where $A$ denotes exogenous technological progress, $n$ is a CES aggregator of labor where social security contributions are unavoidable (abbreviated to primary market, $P$ ) and labor where social security contributions are avoidable (abbreviated to secondary, $S$ ). The elasticity of substitution $\sigma$, between labor from primary and secondary market, is defined by the parameter $\rho$ through the relation $\sigma=\frac{1}{1-\rho} \cdot{ }^{5}$ Hence the extent of labor market duality from the production function is given by $\omega=\frac{n_{S}}{n}$.

Labor is taxed in two forms. Workers pay labor income tax $\tau^{n}$ and employers pay social security contributions $\tau^{s}$. This split replicates the features of many advanced economies. Labor income tax cannot be evaded by workers, whereas social security contributions may be evaded by the firms. Employers face an exogenous probability $p$ of being inspected for evading social security contributions. Firms evade social security contributions by offering workers secondary - nonstandard or atypical - contracts that do not provide the full social benefits of formal employment. This feature of the model replicates the institutional design in many advanced economies. Our motivation is that social security contributions by the employer are a direct cost and firms have an incentive to evade this cost. In a sense, this feature of the model design implies that there is no fully unregistered employment, but an extension to include household labor income tax avoidance is straight forward ${ }^{6}$ If a firm evades social security contributions, it employs a non-zero share of workers on secondary contracts. With an exogenous probability $p$ of being audited and detected for using unregistered labor, it pays a surcharge $s<1$ on evaded social security obligations.

Denote profits when a firm is detected for using unregistered labor by $\pi^{D}$ and when not detected

\footnotetext{
${ }^{5}$ Note, that if the two types of labor are identical, as is perfectly feasible in our setup, they become perfect substitutes in the production function.

${ }^{6}$ See Busato et al. (2012) for an example of such an approach. Typically, the fully informal sector uses no capital input. It makes the theoretical treatment suitable for some forms of secondariness, but not others. It appears that in many advanced economies secondary contracts are associated with a relatively strong bargaining position of a regular, formal employer vis-a-vis some groups of workers in combination with relatively weak enforcement (Williams 2015). Hence, eliminating capital-labor complementarity may not be the most appropriate way to replicate features from the real world in a model.
} 
by $\pi^{N D}$. Denote the user cost of capital by $d$ and the wage paid to workers by $w_{i}, i=\{P, S\}$. Then the firm's expected profit $\pi^{e}$ is given by:

$$
\begin{aligned}
\pi^{e} & =p \pi^{D}+(1-p) \pi^{N D} \\
& =y-d k-\left(1+\tau^{s}\right) w_{P} n_{P}-\left(1+p \bar{s} \tau^{s}\right) w_{S} n_{S}
\end{aligned}
$$

where $\bar{s} \tau^{s} w_{S} n_{S}$ is the penalty on avoided social security contributions which includes the amount owed $\tau^{s} w_{S} n_{S}$ and a surcharge $s w_{S} n_{S}$ so that $\bar{s}=1+s$. For brevity, wages are considered in quasinet terms: gross wage is the wage paid to the worker augmented by social security contributions and net wage is the wage paid to the worker less the labor income tax.

The firm chooses $\left\{k, n_{P}, n_{S}\right\}$ to maximize profits.

\subsection{Households}

A representative household consumes, owns capital used by firms and supplies labor. The household pays labor and capital income taxes. There is no auditing of household tax filings, i.e. households do not have technology to engage in tax evasion. The representative household has utility function:

$$
U\left(c, l\left(n_{P}, n_{S}\right)\right)=\frac{1}{1-\eta}\left(c^{1-\eta}\left(1-\kappa(1-\eta)\left(n_{P}+\phi n_{S}\right)^{1+\frac{1}{\varphi}}\right)^{\eta}-1\right)
$$

where $l=1-n_{P}-n_{S}$. The parameter $\phi$ captures the difference in disutilities from the two types of contracts: primary and secondary. In the utility function, $\eta$ is the inverse of inter-temporal elasticity of substitution, $\varphi$ is Frisch's elasticity of labor supply and $\kappa$ is the weight of labor. ${ }^{7}$ The household faces the budget constraint:

$$
\begin{aligned}
& \left(1+\tau^{c}\right) c+b+x=\left(1-\tau^{n}\right) w_{P} n_{P}+\left(1-\tau^{n}\right) w_{S} n_{S} \quad \Leftrightarrow \text { labor income } \\
& +\pi^{e}+\left(1-\tau^{k}\right)(d-\delta) k_{-1}+\delta k_{-1} \quad \Leftrightarrow \text { capital income } \\
& +R^{b} b_{-1}+s+m \quad \Leftrightarrow \text { interest, transfers and trade }
\end{aligned}
$$

with $\tau^{c}$ denoting tax on consumption $c, b$ denoting new public debt and $x=k-(1-\delta) k_{-1}$ denoting investment in capital stock $k$ which depreciates at rate $\delta . s$ denotes net social transfers and $m$ a trade balance which may also be zero. Such budget constraint implies that the model is in principle neutral in terms of openness. Solving the consumer problem for labor supply and combining with labor demand from the producer problem yields:

$$
\frac{1}{\phi}=\left(\frac{1-\omega}{\omega}\right)^{\rho} \frac{1+p \bar{s} \tau_{s}}{1+\tau_{s}}
$$

which defines the equilibrium in our model.

\footnotetext{
${ }^{7}$ The separability of consumption and labor in the utility function may affect the shape of the Laffer curve even on consumption taxes, for discussion see Hiraga et al. (2016).
} 


\subsection{Government}

Government levies taxes, borrows, consumes and makes transfers to households. Government expenditure equals government consumption $g$, transfers to households $s$ and servicing of outstanding debt plus interest, $R b_{-1}$. The government pays the same interest as firms. The government finances this expenditure from tax revenues $T$ and new borrowing $b$. The governments budget constraint is given by:

$$
\begin{aligned}
T+b & =g+R^{b} b_{-1}+s+x \\
T & =\tau^{c} c+\tau^{k}(d-\delta) k_{-1}+\left(\tau^{n}+\tau^{s}\right) n_{P} w_{P}+\left(\tau^{n}+p \bar{s} \tau^{s}\right) n_{S} w_{S}
\end{aligned}
$$

Labor income tax revenue comes from three sources: labor income tax, social security contributions (whatever share is not avoided) and penalties on identified labor income that was not subjected to social security contributions. Government is not strategic in setting $p \bar{s}$, i.e. we do not assume any optimization on the side of the government.

\subsection{Equilibrium}

The equilibrium is given by prices $\left\{R, w_{P}, w_{S}\right\}$ given the parameters $\left\{\tau^{n}, \tau^{s}, \tau^{k}, p \bar{s}, \tau^{c}, \alpha, \delta, \rho, \phi, \omega\right\}$ which solve the consumer problem and producer problem. In the steady state:

$$
\begin{aligned}
\overline{\left(\frac{k}{y}\right)} & =\left[\frac{(R-1)}{\alpha\left(1-\tau^{k}\right)}+\frac{\delta}{\alpha}\right]^{-1} \\
\overline{\left(\frac{c}{y}\right)} & =\frac{1}{\chi}\left[\left(\eta \kappa n^{1+\frac{1}{\varphi}}\right)^{-1}-\frac{1}{\eta}+1\right] \\
\text { where } \chi & =\frac{1+\tau^{c}}{1-\tau_{n}} \frac{(1-\omega)^{-\rho}(1-\omega(1-\phi))}{1-\alpha}\left(\frac{1+\varphi}{\varphi}\right)
\end{aligned}
$$

Substituting for tax revenues (8) into the households feasibility constraint (5) and using the government budget constraint (7) implies:

$$
\overline{\left(\frac{c}{y}\right)}+(\psi-1+\delta) \overline{\left(\frac{k}{y}\right)}=1+(m-g) \frac{1}{\left(\frac{y}{n}\right)} \frac{1}{n} .
$$

In equation (12), $\psi$ is the steady state growth rate of output. Labor productivity is defined as $\overline{\left(\frac{y}{n}\right)}=\left(A\left(\frac{k}{y}\right)^{\alpha}\right)^{\frac{1}{1-\alpha}}$. Replacing the consumption output ratio $\overline{\left(\frac{c}{y}\right)}$ in (12) with (10) gives a nonlinear equation in labor supply $n$ which can be solved numerically.

\section{Calibration}

Model calibration follows the approach of Trabandt and Uhlig (2011). All standard parameters used in the baseline calibration are summarized in Table 1. In all cases we use the steady state relationships to calibrate individual country parameters so to match capital-output ratios, 
consumption-output ratios and hours worked. Specifically, to exactly match the capital output ratio, we compute $\delta$ using the steady state capital investment relationship and $\alpha$ is calculated as rate of return in equation (9). These values are matched exactly in our model (shown in Figures A1a-A1c). Estimates of TFP growth coincide with the European Commission long-run estimates and with a recent account of US TFP growth prospects (Fernald and Jones 2014).

Table 1: Calibration of model parameters

\begin{tabular}{c|lll}
\hline \hline Parameter & & Value & Source \\
\hline \hline$\alpha$ & Capital share in output & Country Specific & European Commission \\
$\psi$ & TFP growth & 1.017 & European Commission \\
$\bar{R}$ & Gross interest rate & 1.04 & Standard \\
$\eta$ & Inverse of IES & 2 & Standard \\
$\varphi$ & Frisch's elasticity & 1 & Standard \\
$\tau^{c}, \tau^{n}, \tau^{k}$ & Taxes on consumption, labor and capital & Country Specific & OECD \\
$\tau^{s}$ & Social Security Taxes & Country Specific & OECD \\
$b$ & Public debt (in \% of GDP) & Country-specific & OECD \\
$g$ and $s$ & Gov. cons. and social transfers (in \% of GDP) & Country Specific & OECD \\
$m$ and $x$ & Trade balance and other (in \% of GDP) & Country Specific & OECD \\
\hline \hline
\end{tabular}

Notes: OECD figures were computed as averages over 1995-2007. TFP growth long-run estimates by the European Commission

On the utility function, the inter-temporal elasticity of substitution has been set to 2, consistent with values used in the literature (see Havránek 2015). Similarly, Frisch's elasticity is set to 1 (Chetty et al. 2012). Knowing these parameters, we seek $\kappa$ to match the number of hours worked in the economy (expressed in \% of the available time). This follows from inverting the equilibrium relation (12). Given our interest in total hours worked - fully covered and exempt from social security (under-reported) - we match the accounts of self-reported hours worked, we chose the weight of labour $\kappa$ so as to exactly match aggregate hours worked.

We follow Mendoza et al. (1994) approach to move from de iure tax rates (acquired from OECD) to effective aggregate tax rates. Table A1 reports the final effective tax rates. We however need to separate social security taxes contributed by the employer from other labor income related taxes. The method in Mendoza et al. (1994) considers all labor income $\tau^{l}$ taxes as a whole. To obtain $\tau^{n}$ we subtract employer social security contributions from the numerator of the ratio $\tau^{l}$ and compute $\tau^{s}$ as the ratio of employer social security contributions to the denominator of $\tau^{l}$.

In our extension to the Trabandt and Uhlig (2011), there are four new parameters that we need to identify. These are: the expected penalty for avoiding social security contributions $(p \bar{s})$, the disutility of working in the informal sector $(\phi)$ as well as the production function parameters for the substitution and complementarity between primary and secondary work ( $\omega$ and $\rho$ ). In order to pin these parameters, we exploit the data. We specify three equations, two of which have corresponding data counterparts to calibrate $p \bar{s}, \omega$ and $\rho$. We now describe these equations. From the producer optimization, wages are given by:

$$
w_{P}=\frac{1}{1+\tau^{s}}(1-\alpha)(1-\omega)^{1+\rho} \frac{y}{n_{P}} \quad \text { and } \quad w_{S}=\frac{1}{1+p \bar{s} \tau^{s}}(1-\alpha) \omega^{1+\rho} \frac{y}{n_{S}} .
$$


Using these wage rates to compute the labor tax revenue (LTR) and firms social security contributions (FSS) we have the following equations:

$$
\begin{aligned}
& \mathrm{FSS}=\tau^{s}\left(w_{P} n_{P}+p \bar{s} w_{S} n_{S}\right)=\tau^{s}(1-\alpha)\left(\frac{(1-\omega)^{1+\rho}}{1+\tau^{s}}+\frac{p \bar{s} \omega^{1+\rho}}{1+p \bar{s} \tau^{s}}\right) \\
& \mathrm{LTR}=\tau^{n}\left(w_{P} n_{P}+w_{S} n_{S}\right)=\tau^{n}(1-\alpha)\left(\frac{(1-\omega)^{1+\rho}}{1+\tau^{s}}+\frac{\omega^{1+\rho}}{1+p \bar{s} \tau^{s}}\right)
\end{aligned}
$$

Recall the CES aggregate for labor $n=\left((1-\omega) n_{P}^{\rho}+\omega n_{S}^{\rho}\right)^{\frac{1}{\rho}}$. Dividing both sides by $n$ and using the definition of weights $n_{S}=\omega n$ and $n_{P}=(1-\omega) n$ we obtain:

$$
1=\omega^{1+\rho}+(1-\omega)^{1+\rho}
$$

The three equations (13), (14) and (15) are used to pin down the two producer side parameters $\omega$ and $\rho$ and the policy parameter $p \bar{s}$. LTR and FSS are obtained from OECD database and averaged over the available period. Once the three producer side parameters are pinned, the consumer side parameter $\phi$ can be obtained from the equilibrium condition for labor supply and demand expressed in equation (6).

The range of some parameters is intuitive. For instance, $\omega$ is the weight of secondary labor, therefore $0 \leq \omega<1$. If primary and secondary labor are perfect substitutes then the elasticity of substitution $\sigma=\frac{1}{1-\rho} \rightarrow \infty$, so $\rho \rightarrow 1$. These conditions constraint $\phi>1$ which in turn constraints $p \bar{s} \leq 1$.

\subsection{Model solving}

Given the model parameters, we first solve for the capital output ratio $\frac{k}{y}$, productivity $\frac{y}{n}$ and investment to output ratio $\frac{x}{y}$. We use these to express (12) as a function of the labor supply $n$. We then equate equation (12) to (10) which gives a single nonlinear function of $n$. We solve this equation using the trust region reflective algorithm in MATLAB. Once we have solved for $n$, we solve for all other model variables. First we solve for output $y$, then use the budget constraint to obtain the consumption output ratio $\frac{c}{y}$. We then compute tax revenues as given by (7).

Later in our policy experiments, we need to obtain out of the steady state values of the parameters $\omega$ and $\phi$. We use polynomial approximations to obtain these estimates. Specifically, we assume that $\omega$ is a function of the weight of social security tax to total labor income tax, i.e. $\omega=f\left(\frac{\tau^{s}}{\tau^{s}+\tau^{n}}\right)$. We know this ratio and the corresponding values for $\omega$ at the steady state from our calibration and exploit this knowledge to obtain an approximating polynomial for different weights of the tax ratio. We hold the ratio constant while picking different values of $\tau^{s}$ and $\tau^{n}$. Firms' social security contribution (FSS) is given by equation (13). We compute an approximation $\widehat{\mathrm{FSS}}$ using:

$$
\widehat{\mathrm{FSS}}=\tau^{s}(1-\alpha)\left(\frac{(1-\widehat{\omega})^{1+\rho}}{1+\tau^{s}}+\frac{p \bar{s} \widehat{\omega}^{1+\rho}}{1+p \bar{s} \tau^{s}}\right)
$$


where $\widehat{\omega}=P_{m}\left(\frac{\tau^{s}}{\tau^{s}+\tau^{n}} ; \epsilon_{m}\right)^{8}$ is a polynomial of degree $m$ with coefficients $\epsilon_{m}$. We choose the coefficients of the polynomial by minimizing $\frac{1}{2 m} \sum_{j=1}^{m}\left(\mathrm{FSS}_{j}-\widehat{\mathrm{FSS}_{j}}\right)^{2}$ over $m$ grid points using a quasi-Newton minimization routine in MATLAB ( fminunc with BFGS Quasi-Newton). Given a new value of $\tau^{s}$, we approximate a new value of $\omega$ and using these estimates compute a new value of $\phi$ following equation (6). In the out of steady state simulations, we show results for cases where we hold the parameter $\phi$ constant and where it varies. For computing Laffer curves we hold all estimated parameters constant at steady state.

Given this solution method, we are able to treat each share of $\tau^{s}$ in $\tau^{n}+\tau^{s}$ as a counterfactual steady state and re-solve the model under a new policy mix where the weight of $\tau^{s}$ in total labor taxation varies. This requires new estimates of the model parameters: work in the uncovered secondary sector $(\omega)$, the substitution parameter $(\rho)$, the penalty $(p \bar{s})$ and the disutility from working in secondary employment $(\phi)$. Given that the main calibration involves actual data, it would be questionable to re-estimate $(p \bar{s})$, so this parameter is fixed from the original calibration onwards. By the same token, if $\rho$ reflects technology, then in the short run analyses grounds for re-estimating $\rho$ in counter-factual scenarios are weak. However, depending on the interpretation attributed to the other parameters, fixing their values may be desirable or not. For example, with $\omega$ fixed, the economy cannot adjust at all to new labor tax policy mix, so such modeling choice would not be informative of the adjustment to the new equilibrium. On the other hand if one interprets $\phi$ as actual disutility of lower social security and employment protection, then using a single, data driven calibration for all the policy experiments seems appropriate. Yet, if one interprets it as social perception of working in "secondary" sector, then prevalence is likely to affect social preferences, thus making it appropriate to allow $\phi$ to vary in subsequent re-estimations. Consequently, we fix $\rho$ and $p \bar{s}$ at values implied by data. We re-estimate $\omega$ for each counter-factual scenario. In each case, we show results where $\phi$ is fixed or varying (to evaluate if the eventual changes in $\phi$ may significantly affect the conclusions).

Knowing the outcomes, we perform welfare evaluations. Expressed in consumption equivalent units

$$
\lambda=1-\left(\frac{1+(1-\beta)(1-\eta) \text { Welfare }_{\text {baseline }}}{1+(1-\beta)(1-\eta) \text { Welfare }_{\text {reform }}}\right)^{\frac{1}{\eta-1}}
$$

that is consumers would be willing to give up $\lambda$ to avoid a change from baseline to reform. Welfare is computed as utility of consumers defined by (4).

\section{$3.2 \quad$ Model properties}

Given the calibrated parameters, we solve for the labor supply in the steady state from the equilibrium condition equation (12). Having chosen parameters to perfectly fit the great ratios, the model predicted values exactly match the data (see Figures A1a-A1f). The key variables of interest are the estimated parameters $\phi, \omega, \rho$ and $p \bar{s}$. The final fit of the labor income tax share

\footnotetext{
${ }^{8}$ In making approximations of the value of $\omega$ outside the steady state when changing the expected penalty $p \bar{s}$, we use a tensor product polynomial in two variables: $\widehat{\omega}=P_{m}\left(\frac{\tau^{s}}{\tau^{s}+\tau^{n}}, p \bar{s} \times \tau^{s} ; \epsilon_{m}\right)$. This is because $p \bar{s}$ enters the equation for FSS multiplied by the tax rate $\tau^{s}$.
} 
in GDP is depicted in Figure A1e. The nonlinear nature of the relationships required to fit the labor tax revenues imply that we obtain a less that perfect fit in solving for these parameters. The parameters $\omega, \rho$ and $p \bar{s}$ as well as $\phi$ fit for every country are reported in Table A2.

The values we find are generally plausible, while model predictions are reasonably close to empirical estimates. For instance, the Pearson correlation coefficient between our model implied size of the secondary employment and self-reported incidence of atypical employment based on the European Social Survey (ESS) data summarized by Flórez and Perales (2015) is 0.6966 with a $p$-value of $0.027^{9}$. Using the model parameters we also find the share of output produced using secondary workers in the economies analyzed. ${ }^{10}$ We compare these to the estimates of Schneider (2014) on the size of the informal sector in an economy. Our model replicates the dispersion in the size of the informal economy suggested by Schneider (2014) with Pearson's correlation coefficient 0.6419 ( $p$-value 0.0073 ). This is reassuring, as our model focuses only on the scope and scale for partial tax avoidance. ${ }^{11}$

Moreover, it appears that the relationship between the tax mix (from the data) and the estimated parameter of $\omega$ also display plausible relationship, both in terms of range and in terms of cross-sectional dispersion, see Figure 2a. While our model performs reasonably well and the estimated parameters have plausible magnitude and correct signs, the model cannot explain the substantially smaller prevalence of atypical employment in Ireland, UK and USA (which coincides with generally larger share of underground economy in these countries). For the other countries, our model systematically expects somewhat smaller size of the irregular employment. This last observation is not a surprise given the highly stylized nature of our framework. However, the consistent misalignment of these three countries requires further comment. First, these countries do stand out in terms of low social security contributions - second to fourth lowest in our sample. ${ }^{12}$ The fit of the model to the ESS data exhibits high correlation.

Given that the model performs reasonably well, we move to addresing the main question of this study about the optimal mix between avoidable and unavoidable labor taxes.

\section{Results}

The results are reported in two substantive parts. First, we show the intuition for the changes to the Laffer curve relative to a benchmark model of Trabandt and Uhlig (2011). We then utilize the model to produce several counter-factual scenarios. Keeping the overall labor taxes unchanged, we manipulate the composition of avoidable and unavoidable taxes, showing how the proportions in

\footnotetext{
${ }^{9}$ Rank correlation coefficients: Kendall's $\tau=0.2762$ ( $p$-value $\left.=0.1493\right)$ Spearman's $\rho=0.3194(p$-value $=0.2279)$. Similarly close match is held to cross-country dispersion in informal, atypical and irregular employment based on a smaller scale survey, the Eurobarometer, as reported by Williams (2015), Williams and Windebank (2015), detailed results available upon request.

${ }^{10}$ The share of output due to secondary workers is computed as the share of secondary labor : $y_{S}=\frac{(1-\alpha) \omega^{1+\rho}}{1+p \bar{s} \tau^{s}}$.

${ }^{11}$ The rank correlations for results from Schneider (2014) and our model are positive and statistically significant: Kendall's $\tau=0.3629$ ( $p$-value $=0.0577)$ and Spearman's $\rho=0.4484(p$ value $=0.0815)$.

${ }^{12}$ Admittedly, the country with the lowest share of social security contributions - Denmark - is not in the same country group as Ireland, UK and USA. One potential reason may be that Denmark is characterized by relatively high overall labor taxation.
} 
Figure 2: Model predictions and empirical sources on prevalence of labor market duality

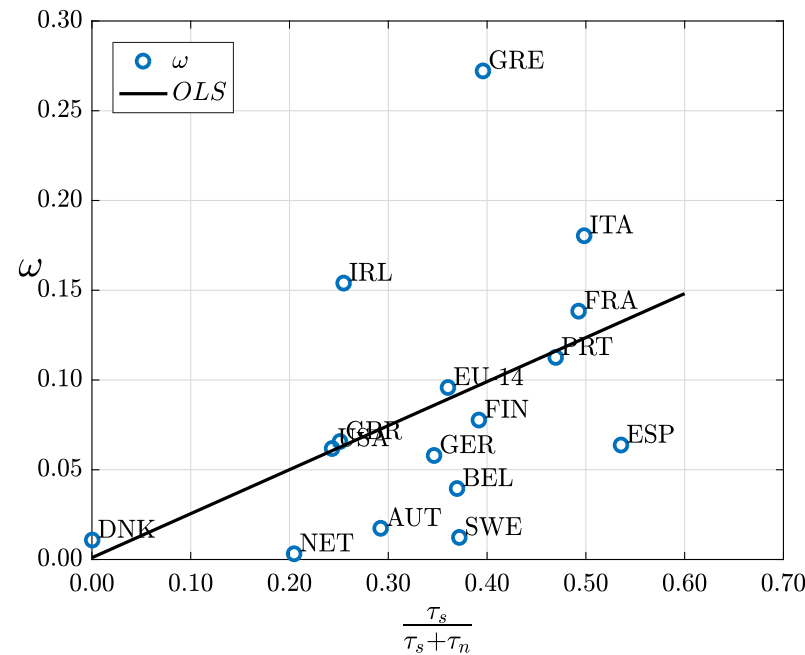

(a) Model predicted $\omega$ vs tax structure

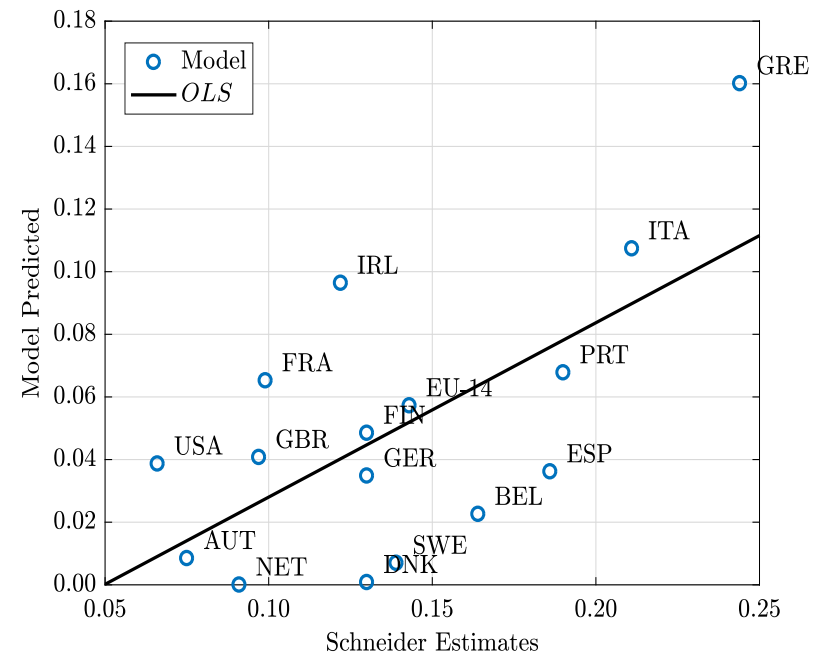

(b) Informal economy (Schneider 2014)

Notes: Pearson's $r$ for 2a at $0.4553(p$-value $=0.0764)$ and for $2 \mathrm{~b}$ at $0.6419(p$-value $=0.0073)$.

this policy mix affect tax revenues and welfare. We also analyze the path of transition if a country wanted to alter the composition of labor taxes. The second set of counter-factual experiments concerns possible effects of strategic action by the government: varying the expected penalty associated with avoiding social security contribution.

\subsection{How does the Laffer curve change with tax evasion?}

Note that in our framework, government is not strategic in detecting tax avoidance on social security contributions. Also, firms always engage in some tax avoidance. Given the model setup and these premises, one would expect the Laffer curve to be more responsive to the tax rate (i.e. more curved) and peak at lower combined labor taxation. Indeed, this is the case. The results are depicted in Figure 3 for the EU-14 and the US (respective results for all other countries are included in Figure A2 in the Appendix). We report Laffer curves for aggregate tax revenue, including both components of the labor taxation (unavoidable income tax and partially avoidable social security contribution). We show two specifications. For comparative purposes, we replicate the results of Trabandt and Uhlig (2011), i.e. the model comprises both taxes together, but there is no tax avoidance (all employed labor is fully taxed). This scenario is denoted as 'no evasion'. Second, we report the results of the full model with tax avoidance in social security contributions. This scenario is denoted as 'evasion' scenario.

The effects of avoidance on labor tax revenues are only indirect, as all supplied labor remains taxed, only social security contributions may be avoided. We find confirmation of this conjecture. The shape of Laffer curves depicted in Figure 3 (and A2 alike) also exhibit some less intuitive findings. First, current rates for labor tax and social security contributions are to the left of 
Figure 3: The shape of Laffer curves
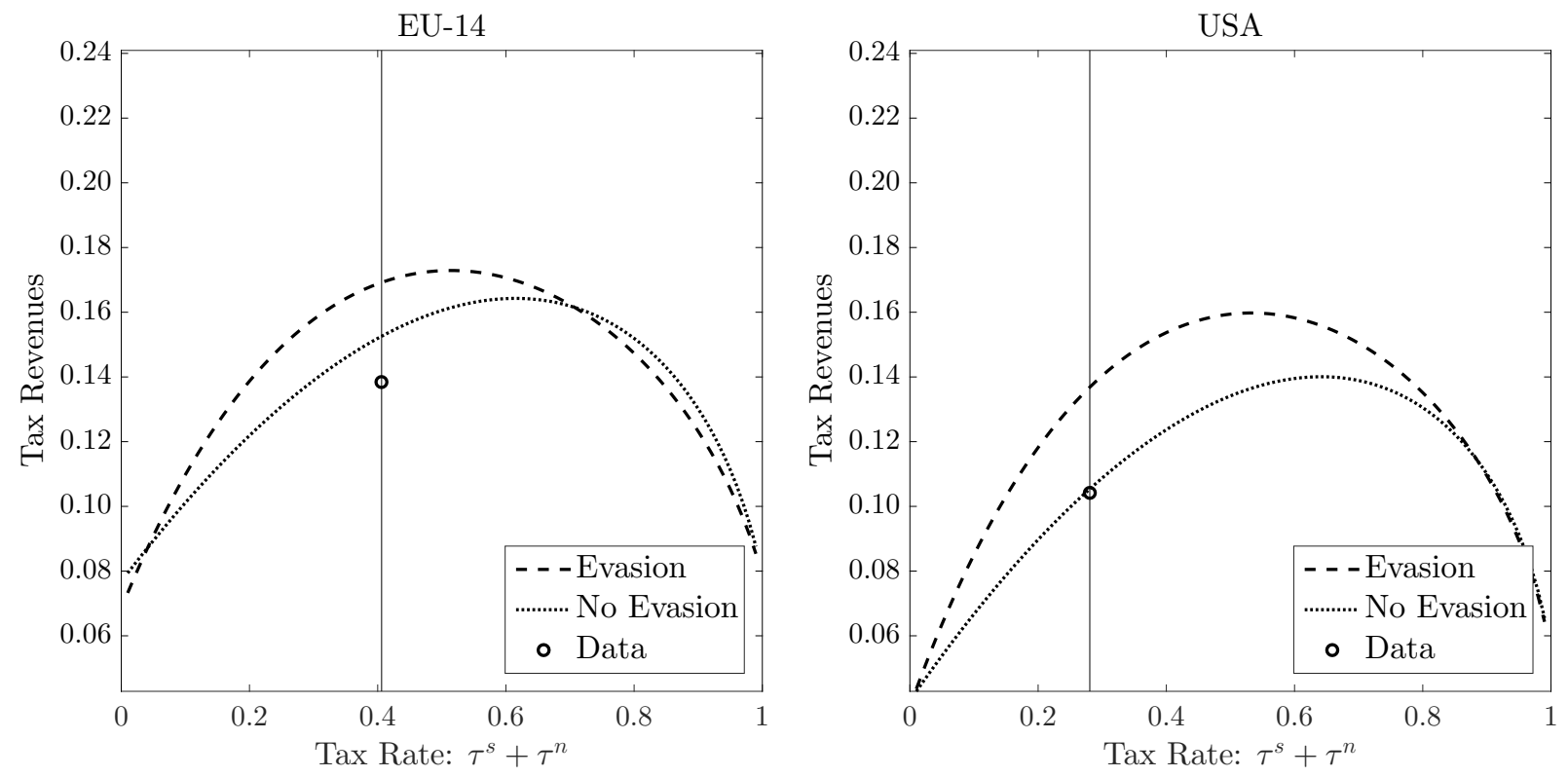

Notes: Results for all the analyzed countries reported in Figure A2 in the Appendix. Tax revenue refer to overall tax revenue $T$. We compute the figures as if each of the respective tax values occurred in steady state. Parameters conditional on $\tau^{s}$ and $\tau^{n}$ fixed.

maximum revenues. Admittedly, in our setting labor taxes are flat, with no kinks due to tax progression or deductions. Thus, these results are likely to understate the possible effects of raising the labor tax rates and/or social security contributions (see section 4.4 for a further treatment). However, the results seem to suggest that in most European countries and in the US the current surcharges on labor may be increased. This finding may be viewed as optimistic for two main reasons. First, most of the European countries struggle with growing deficits in the pension systems, whereas increasing contribution rates is one of the considered policy alternatives. Second, in our model an increase in social security contributions is likely to reduce its coverage. While the social security contributions vary substantially between countries, as evidenced in section 3.2, the scope of irregular employment does to a much smaller extent. This suggests a mild empirical extensive margin elasticity to changes in social security contributions.

The analyses of the Laffer curves as depicted by Figure 3 cannot inform about the optimal mix of avoidable $\left(\tau^{s}\right)$ and unavoidable $\left(\tau^{n}\right)$ tax. Basic intuition suggest that if social security contributions are avoidable, tax revenues should be maximized with all labor taxation occurring via labor tax. However, changing these proportions increases effective taxation of labor, thus generating general equilibrium effects, higher labor taxes affect the relative price of labor, thus changing the overall labor demand and supply. Given that the direct and indirect effects work in the opposite directions, quantifying the overall effect is an empirical question of quantifying their respective strength. 


\subsection{How optimal is the mix of avoidable and unavoidable taxes?}

We perform a set of counter-factual experiments in which we gradually vary the share of (avoidable) social security contributions $\tau^{s}$ in total taxation of labor from 0 to 1 . In all the simulations we keep the total tax rate $\tau^{s}+\tau^{n}$ unchanged. To perform these simulations, we effectively solve the model for each of the respective combinations, but in these experiments some parameters are held constant. Namely, from the parameters calibrated to reflect features of respective economies we solve for the counter factual steady states, treating as given labor share $(\alpha)$ and elasticity of substitution between the two types of labor $(\rho)$. Clearly, we do allow the contributions of each type of labor to adjust $(\omega)$. We also fix the expected penalty for tax evasion $(p \bar{s})$ to values estimated in section 3. For the household parameters, we provide two specifications. In the first one, we allow the additional disutility of working without social security contribution $(\phi)$ to vary. In the second we keep it at the level estimated from the data.

The changing share of $\tau^{s}$ in total labor taxation has a two effects. First, it is changing the incentives for labor supply decision - higher $\tau^{s}$ reduces labor supply. Second, it has composition effects for the labor demand - higher $\tau^{s}$ increases gains from avoiding formal employment. Since we keep rate of total labor taxation constant, the overall price of hiring labor may be reduced if the lower price of labor uncovered with social security contributions leads to lowering the overall price of labor (that is, if quantitative adjustment in the composition of labor is larger than the increase in price of formal labor). Alternatively, if composition effects do not dominate price effects, the price of labor increases, leading to changes in the relative demand for capital. Consequently, there would be changes in capital/labor ratio and the subsequent general equilibrium effects.

Figure 4 shows the results of this counter-factual simulations scenarios for EU-14 and the US (set of results for other analyzed countries is reported in Figure A3 in the Appendix). For convenience, we mark on these figures the steady state share of $\tau^{s}$ (and the corresponding steady state tax revenue, as \% of GDP from section 4.1). The asterisk denotes total tax burden on labor. The vertical axis, as before, measures total tax revenues as a share in GDP.

Somewhat surprisingly, tax revenues are a relatively linear function of $\frac{\tau_{s}}{\tau^{s}+\tau^{n}}$. This finding is general (compare Figure A3) and seems to suggest that in fact for most of the countries the trade off between higher rates and lower coverage of social security contribution is strongly dominated by the downward quantitative adjustment in demand for fully covered labor. Static comparisons seem to suggest then, that with lower social security contributions and higher unavoidable labor taxation fiscal revenues could be increased in virtually all countries. ${ }^{13}$ One of the possible interpretations of this findings is that the scope for tax evasion on social security contributions is too broad in the analyzed countries, thus suggesting too weak enforcement. An alternative view, however, would focus on the changing nature of labor, thus hinting that evading social security contributions may be in line with how contemporary labor markets function in some industries and for some occupations. Our model cannot discriminate between the two explanations, but keeping in mind that most individuals will be eligible to some form of old age benefits (if not pension then social assistance), the second explanation seems less well suited to actual policy challenges.

\footnotetext{
${ }^{13}$ Given the specific conditions of Denmark, our model poorly matches the outcomes in this country. However, in other countries with relatively lower share of social security contributions, such as the UK it performs relatively well.
} 
Figure 4: Alternative policy mix: fiscal revenues
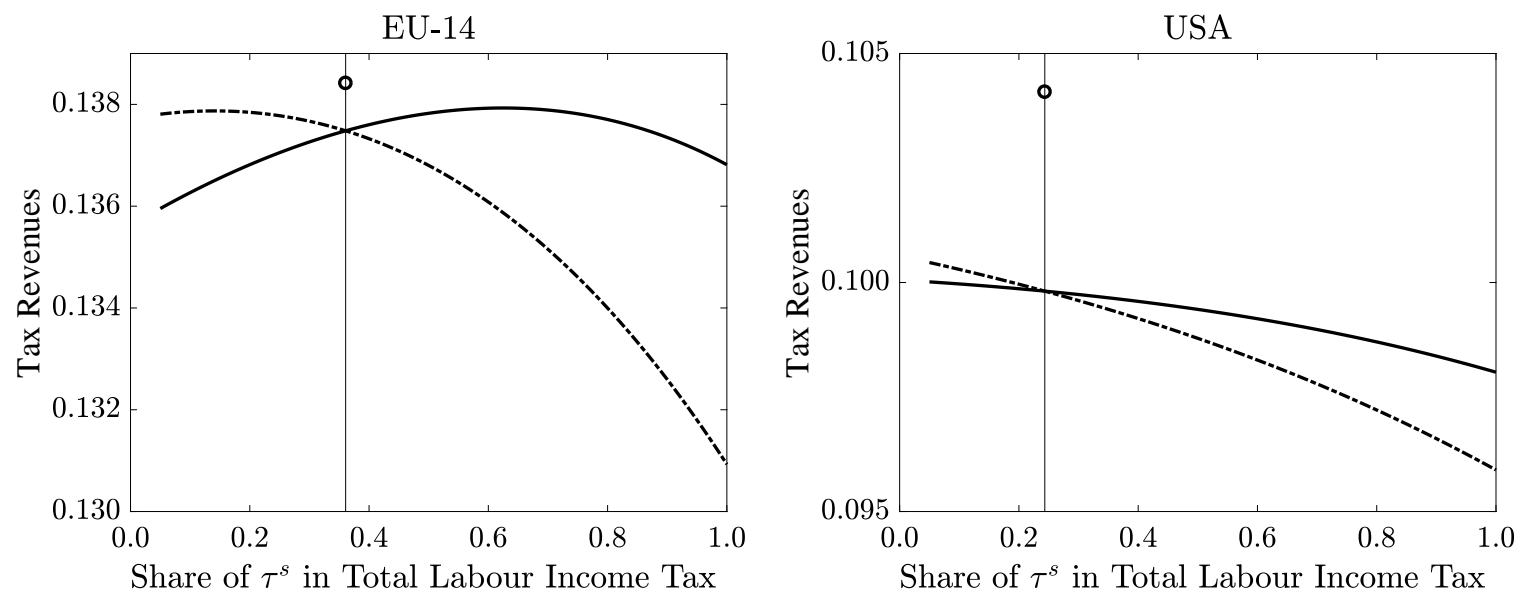

Notes: Tax revenues refers to overall tax revenue $T$. We compute the subsequent shares as if they were the steady state conditions. The solid line is the tax revenue when the parameter $\phi$ is fixed at the steady state level. The dotted dashed line allows $\phi$ to change based on $\omega$ and $\tau^{s}$. The vertical line and circle indicate the steady state share of $\tau^{s}$ in labor income taxes and the corresponding tax revenue. Results for all the analyzed countries reported in Figure A3 in the Appendix.

While a given proportion of between $\tau^{s}$ and $\tau^{n}$ may maximize tax revenues, it is not warranted that it also optimizes welfare. We operationalize welfare as difference in the utilities between the actual combination of $\tau^{s}$ and $\tau^{n}$ and the counter-factual ones, providing estimates of the welfare effects of departing from the steady state. We plot it against share of secondary employment $(\omega)$ consistent with a given counter-factual steady state. These results are displayed for EU-14 and the US in Figure 5 (set of results for other analyzed countries is reported in A4 in the Appendix).

Clearly, in some cases a welfare gain is possible from changing the proportions between $\tau^{s}$ and $\tau^{n}$. Figure 5 reports static comparisons of welfare, relative to the equilibrium defined by data, for the alternative shares of $\tau^{s}$ in total labor taxation. We compute welfare following equation (16), where baseline is taken from the data and reform is the re-estimated counter-factual equilibrium for alternative proportion of avoidable tax in labor tax wedge. Negative values of $\lambda$ signify that welfare is lower in the reform scenario than in the baseline scenario (consumers ought to be compensated to accept the change).

The share of labor working without social security contributions is a convex function increasing in $\tau^{s}$. The degree of convexity depends on the relationship between the calibrated values of $\rho$, i.e. the degree of substitutability between the two types of labor. This feature seems to be general to the extent that it is replicated in all analyzed economies and stems from the properties of the production function. However, the relationship between the share of $\tau^{s}$ and welfare is not necessarily negative. There are two effects affecting the overall welfare: (a) the reduced effective labor taxation and increased earned income, which enables higher consumption if more labor taxation is avoided and (b) increased disutility from working per se and working in the uncovered sector. If the calibrated values of the preference parameter $\phi$ signify that uncovered secondary sector yields higher disutility from work than the covered primary sector, then the two effects operate in opposite directions, 
making the overall effect an empirical question. Our exercise reveals that income effect does not compensate for the disutility from more work in the uncovered sector in any of the cases where uncovered sector yields higher disutility of work. However, if consumers are indifferent between the sectors or actually have preference the uncovered sector - as is the case of estimations for Denmark and the Netherlands - then earned income makes up for the disutility stemming from more work (also because there is no extra disutility from higher prevalence of work in the uncovered sector). As a consequence, the income effect dominates, rendering welfare effects negative (see also Figures A7c and A7i in the Appendix).

Figure 5: Alternative policy mix: employment and welfare
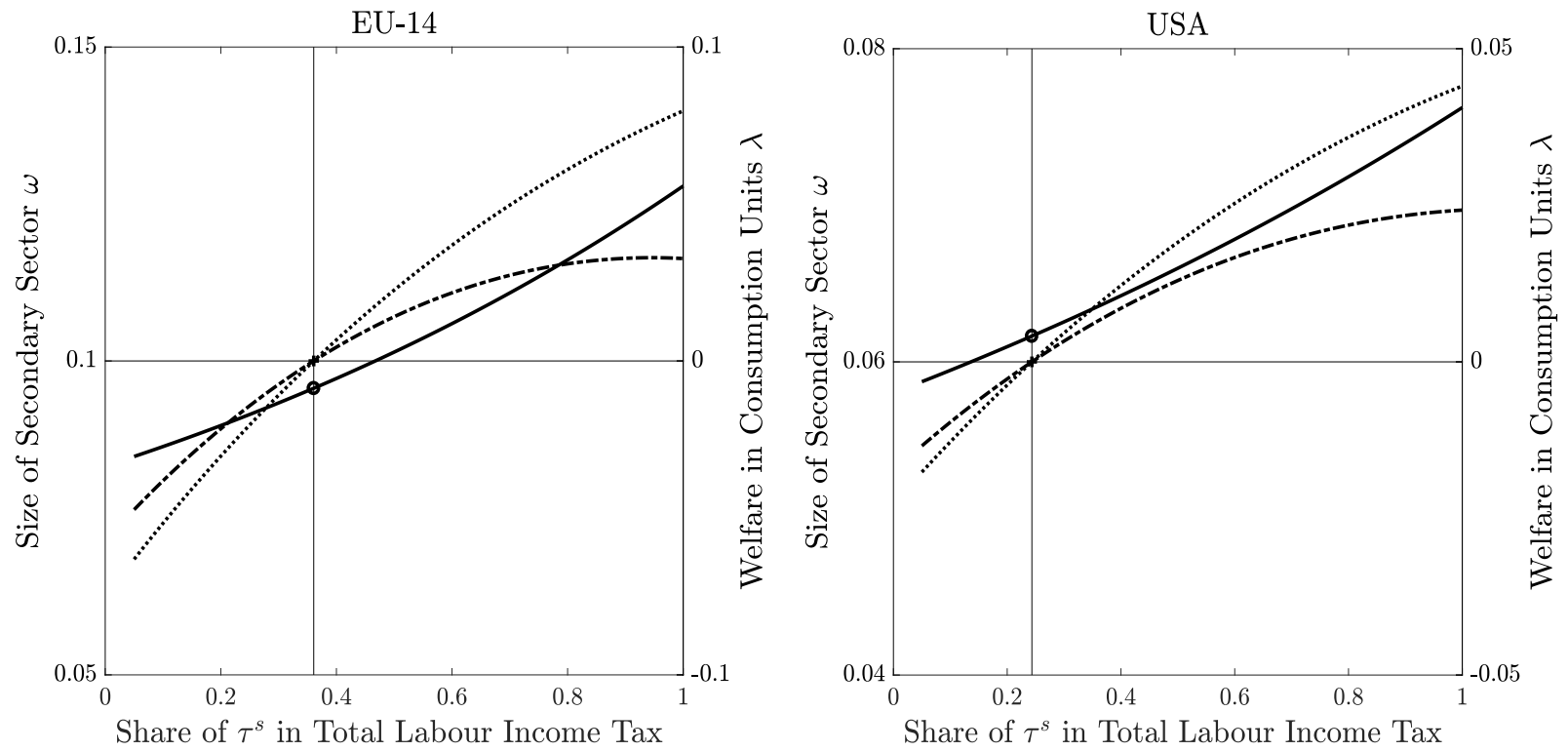

Notes: See note under Figure 4. $\omega$ (solid line) is computed from the polynomial approximation described in 3.1. The vertical line and circle indicate the steady-state values of $\omega$ and $\tau^{s}$ respectively. The dotted and dashed lines shown welfare computed using fixed and varying $\phi$ respectively. Welfare is computed as difference between a given counterfactual steady state and data steady state in consumption equivalent terms, $\lambda$, following equation (16). Results for all the analyzed countries are reported in Figure A4 in the Appendix.

These results suggest that in terms of comparative statics there are welfare and fiscal gains from changing the proportions between $\tau^{s}$ and $\tau^{n}$ for most analyzed cases. In the final section we present transition analyses for the scenario where the initial steady state is the actual calibrated result for a given country, while the final steady state is the proportion suggested as optimal in the counter-factual experiments described above.

\subsection{How optimal is the expected penalty for tax evasion?}

We perform a second set of counter factual experiments where we vary the expected penalty from 0 to 1 . In our model and calibration, the probability of being caught $p$ and the surcharge $\bar{s}$ are non-separable i.e. the two parameters always enter the model as the product $p \bar{s}$. Across countries, 
our calibration results have $p \bar{s}$ varying from a low of 0.01 in Portugal to a high of 1.12 in France. The number $p \bar{s}=0.01$ in Portugal could for example reflect a probability of being caught $p=0.005$ accompanied by a surcharge $\bar{s}=2$ when caught. However, most administrations do not disclose the effective identified non-compliance rates, neither is the detailed information about actual penalties available. Given these constraints, some studies rely on legislation. Busato et al. (2012) use earlier work by Joulfaian and Rider (1998) who derive penalties from the United States tax code to calibrate their tax evasion model of the Italian economy with $p=0.03$ and a surcharge factor $\bar{s}=2$ so that $p \bar{s}=0.06$. In another paper, Busato et al. (2011) use the values $p=0.05$ and $\bar{s}=1.75$ for the United States. In the US case, their calibration would mean a value of $p \bar{s}=0.0875$. For comparison, our calibration for the United States and Italy results into $p \bar{s}$ of 0.0543 and 0.0398 respectively. These values are very close to those of Busato et al. (2011) and Busato et al. (2012) even though we determine these numbers from aggregate tax revenue data.

We change the expected penalty $p \bar{s}$ from the steady state value to unity, the maximum expected penalty a government can impose. This means that either the audit rate $p$ is increased or the surcharge $\bar{s}$ increases. We summarize the findings in Figures 6 and 7 . Figure 6 shows the effect on tax revenues as the expected penalty $p \bar{s}$ increases to the maximum in the static equilibrium. Figure 7 shows the size of the secondary sector implied by the model and the static welfare effects associated with such reform.

Figure 6: Fiscal revenues with changing expected penalty
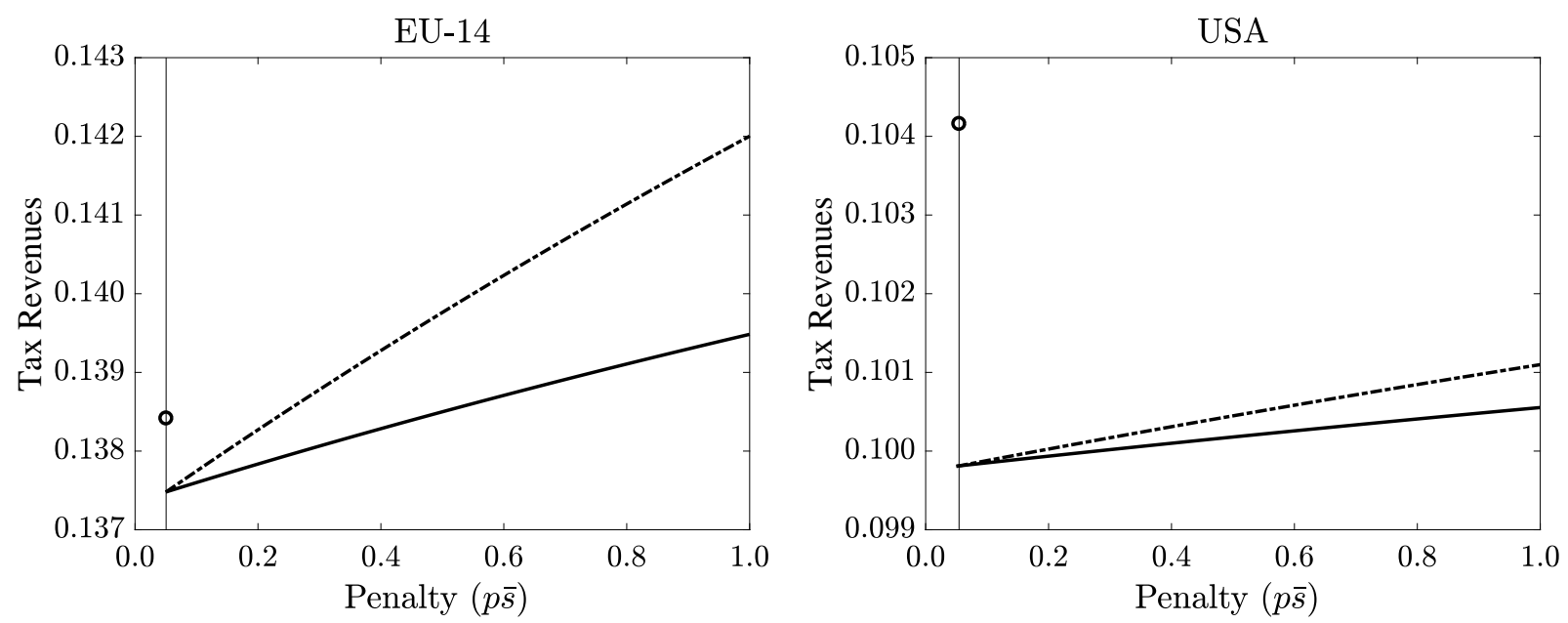

Notes: Tax revenues refers to overall tax revenues $T$. The solid line is the tax revenue when the parameter $\phi$ is fixed at the steady state level. The dotted dashed line allows $\phi$ to change based on $p \bar{s}$. The vertical line and circle indicate the steady state value of $p \bar{s}$ and the corresponding tax revenue. Results for all the analyzed countries reported in Figure A5 in the Appendix.

\subsection{Policy experiments and transition}

We start from the actual steady state and implement two types of reform. The first transition exercise concerns the changes in the mix of avoidable and unavoidable labor taxes. Second, we vary 
Figure 7: Employment and welfare with changing expected penalty
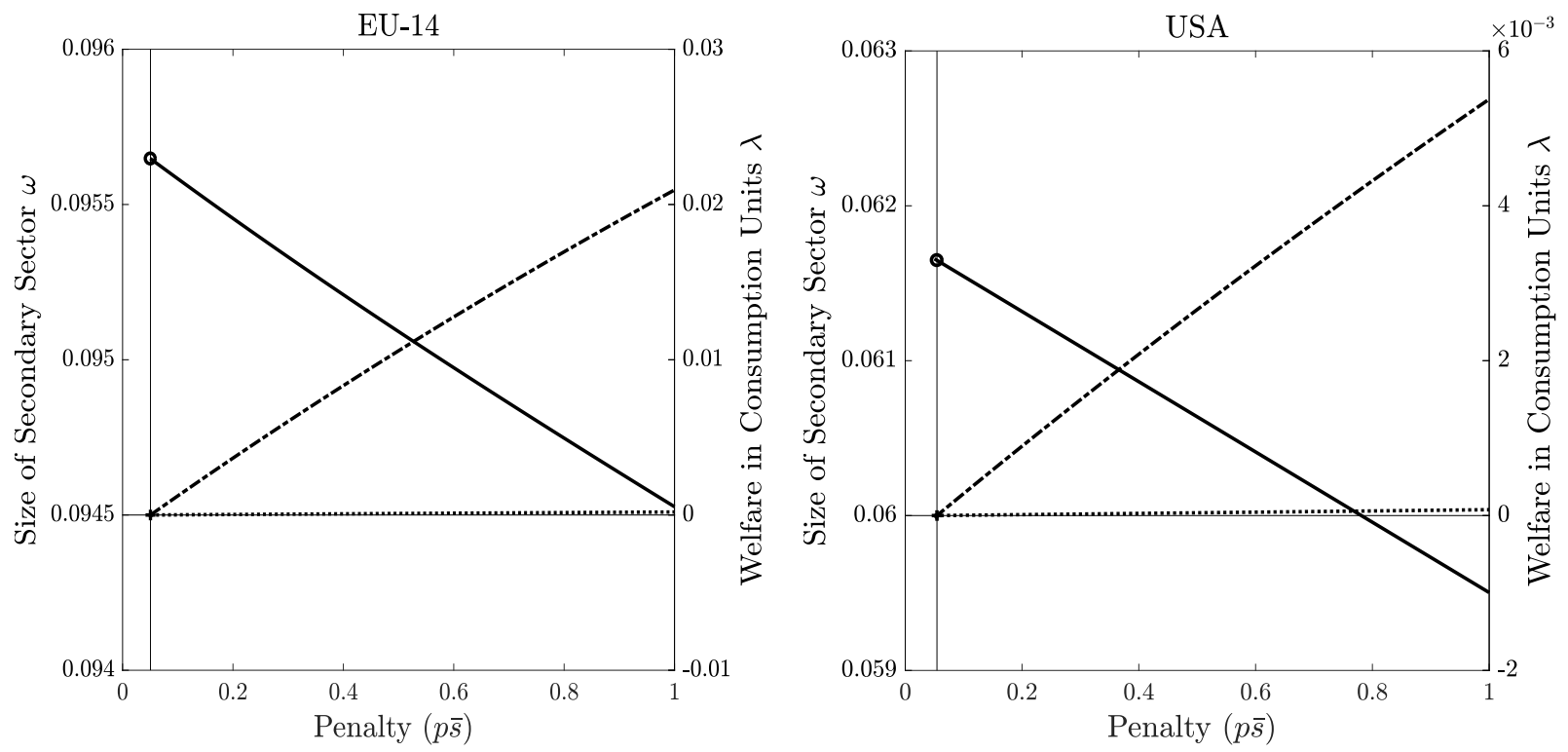

Notes: See note under Figure 4. $\omega$ (solid line) is computed from the polynomial approximation described in 3.1. The vertical line and circle indicate te steady-state values of $\omega$ and $\tau^{s}$ respectively. The dotted and dashed lines shown welfare computed using fixed and varying $\phi$ respectively. Welfare is computed as difference between a given counterfactual steady state and data steady state in consumption equivalent terms, $\lambda$, following equation (16). Results for all the analyzed countries reported in Figure A6 in the Appendix.

the penalty associated with evading social security contributions. In the transition figures that follow, an initial steady state is the actual data estimation. In each panel, a circle displays a value associated with the steady state at the initial constant values of the policy vector. Steady state prevailed before the policy change at $T=10$ was announced. Before date $t=T=10$, the response of each variable is entirely due to expectations about future policy changes. After date $t=10$, the response of each variable represents a purely transient response to a new stationary level of the policy vector that has attained its new permanent level, so that the only sources of dynamics are transient.

\subsubsection{Changing the mix of avoidable and unavoidable labor taxation}

We analyze two reforms. In the first reform, the proportions are set at par with Denmark, which implies that virtually all labor is taxed with a general labor tax, but there are no separate social security contributions. In the second policy experiment we take the opposite direction. In fact, in the sample of 15 analyzed countries, there are three, whose share of social security contributions in labor tax is high relative to others, as it contributes to approximately $50 \%$ (these are France, Italy and Spain). Thus, in the second experiment we raise the share of $\tau^{s}$ in total taxation to $50 \%$.

Given that both are large policy changes and given the complex nature of $\phi$ we run the simulations in two versions. In the first version, we keep the additional disutility from working without social security coverage at the level consistent with the data. We denote this version as 
Figure 8: Policy experiments in tax mix for EU-14: transition paths
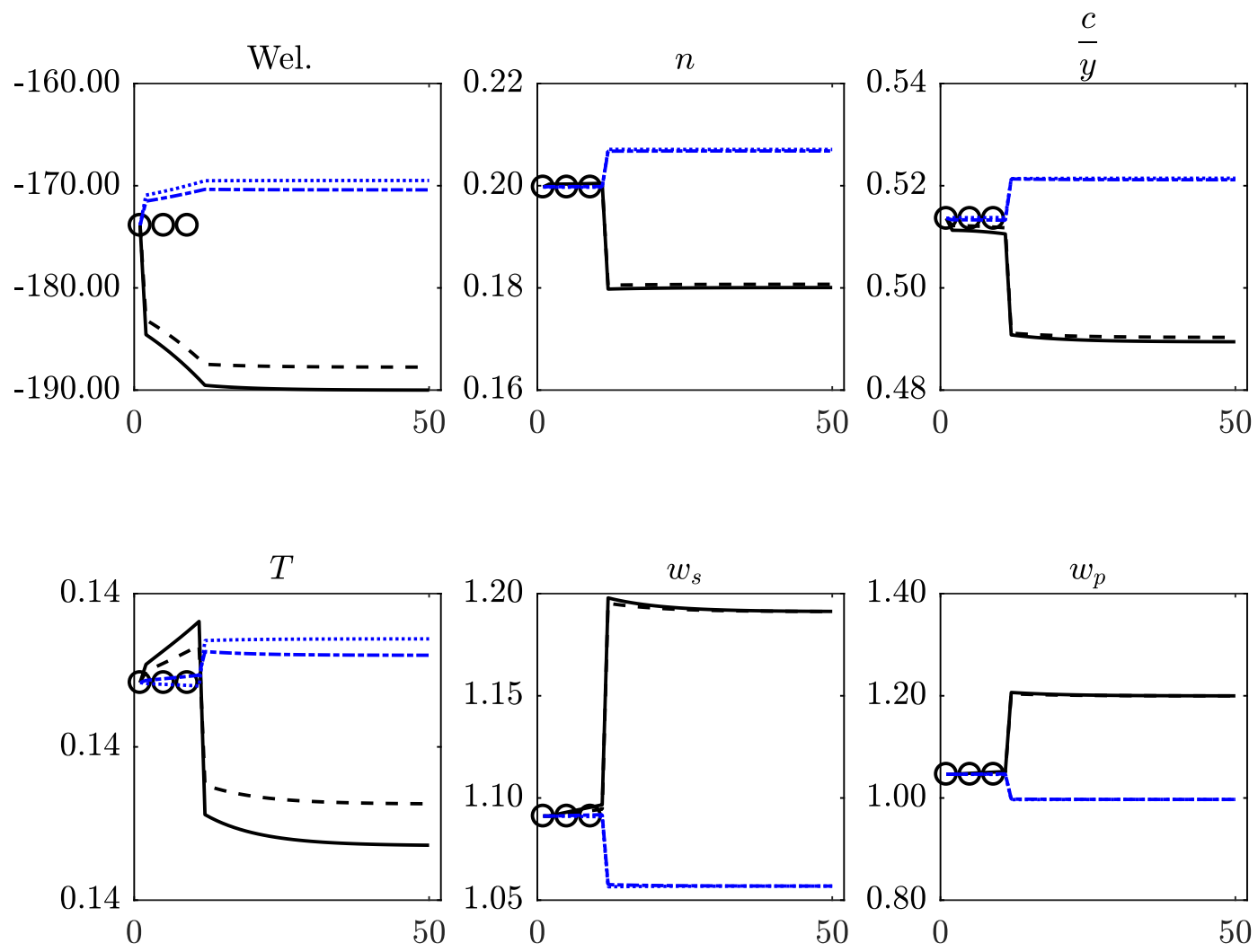

Notes: This figure shows responses to a foreseen once-and-for-all change in the ratio of taxes, i.e. from $\tau^{s}=0.147$ to $\tau^{s}=0.0$ (black line - Policy 1: DNK) and to 0.204 (blue line - Policy 2: FRA), $\tau^{n}$ adjusts accordingly. The change occurs at period $T=10$, where $t=1$ is the initial time period. Prices induce effects that precede the policy changes that cause them. Dashed line indicates simulations with varying $\phi$, solid lines with $\phi$ fixed at the level estimated in the data steady state. Results for the US in Figure 9, results for all the analyzed countries in Figures A7a-A7m in the Appendix.

fixed $\phi$ (solid lines). However, such a large structural change could affect social and individual preference for this type of work. Thus, in the second version, we reestimate $\phi$ in the final steady state (an approach similar to section 4.2). This version we denote as varying $\phi$ (dashed lines). In fact for the EU-14, the reduction in the proportion of $\tau^{s}$ as described in Policy 1 ("Denmark") implies a change of $\omega$ to $8.3 \%$ from the initial $9.6 \%$ in the scenario with varying $\phi$ (which changes from 1.1099 to 0.9736 ). In the scenario of increasing the proportion of $\tau^{s}$ to $50 \%$ (Policy 2), $\omega$ increases to $10.1 \%$ with an accompanying adjustment in $\phi$ to 1.1631 .

A change in the structure of taxes resembling Denmark (Policy 1), that is increasing the component that is not evaded while decreasing the avoidable component, yields effectively an increase in labor income taxes. Because labor supply is elastic, hours decline in response to the tax hike, reducing output and tax revenues. This implies a fall in future government expenditure. Because the present value of taxes falls immediately, consumption rises immediately in anticipation of the fall in the overall tax burden. However, as labor supply in the future is lower, there is an 
Figure 9: Policy experiments in tax mix for US: transition paths
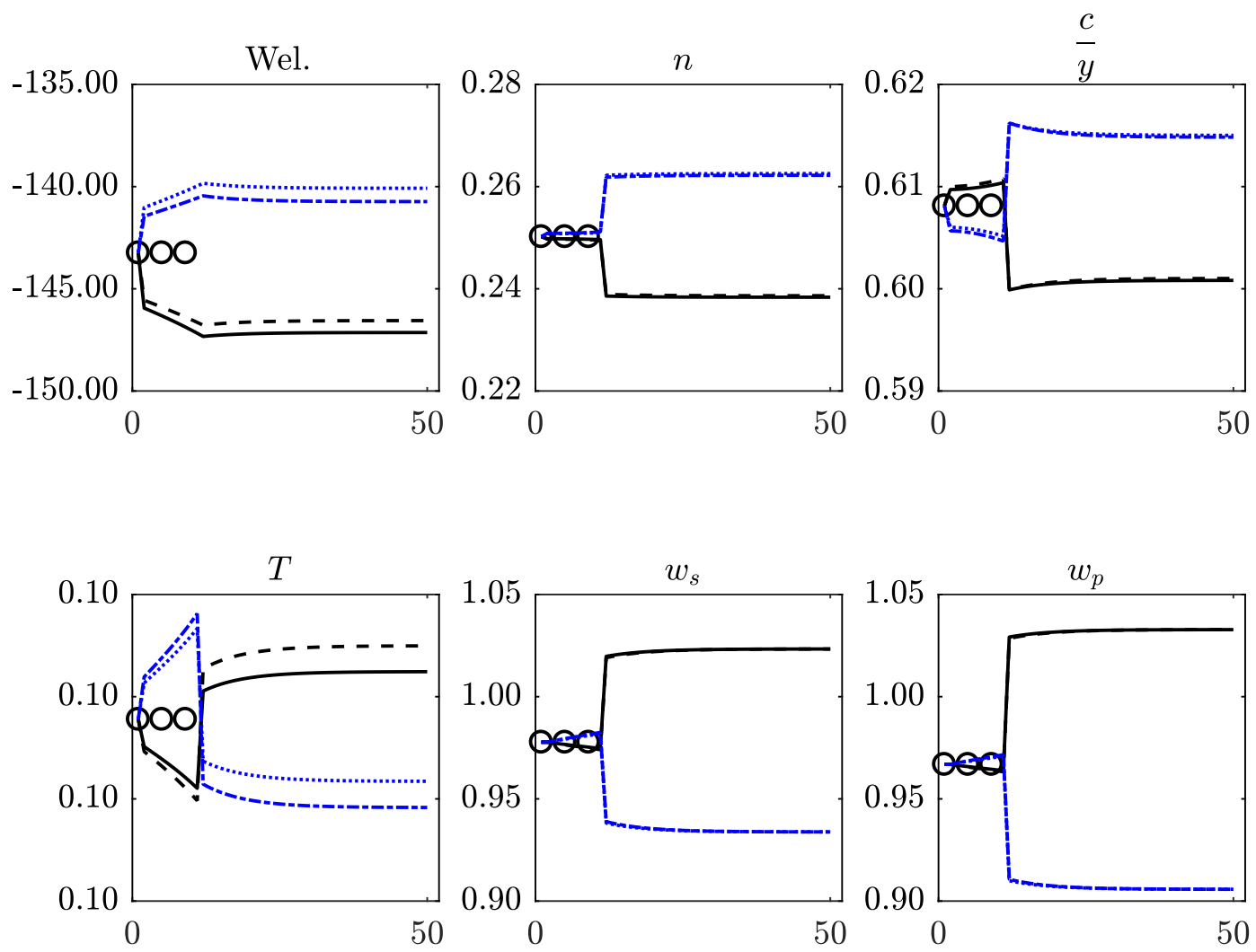

Notes: See Figure 8, the tax rates change from $\tau^{s}=0.068$ changes to $\tau^{s}=0.0$ (Policy 1 ) and to $\tau^{s}=0.14$ (Policy $2), \tau^{n}$ adjusts accordingly.

adverse wealth effect through a fall in output. Although the steady-state value of the capital stock is unaffected ${ }^{14}$, adjustment in consumption cause adjustments in capital stock over time (in fact, variation in the capital stock helps smooth consumption over time).

Overall, the tax revenues decrease because of downward adjustment in labor tax base and capital tax base, despite an increase in the consumption tax base. Thus, although consumption taxes are the largest share of tax revenues, they are not enough to compensate for the discouraging effect of increased labor taxation. Note that in the case of Policy 1, there is almost no difference between the scenario in which household preferences adjust to new institutional setting and the scenario in which they are kept at the level adequate for the initial steady state. By the same token, increasing the share of avoidable taxation in Policy 2, yields the opposite adjustments. The major difference is a stark increase in wages for both segments of the labor market. Although US economy starts from much lower tax rates and much lower social security contributions, policy experiments yield the same outcomes. We obtain similar results for the other 13 economies which suggests that the results are not driven by any specific calibration, see Figures A7a-A7m in the Appendix.

While reducing the scope for tax evasion reduces tax revenues in the US, there is an increase

\footnotetext{
${ }^{14}$ This follows from the fact that $\tau^{n}$ and $\tau^{s}$ do not appear in the steady state Euler equation (9)
} 
in labor supply, output and welfare. In both the EU-14 and the US, an increase in the avoidable social security component results into welfare gains equivalent to approximately $3 \%$ of lifetime consumption both in the scenario of varying $\phi$ and if disutility of work in the uncovered sector is allowed to adjust to the new institutional setting, see Figure 8 and 9. In contrast, a policy of reducing firms' social security contributions (which yields higher tax revenues in the US), reduces welfare; causing approximately $7 \%$ utility loss in consumption equivalent terms for EU-14 consumers ( $2 \%$ for the US). Clearly, the welfare effects are the outcome of two opposing adjustments. First, a change in hours worked and consumption per se affect the utility in the reform scenarios, relative to baseline. However, it is also the composition of work that matters. In fact, increasing work in the uncovered sector yields more disutility than an equivalent increase in hours worked with full coverage. This second order effect is non-negligible.

\subsubsection{Changing the expected penalty of avoiding social security contributions}

Our second policy experiment is changing the expected penalty for tax evasion. The policy experiment varies the expected penalty from the steady value in a given country to the maximum a government can impose as described in section 4.3, i.e. $p \bar{s}=1$. This is a substantial reform, in most countries the estimated internally consistent values of expected penalty a roughly 20 times lower. The reform is a once and for all change, as in the case of previous experiments. Prices induce effects that precede the policy changes that cause them. By analogy to the previous case, we also present two variants: with fixed $\phi$ and with re-estimated post reform: they represent lower and upper boundary of the likely effect. Figures 10 and 11 summarize the change in outcomes once an economy has attained a new steady state.

Despite reform being of enormous scale, the estimated effects are virtually negligible. Adjustments in wages are only transitory, which reflects the features of the production function - until firms change technology, there is little room for adjustments, so marginal products in primary sector will remain unaffected and workers will "pay" part of the penalty costs increase in lower wages. Total labor demand virtually does not move. If we allow part of the reform effects to exhibit in changing perceptions of secondary contracts - the scenario with varying $\phi$ - the consumption output ratio marginally adjust upwards in response to the changes in earned income of the households, which leads to slight increase in welfare. If we shut down the $\phi$ channel, there is no change in welfare or consumption: just transfer from secondary contract workers to the budget.

\subsection{Discussion of results}

The results of our model and subsequent policy experiments suggest three important conclusions. First, there is substantial room for welfare improvement by adjusting the tax mix, if one acknowledges that at least in some countries non-standard employment contracts may aid employers in evading taxes rather than reflect the flexibility needed by both sides of the contract.

Second, the stunning asymmetry in the mix of labor taxation between avoidable and unavoidable taxes is reflected to a large extent in how our model projects the static and dynamic effects of policy changes. While generally reforms making countries more similar to Denmark - low avoidable taxes 
Figure 10: Policy experiments in penalty for avoidance for EU-14: transition paths
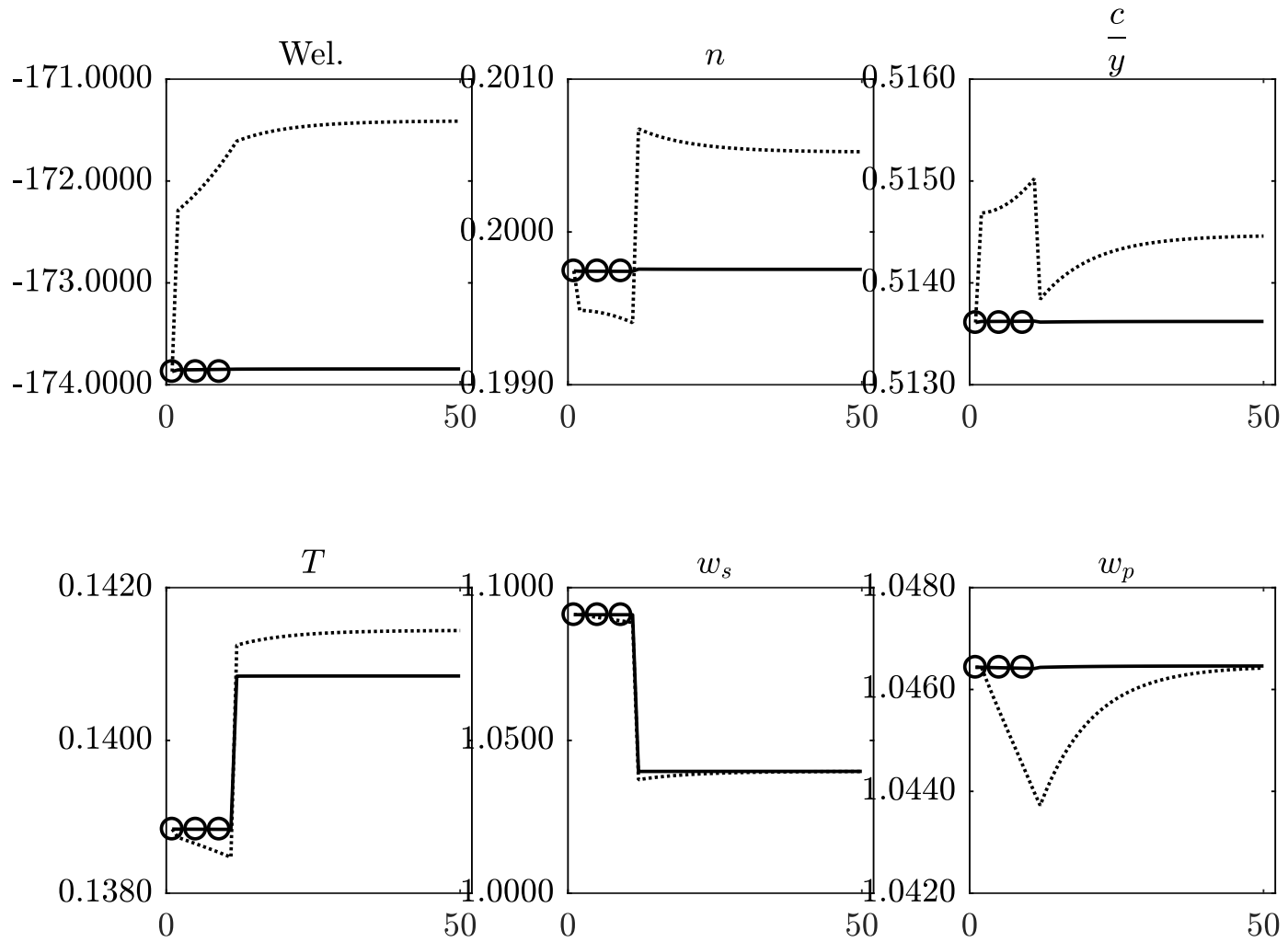

Notes: Expected penalty is increased from $p \bar{s}=0.050$ to $p \bar{s}=1$. The change occurs at period $t=10$, where $t=1$ is the initial time period. Dashed line indicates simulations with varying $\phi$, solid lines with $\phi$ fixed at the level estimated in the data steady state. Results for the US in Figure 11. Results for all the other analyzed countries in the Appendix. 
Figure 11: Policy experiments in penalty for avoidance for USA: transition paths
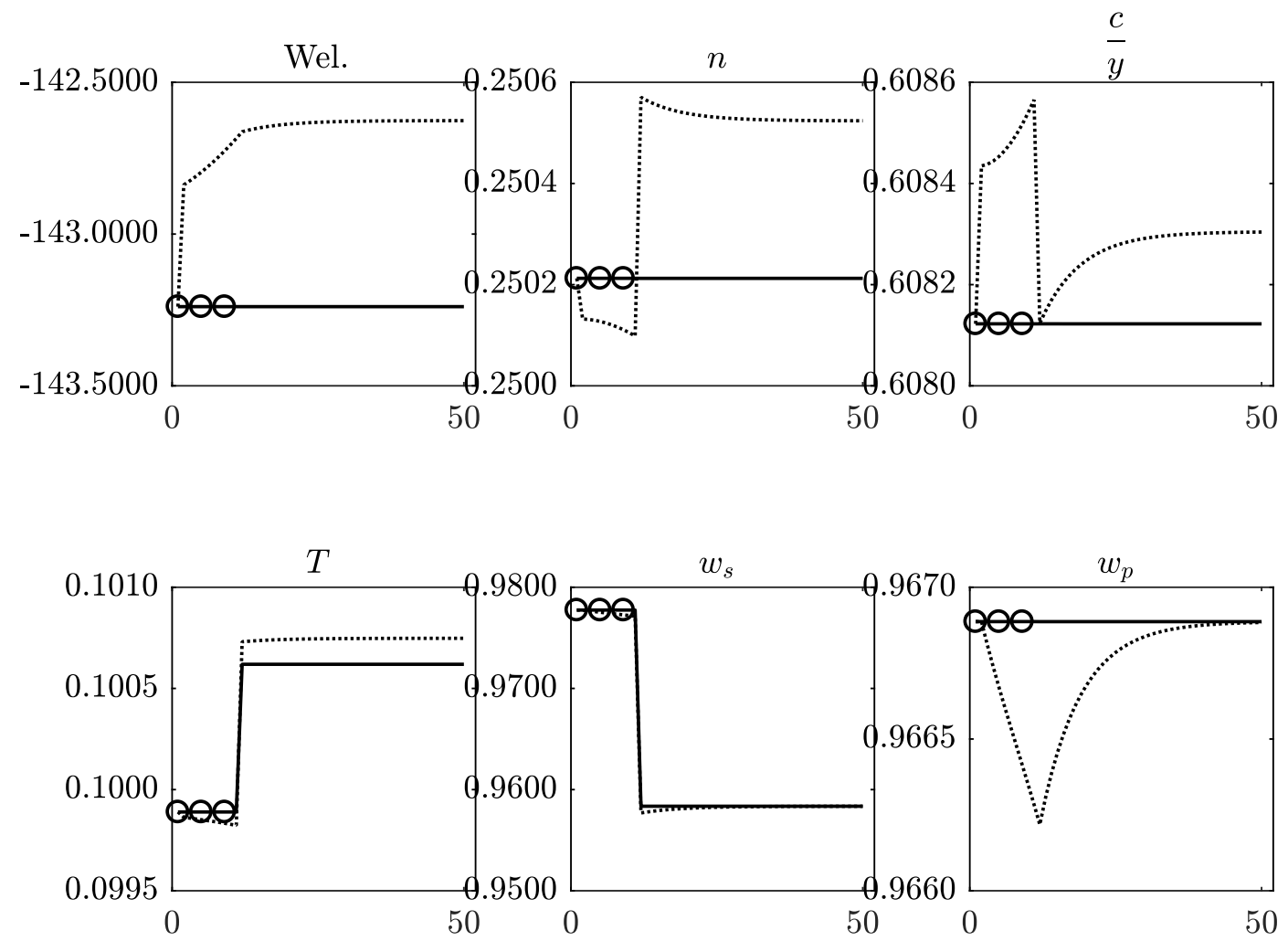

Notes: See notes under Figure 10. The change in the penalty is from $p \bar{s}=0.0543$ to $p \bar{s}=1$. Results for all the other analyzed countries in the Appendix. 
Figure 12: Policy experiments transition summary in consumption units

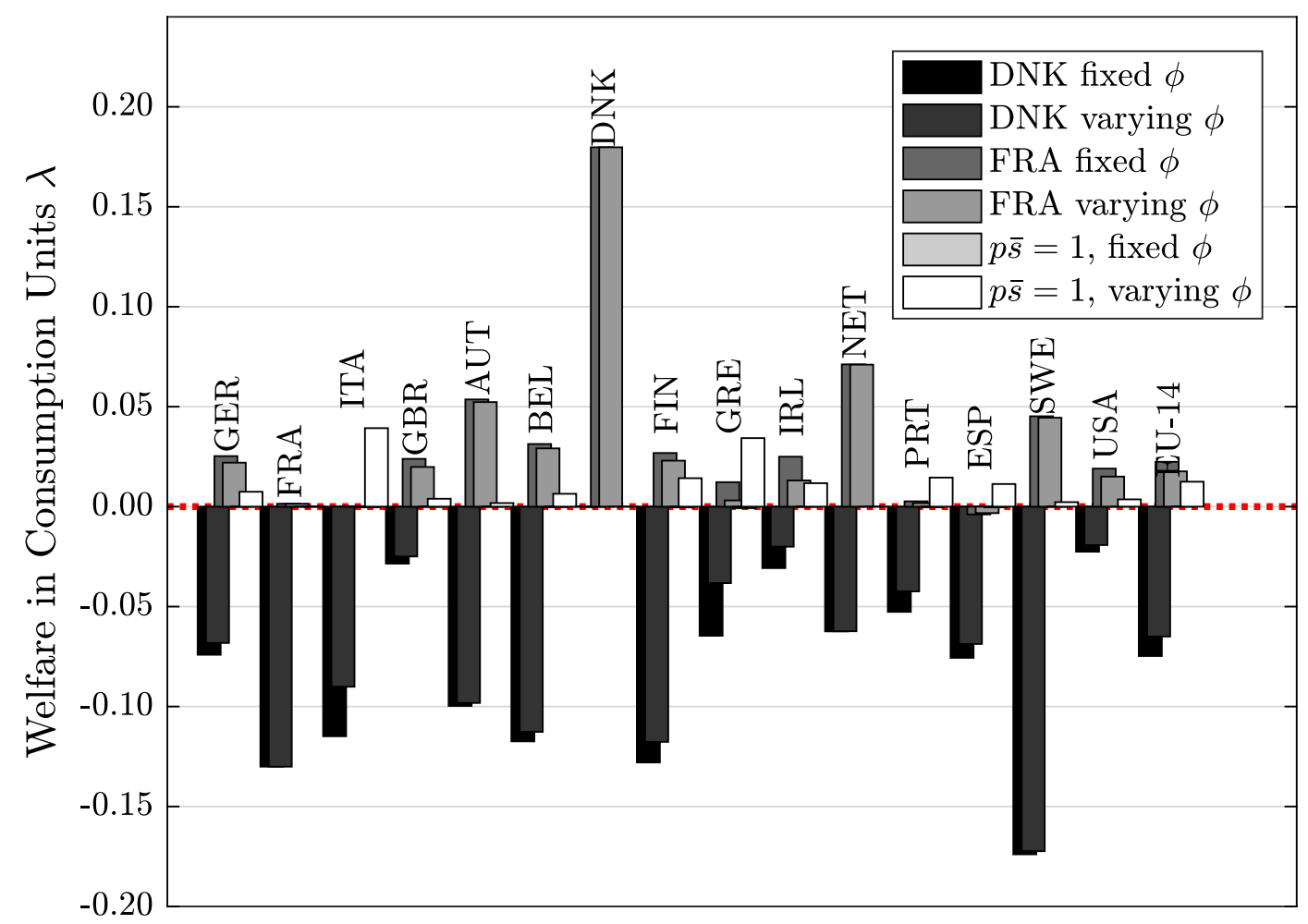

Notes: This figure summarizes the welfare effects of each policy experiments reported in the main text and appendices. The bars represent welfare changes in equivalent consumption units (16) at the end of transitioning to a new steady state.

and high unavoidable taxes - are detrimental to welfare, the scale of these costs differs substantially across countries. Similar effects hold for reforms which increase the share of avoidable taxes in total labor taxation: welfare gains range from a small percentage of lifetime consumption to even 10-20\%, as illustrated in Figure 12, which shows the change in welfare after transitioning to a new steady state.

Third, against this background, the often invoked policies of increasing the institutional capacity to audit and penalize cases of abuse on the side of employer are not likely to deliver comparable gains. Even complete detection, as is our policy experiment, yields marginal welfare effects, admittedly positive. The exceptions from this rule are the few cases where our model is relatively less successful in fitting the economy features.

Naturally, as is usually the case, our model has some shortcomings, which necessitate caution in interpreting the findings. First, it is fairly stylized representation of economy, with a passive government without any objective. Typically, the structure of taxation is a political economy question similar to that of the total labor tax wedge. There is also path dependence in a sense that many of the asymmetries in the labor taxation stem from many subsequent partial reforms of labor markets and social security systems in response to instantaneously identified immediate fiscal or equality challenges. Hence, our thought experiments can only serve as a suggestion of what could 
be feasible - not a policy recommendation what should be done.

Second, while households optimize labor supply (and consumption) our model does not include features such as bargaining over compensated market work and usually uncompensated home work. Nor do we account for rather frequent phenomenon of kinks in marginal taxation of labor in the case of couples (or couples with children). Such features may be easily represented in a study focused on one country with the use of our proposed approach and until then we recognize that the final effects of general changes in labor tax mix may indeed differ from a single representative household solution.

Third, in our setting an avoidable tax is calibrated to reflect the social security, because nonstandard contracts such as self-employment or non-employment contracts are exempt (fully or partially). However, in a longer term horizon agents may become increasingly inclined to (for example) contribute to a pension system if the internal rate of return is favorable in comparison to the capital markets (i.e. if there is an implicit subsidy in a pension system, conditional on contributions). Analogously, if workers would rather evade social security contributions (e.g. because of an implicit taxation in a pension system) then we are likely to overstate the benefits of symmetric coverage. Our model has infinitely lived agents rather than ageing agents with an overlapping generations structure. Hence, we cannot account for this additional, tacit value of avoidable taxes to the workers in ways other than calibrated disutility of work. If that treatment falls short of adequately addressing the issue - e.g. due to life-cycle patterns - then our results may be biased downward or upwards, depending on the sign of deviation.

\section{Conclusions}

It is frequent in public economics to discuss the optimal rate of taxation. However, with the diversity of employment and taxation forms, more understanding on the interplay between the forms of taxation and the forms of employment is needed. In many advanced economies, contracts without full social protection (and thus exempt from social security contributions) are used and often abused. This form of labor market duality has been analyzed from many angles in the labor economics literature, but so far little attention was devoted to the optimal composition of various labor taxes from the fiscal and welfare perspective.

In this paper we have developed a general equilibrium model with substitutable workers, who work in the primary labor market (with employers paying social security contributions and workers subject to labor taxation) or in the secondary labor market (where employers avoid social security contributions, but workers are still subject to labor taxation). Employers who avoid full employment contracts face a non-zero probability of detection and a penalty. In principle, this implies that there is some labor on which the total tax wedge is unavoidable and some labor on which part of the burden - namely social security contributions - can be avoided. The model in the spirit of Trabandt and Uhlig (2011) generates Laffer-type effects even with no evasion (on social security contributions or other taxes). When calibrated with the partial avoidance of social security contributions, the estimated Laffer curves are more elastic to the tax rate changes.

However, our model also provides less intuitive insights. First, we show that income effects 
dominate the disutility from working, i.e. it is optimal for welfare to reduce the share of social security contribution in total labor taxation. Yet, it has direct implications for reducing output, capital stock and total tax revenues. Second, it seems that in most of the analyzed economies, there is scope for increasing tax revenues by increasing the overall labor taxation even if model accounts for tax evasion. If the two types of a reform were combined - increased tax rate and reduced share of social security contributions, the opposite fiscal effects could actually neutralize each other. Naturally, this class of models yields adverse conclusions in terms of output, capital stock and employment.

Our paper offers important policy implications. First, in many countries the total labor tax revenues may be increased without changing the overall taxes but by an adjustment to the combination of labor income tax and the social security contributions. Moreover, welfare enhancing policies are not necessarily detrimental to tax revenues. Finally, labor market duality is not always undesirable - reducing the size of secondary labor market to zero is not always an optimum, either from the fiscal or welfare perspective.

Our approach may be extended to a framework with a fully "informal" sector, i.e. a segment of the labor market avoiding the entire labor tax wedge. Such extension would not alter the general findings concerning the optimal proportion between avoidable and unavoidable labor taxes. The model may also be extended to incorporate a labor market mechanism explicitly separating primary from secondary labor markets, with frictions, idiosyncratic shocks and insurance. In the deterministic setup and no implicit savings in the social security contributions agents have little intrinsic motivation to choose between primary and secondary employment. Disentangling the insurance motive and asymmetric costs of obtaining employment in the two segments of the labor market would enrich further the policy relevance of this field of literature. 


\section{References}

Alanon, A. and Gomez-Antonio, M.: 2005, Estimating the size of the shadow economy in Spain: a structural model with latent variables, Applied Economics 37(9), 1011-1025.

Allingham, M. G. and Sandmo, A.: 1972, Income tax evasion: a theoretical analysis, Journal of Public Economics 1(3-4), 323-338.

Ardizzi, G., Petraglia, C., Piacenza, M. and Turati, G.: 2014, Measuring the underground economy with the currency demand approach: a reinterpretation of the methodology, with an application to Italy, Review of Income and Wealth 60(4), 747-772.

Atkinson, A. B. and Stiglitz, J. E.: 1976, The design of tax structure: direct versus indirect taxation, Journal of Public Economics 6(1), 55-75.

Bergolo, M. and Cruces, G.: 2014, Work and tax evasion incentive effects of social insurance programs: Evidence from an employment-based benefit extension, Journal of Public Economics 117, 211-228.

Bernasconi, M., Levaggi, R. and Menoncin, F.: 2015, Tax evasion and uncertainty in a dynamic context, Economics Letters 126, 171-175.

Breusch, T.: 2005, Estimating the underground economy using mimic models, Technical report, EconWPA.

Busato, F. and Chiarini, B.: 2013, Steady State Laffer Curve with the Underground Economy, Public Finance Review pp. 109-114.

Busato, F., Chiarini, B. and Marchetti, E.: 2011, Indeterminacy, underground activities and tax evasion, Economic Modelling 28(3), 831-844.

Busato, F., Chiarini, B. and Rey, G. M.: 2012, Equilibrium implications of fiscal policy with tax evasion: A long run perspective, International Review of Law and Economics 32(2), 197-214.

Cappariello, R. and Zizza, R.: 2010, Dropping the books and working off the books, Labour 24(2), 139-162.

Castellucci, L. and Bovi, M.: 1999, What Do We Know about the Size of the Underground Economy in Italy Beyond the" Common Wisdom"?: Some Empirically Tested Propositions, Università degli studi di Roma" Tor Vergata".

Castillo, P. and Montoro, C.: 2010, Monetary policy in the presence of informal labour markets, Technical report, Banco Central de Reserva del Perú.

Chetty, R., Guren, A., Manoli, D. and Weber, A.: 2012, Does indivisible labor explain the difference between micro and macro elasticities? a meta-analysis of extensive margin elasticities, NBER Macroeconomics Annual 2012, Volume 27, University of Chicago Press, pp. 1-56. 
Dell'Anno, R.: 2003, Estimating the shadow economy in Italy: A structural equation approach, Working Paper 2003-7, Department of Economics, University of Aarhus.

Di Caro, P. and Nicotra, G.: 2015, Short, long and spatial dynamics of informal employment, Regional Studies pp. 1-15.

Diamond, P. A. and Mirrlees, J. A.: 1971a, Optimal taxation and public production I: Production efficiency, The American Economic Review 61(1), 8-27.

Diamond, P. A. and Mirrlees, J. A.: 1971b, Optimal taxation and public production ii: Tax rules, The American Economic Review 61(3), 261-278.

Fernald, J. G. and Jones, C. I.: 2014, The future of US economic growth, The American Economic Review 104(5), 44-49.

Flórez, L. A. and Perales, F.: 2015, Labour protection and informal work: A cross-national analysis of European countries, 2004-2012, International Labour Review .

Havránek, T.: 2015, Measuring intertemporal substitution: The importance of method choices and selective reporting, Journal of the European Economic Association 13(6), 1180-1204.

Hilton, D., Charalambides, L., Demarque, C., Waroquier, L. and Raux, C.: 2014, A tax can nudge: The impact of an environmentally motivated bonus/malus fiscal system on transport preferences, Journal of Economic Psychology 42, 17-27.

Hiraga, K., Nutahara, K. et al.: 2016, When is the Laffer curve for consumption tax hump-shaped?, CIGS Working Paper Series 16-002E, The Canon Institute for Global Studies.

Joulfaian, D. and Rider, M.: 1998, Differential Taxation and Tax Evasion by Small Business, National Tax Journal 51(4), 676-687.

Krueger, A. B. and Meyer, B. D.: 2002, Labor supply effects of social insurance, Handbook of public economics 4, 2327-2392.

Loayza, N.: 1996, The economics of the informal sector: a simple model and some empirical evidence from Latin America, Carnegie-Rochester Conference Series on Public Policy, Vol. 45, pp. 129-162.

Loayza, N., Oviedo, A. M. and Serven, L.: 2005, The impact of regulation on growth and informality cross-country evidence, World Bank Policy Research Working Paper (3623).

Lusardi, A. and Mitchell, O. S.: 2011, Financial literacy around the world: an overview, Journal of Pension Economics and Finance 10(04), 497-508.

Mendoza, E. G., Razin, A. and Tesar, L. L.: 1994, Effective tax rates in macroeconomics: Cross-country estimates of tax rates on factor incomes and consumption, Journal of Monetary Economics 34(3), 297-323. 
Merz, J. and Wolff, K. G.: 1993, The shadow economy: illicit work and household production: a microanalysis of West Germany, Review of Income and Wealth 39(2), 177-194.

Mirrlees, J. A.: 1971, An exploration in the theory of optimum income taxation, Review of Economic Studies 38(2), 175-208.

Orsi, R., Raggi, D. and Turino, F.: 2014, Size, Trend, and Policy Implications of the Underground Economy, Review of Economic Dynamics 17(3), 417-436.

Pappa, E., Sajedi, R. and Vella, E.: 2015, Fiscal consolidation with tax evasion and corruption, Journal of International Economics 96, S56-S75.

Pickhardt, M. and Prinz, A.: 2014, Behavioral dynamics of tax evasion-a survey, Journal of Economic Psychology 40, 1-19.

Pickhardt, M. and Sardà Pons, J.: 2006, Size and scope of the underground economy in Germany, Applied Economics 38(14), 1707-1713.

Piketty, T. and Saez, E.: 2013, Chapter 7 - Optimal Labor Income Taxation, Vol. 5 of Handbook of Public Economics, Elsevier, pp. 391-474.

Rakowski, C. A.: 1994, Convergence and divergence in the informal sector debate: A focus on Latin America, 1984-92, World Development 22(4), 501-516.

Sandmo, A.: 2005, The theory of tax evasion: A retrospective view, National Tax Journal pp. 643663.

Schneider, F.: 2011, The shadow economy and shadow economy labor force: What do we (not) know?, IZA Discussion Paper 5769, Institute for the Study of Labor (IZA).

Schneider, F.: 2014, The shadow economy and shadow labor force: A survey of recent developments, IZA Discussion Paper 8278, Institute for the Study of Labor (IZA).

Schneider, F. and Enste, D.: 2000, Shadow economies: Size, causes, and consequences, Journal of Economic Literature 38, 77-114.

Schneider, F. and Hametner, B.: 2014, The shadow economy in Colombia: Size and effects on economic growth, Peace Economics, Peace Science and Public Policy 20(2), 293-325.

Slemrod, J. and Weber, C.: 2012, Evidence of the invisible: toward a credibility revolution in the empirical analysis of tax evasion and the informal economy, International Tax and Public Finance 19(1), 25-53.

Slemrod, J. and Yitzhaki, S.: 2002, Tax avoidance, evasion, and administration, Handbook of Public Economics 3, 1423-1470.

Stavrunova, O. and Yerokhin, O.: 2014, Tax incentives and the demand for private health insurance, Journal of Health Economics 34, 121-130. 
Tonin, M.: 2011, Minimum wage and tax evasion: Theory and evidence, Journal of Public Economics 95(11), 1635-1651.

Trabandt, M. and Uhlig, H.: 2011, The Laffer curve revisited, Journal of Monetary Economics 58(4), 305-327.

Williams, C. C.: 2013, Beyond the formal economy: evaluating the level of employment in informal sector enterprises in global perspective, Journal of Developmental Entrepreneurship 18(04), 1350027.

Williams, C. C.: 2015, Cross-national variations in the scale of informal employment: An exploratory analysis of 41 less developed economies, International Journal of Manpower 36(2), 118-135.

Williams, C. C. and Windebank, J.: 2015, Evaluating competing theories of informal employment: some lessons from a 28-nation european survey, International Journal of Business and Globalisation 15(1), 45-62. 


\section{A Calibration}

Table A1: Tax rates used for calibration

\begin{tabular}{c|rrrr}
\hline \hline & $\tau^{s}$ & $\tau^{k}$ & $\tau^{n}$ & $\tau^{c}$ \\
\hline \hline GER & 0.143 & 0.233 & 0.269 & 0.155 \\
FRA & 0.225 & 0.355 & 0.231 & 0.183 \\
ITA & 0.232 & 0.340 & 0.234 & 0.145 \\
GBR & 0.070 & 0.356 & 0.208 & 0.163 \\
AUT & 0.146 & 0.240 & 0.354 & 0.196 \\
BEL & 0.180 & 0.424 & 0.307 & 0.173 \\
DNK & 0.000 & 0.506 & 0.474 & 0.349 \\
FIN & 0.191 & 0.313 & 0.296 & 0.271 \\
GRE & 0.161 & 0.160 & 0.245 & 0.154 \\
IRL & 0.068 & 0.207 & 0.199 & 0.257 \\
NET & 0.090 & 0.293 & 0.348 & 0.194 \\
PRT & 0.147 & 0.234 & 0.166 & 0.208 \\
ESP & 0.190 & 0.296 & 0.165 & 0.144 \\
SWE & 0.208 & 0.409 & 0.351 & 0.255 \\
USA & 0.068 & 0.364 & 0.212 & 0.047 \\
EU-14 & 0.147 & 0.327 & 0.260 & 0.170 \\
\hline \hline
\end{tabular}

Notes: Computed based on OECD figures (averaged over 1985-2010, or longest available time series). Values used in the model obtained following the procedure proposed by Mendoza et al. (1994).

Table A2: Model results

\begin{tabular}{l|cccccc}
\hline \hline & $\alpha$ & $\delta$ & $p \bar{s}$ & $\rho$ & $\phi$ & $\omega$ \\
\hline \hline GER & 0.3690 & 0.0667 & 0.0551 & 0.0134 & 1.0923 & 0.0578 \\
FRA & 0.4075 & 0.0686 & 1.1462 & -0.0009 & 0.9754 & 0.1382 \\
ITA & 0.3889 & 0.0704 & 0.0398 & 0.0094 & 1.2037 & 0.1802 \\
GBR & 0.3574 & 0.0641 & 0.0539 & 0.0109 & 1.0355 & 0.0656 \\
AUT & 0.3887 & 0.0707 & 0.0604 & 0.0516 & 0.9221 & 0.0172 \\
BEL & 0.3910 & 0.0837 & 0.0575 & 0.0153 & 1.1123 & 0.0394 \\
DNK & 0.3959 & 0.0923 & 0.1060 & 0.4605 & 0.1242 & 0.0107 \\
FIN & 0.3372 & 0.0697 & 0.0528 & 0.0188 & 1.1252 & 0.0775 \\
GRE & 0.3991 & 0.0609 & 0.0300 & 0.0122 & 1.1413 & 0.2720 \\
IRL & 0.3577 & 0.0861 & 0.0440 & 0.0116 & 1.0442 & 0.1538 \\
NET & 0.3819 & 0.0771 & 0.3556 & 1.7997 & 0.0000 & 0.0030 \\
PRT & 0.3876 & 0.0977 & 0.0485 & 0.0039 & 1.1295 & 0.1124 \\
ESP & 0.4242 & 0.0855 & 0.0545 & 0.0007 & 1.1757 & 0.0636 \\
SWE & 0.3617 & 0.0478 & 0.0610 & 0.0215 & 1.0850 & 0.0121 \\
USA & 0.3473 & 0.0833 & 0.0543 & 0.0131 & 1.0272 & 0.0616 \\
EU-14 & 0.3812 & 0.0702 & 0.0505 & 0.0111 & 1.1099 & 0.0956 \\
\hline \hline
\end{tabular}

Notes: $\alpha$ and $\delta$ are computed to exactly match the capital output ratio. $p \bar{s}, \rho, \phi, \omega$ are computed jointly from four non-linear equations. We assume that the labor tax revenue consists of tax contributions and proceeds from finining the tax evaders. Using the equation for labor tax revenue and the form of the production function, we get four non-linear equations in the four parameters. We solve for the parameters using non-linear least squares in MATLAB. 
Figure A1: Model fit

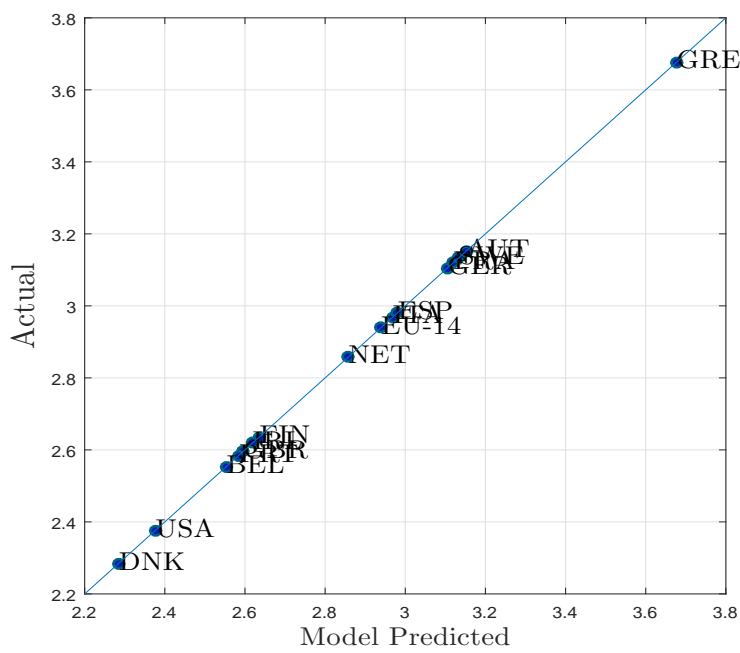

(a) Capital to output ratio

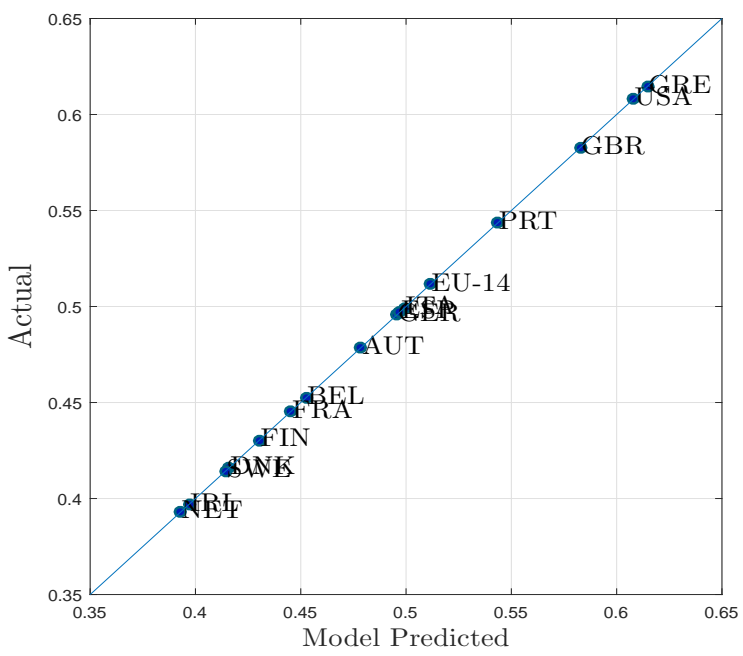

(c) Consumption to output ratio

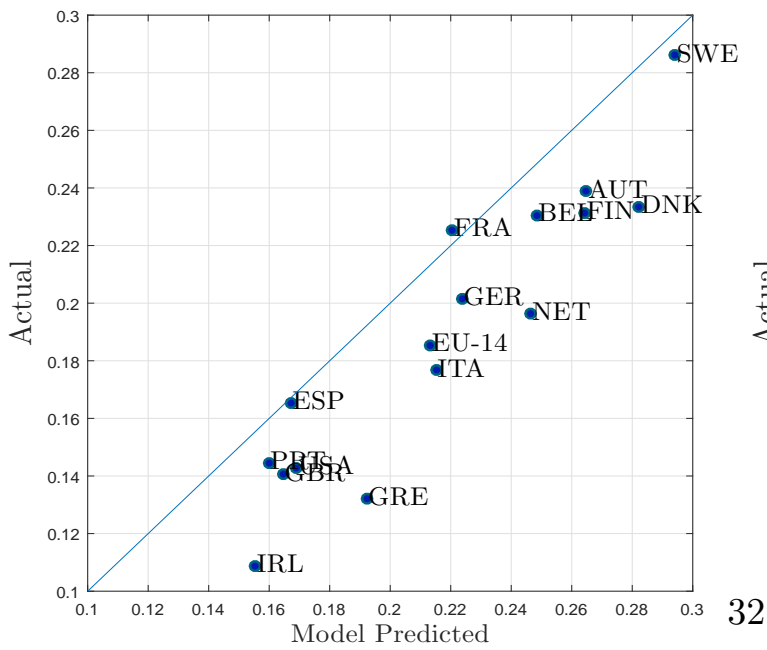

(e) Labor tax revenues

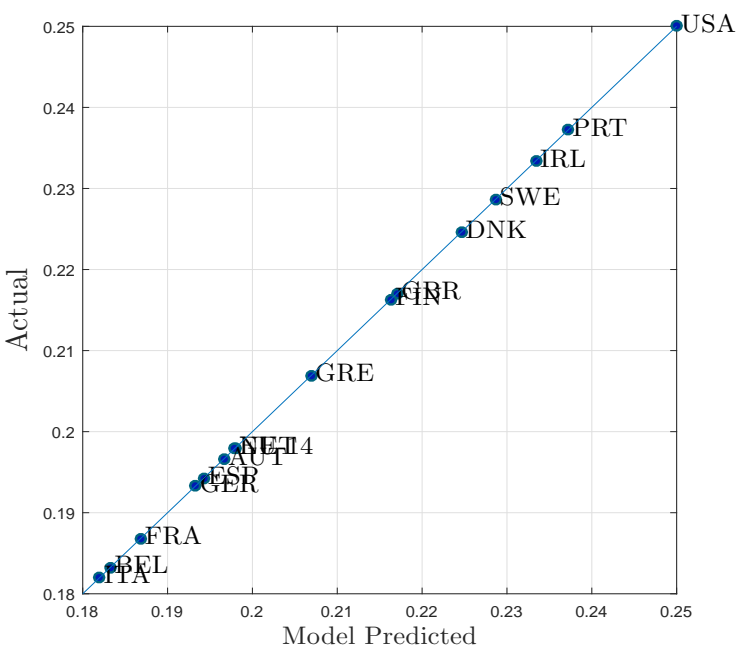

(b) Labor supply

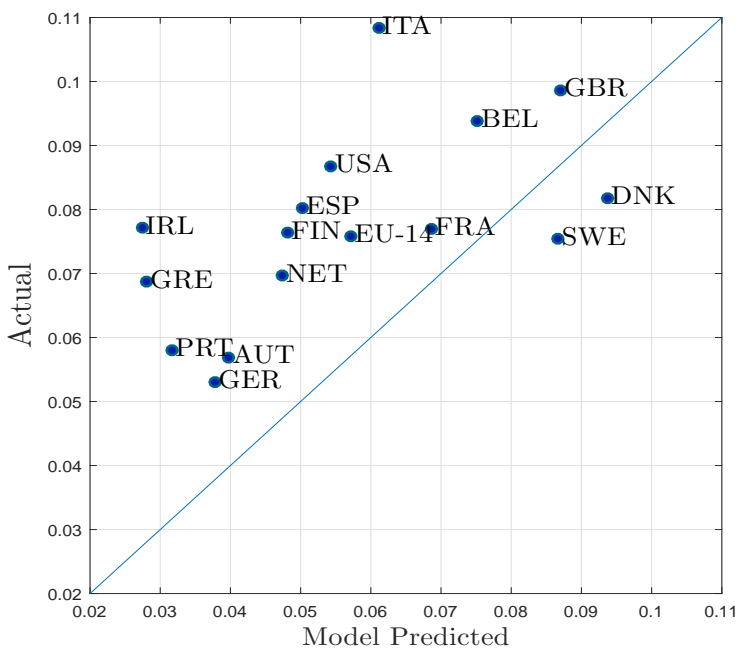

(d) Capital tax revenues

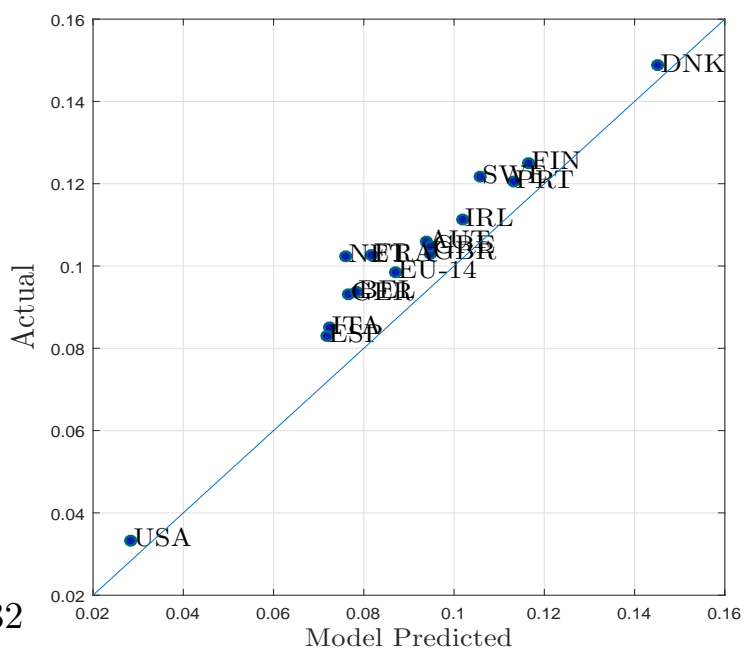

(f) Consumption tax revenues 
Figure A2: Laffer curves
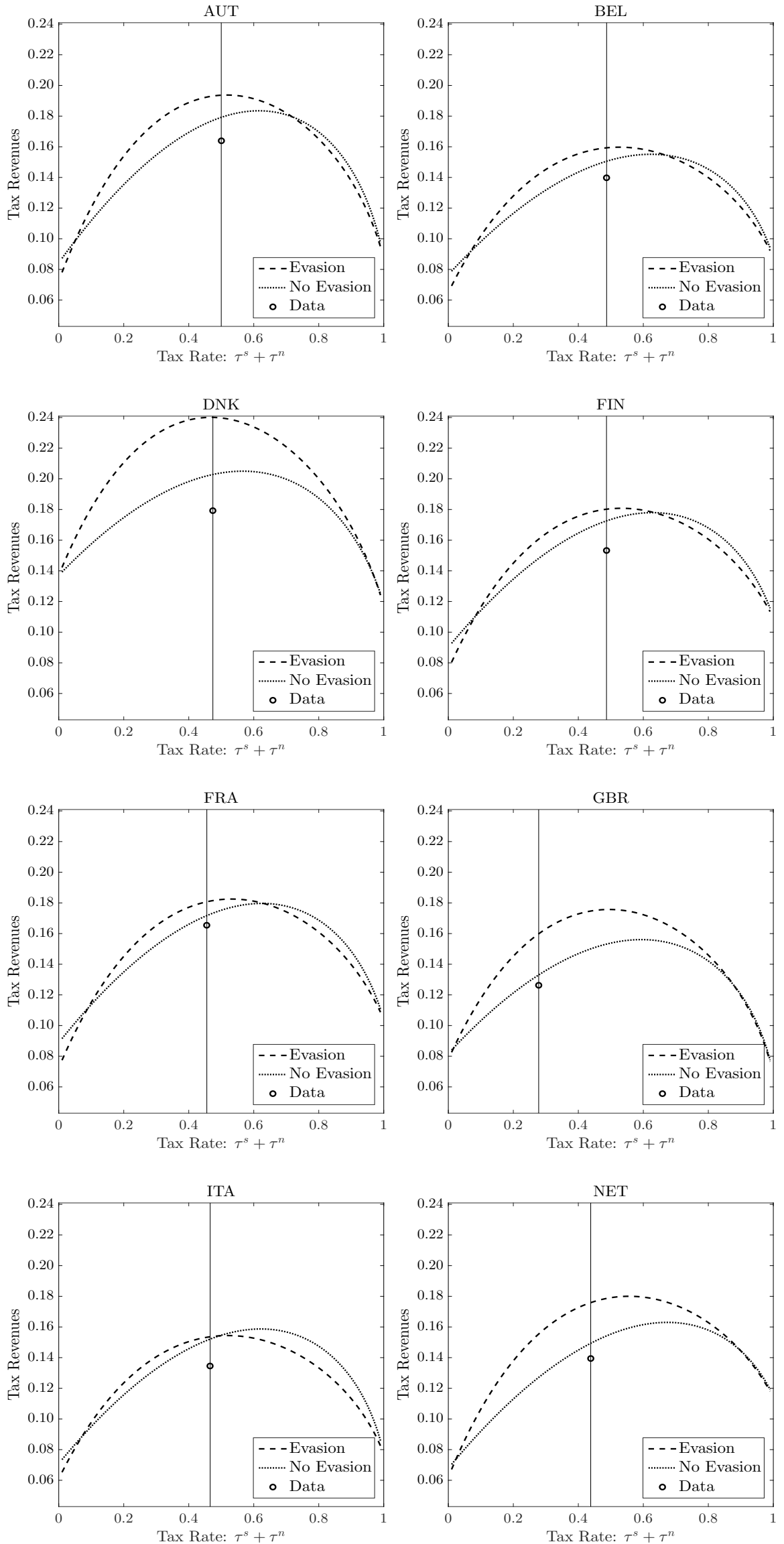
Figure A2: Laffer curves (cont.)
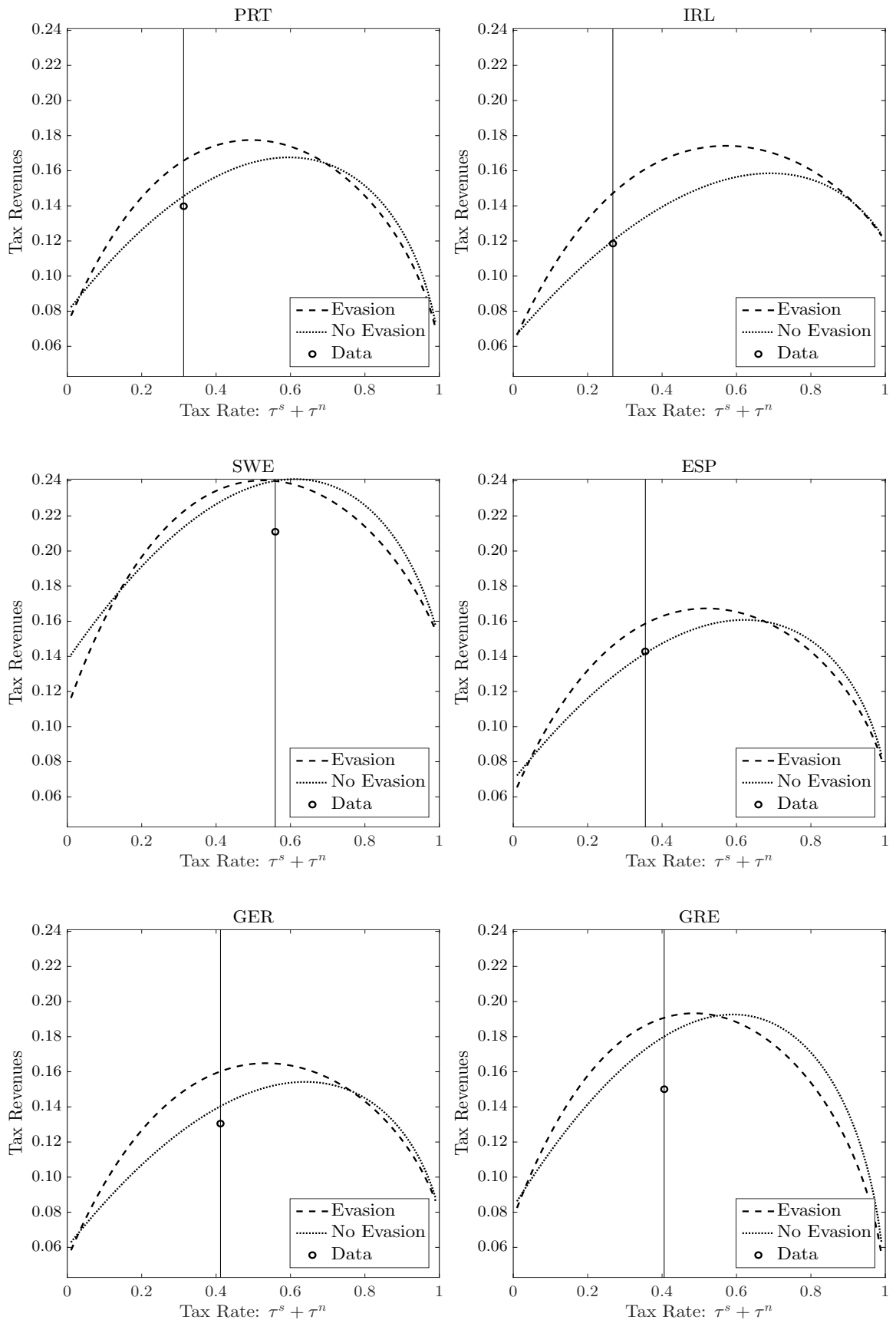
Figure A3: Optimal policy mix - tax revenues
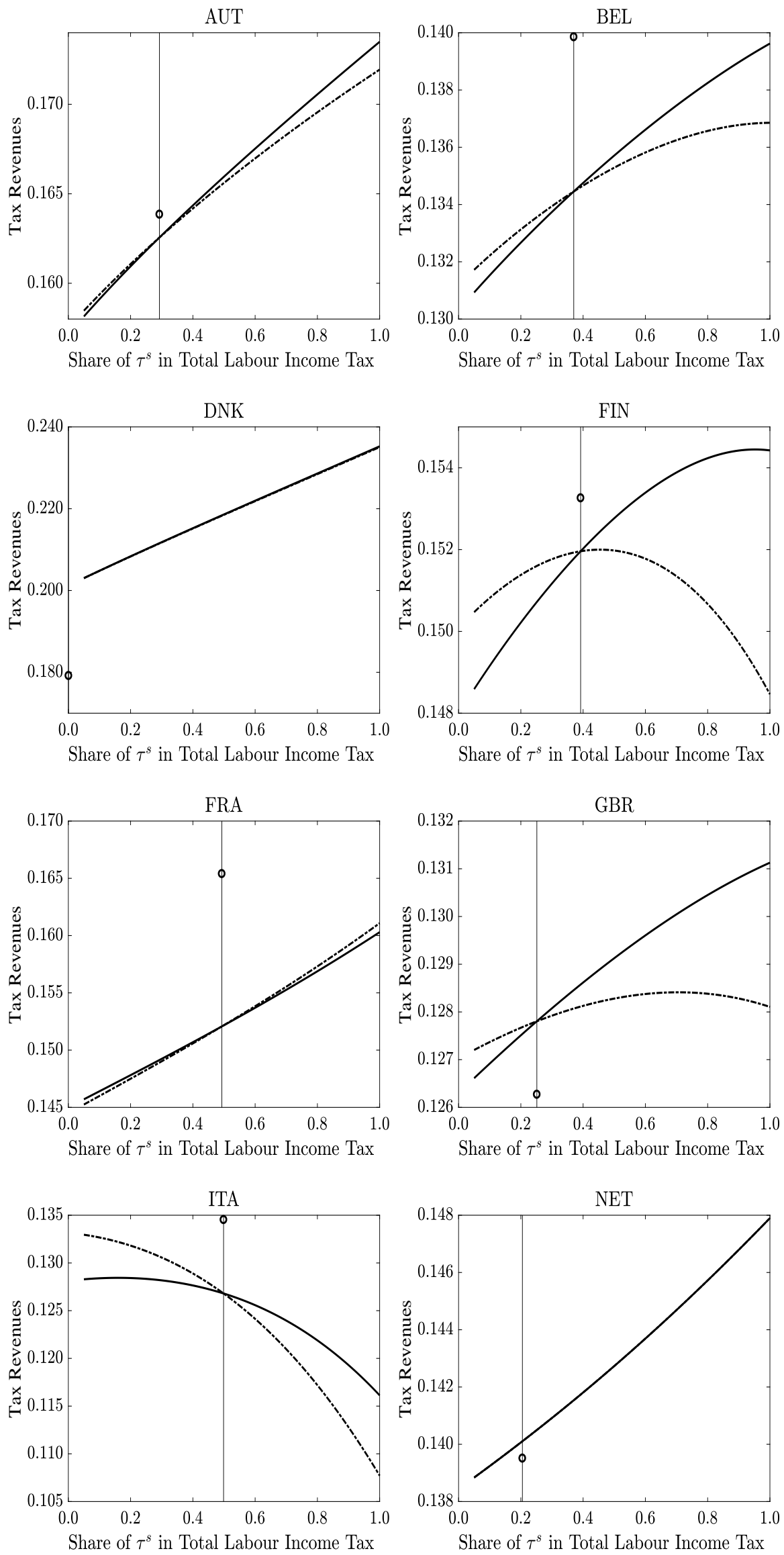
Figure A3: Optimal policy mix - tax revenues (cont.)
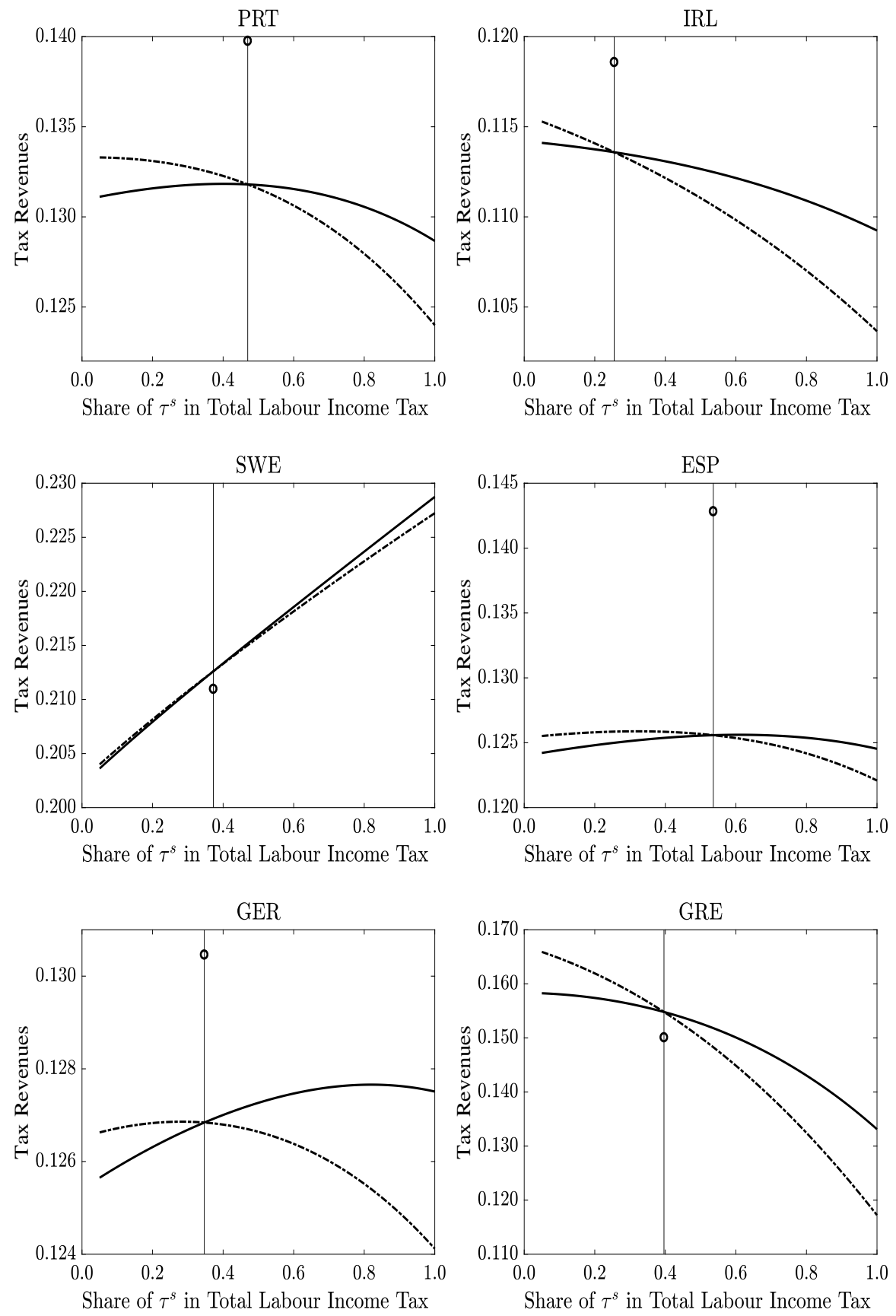
Figure A4: Optimal tax policy mix - employment and welfare
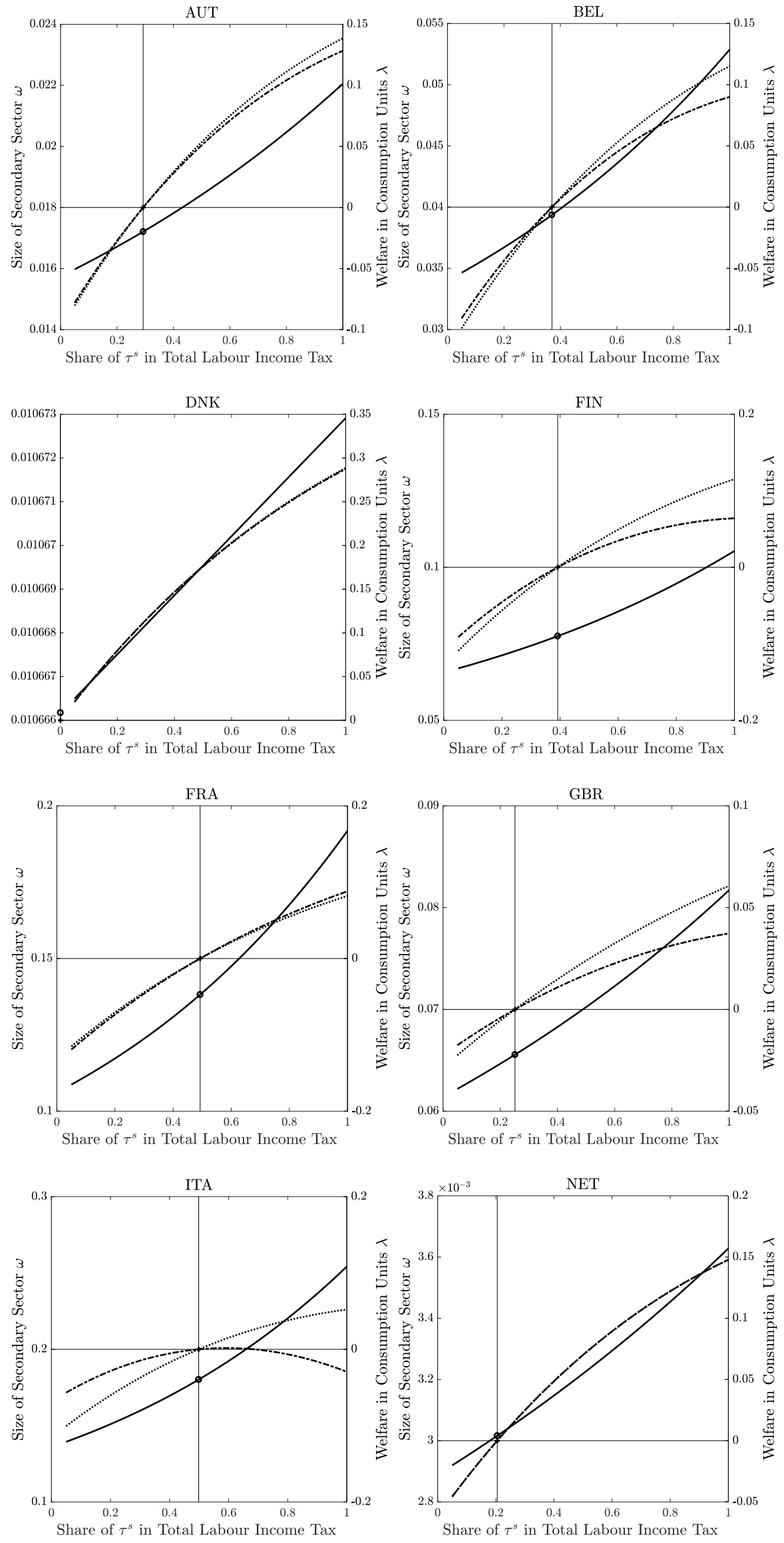
Figure A4: Optimal tax policy mix - employment and welfare (cont.)
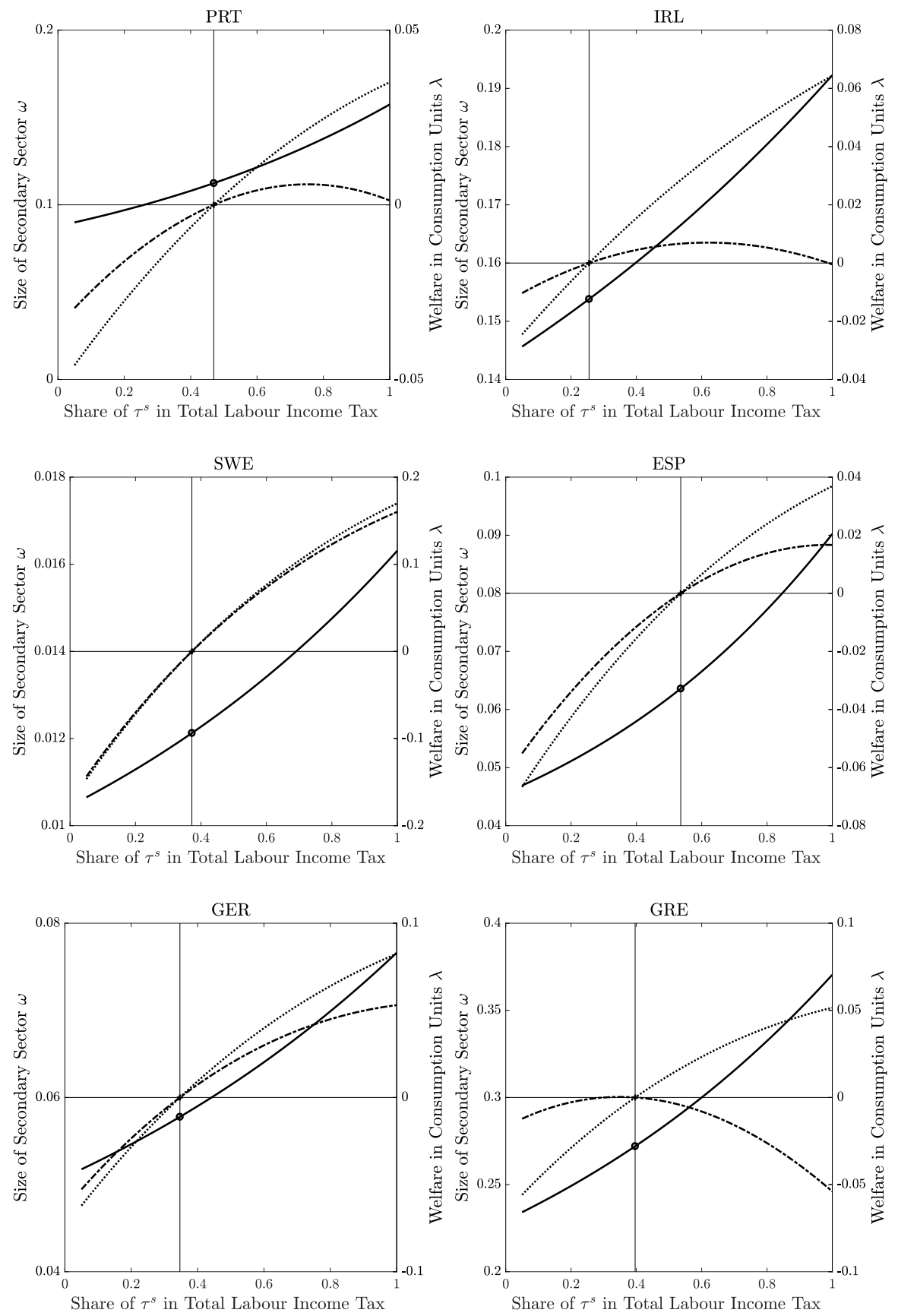
Figure A5: Optimal penalty - tax revenues
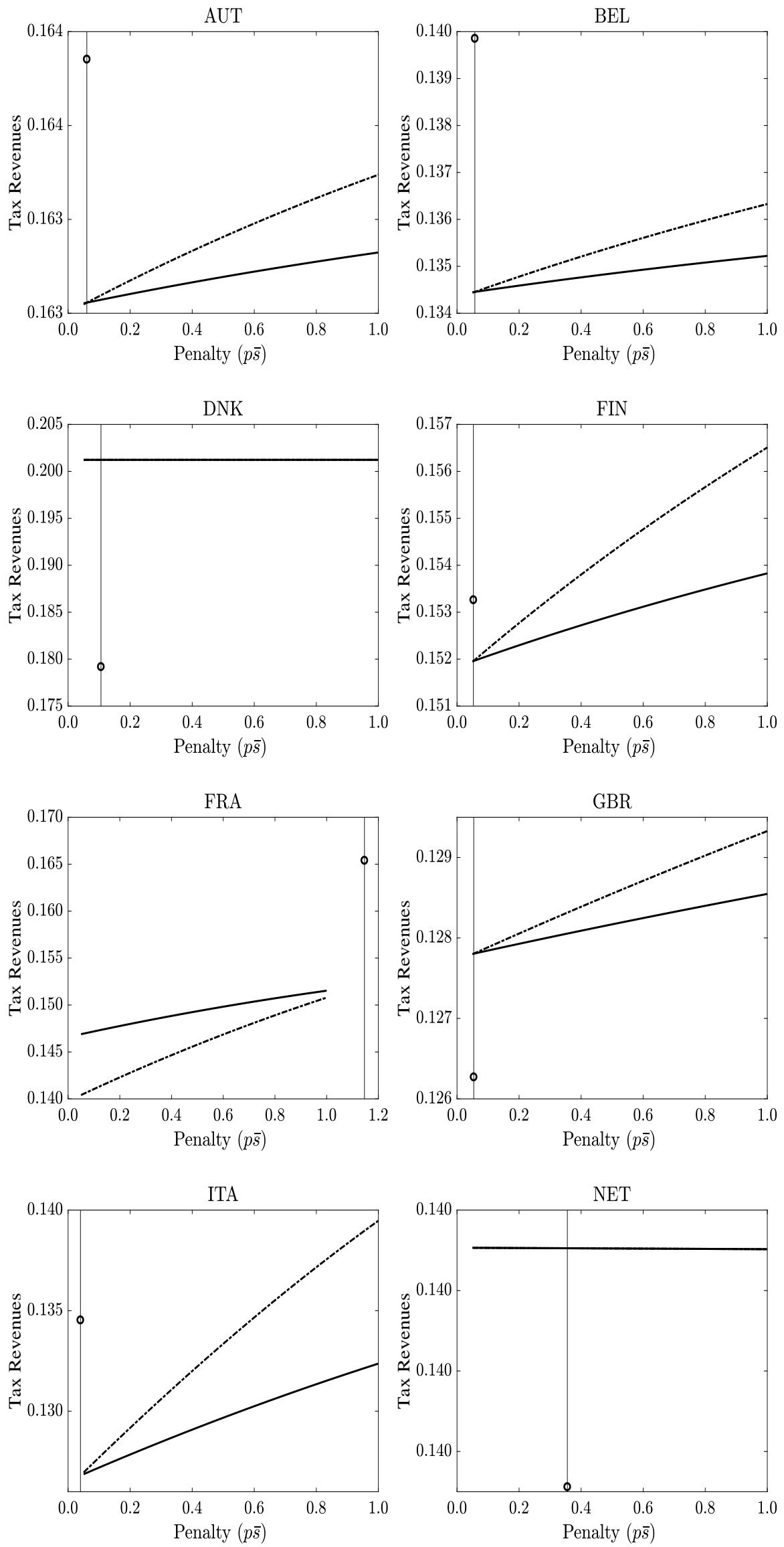
Figure A5: Optimal penalty - tax revenues (cont.)
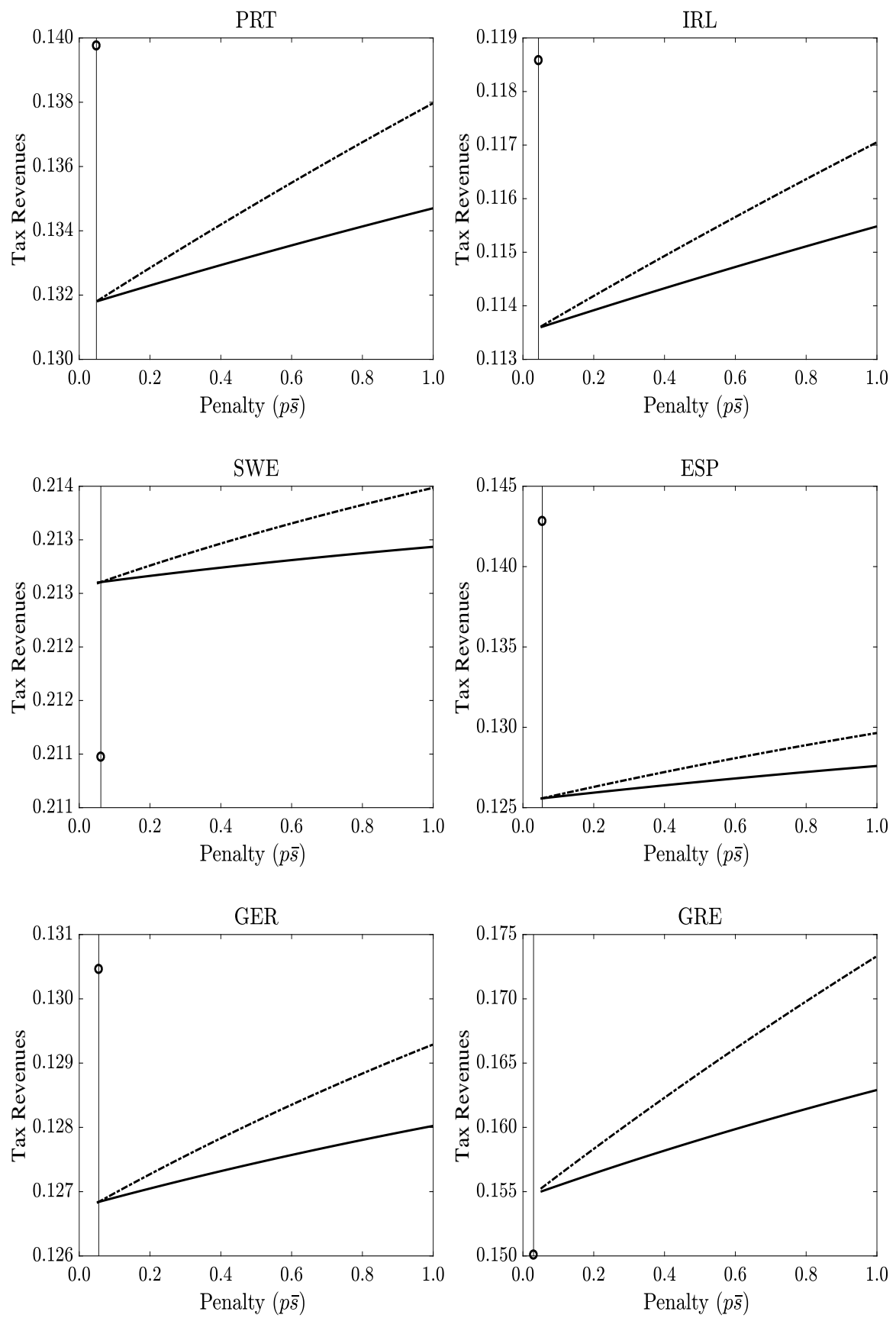
Figure A6: Optimal penalty - employment and welfare
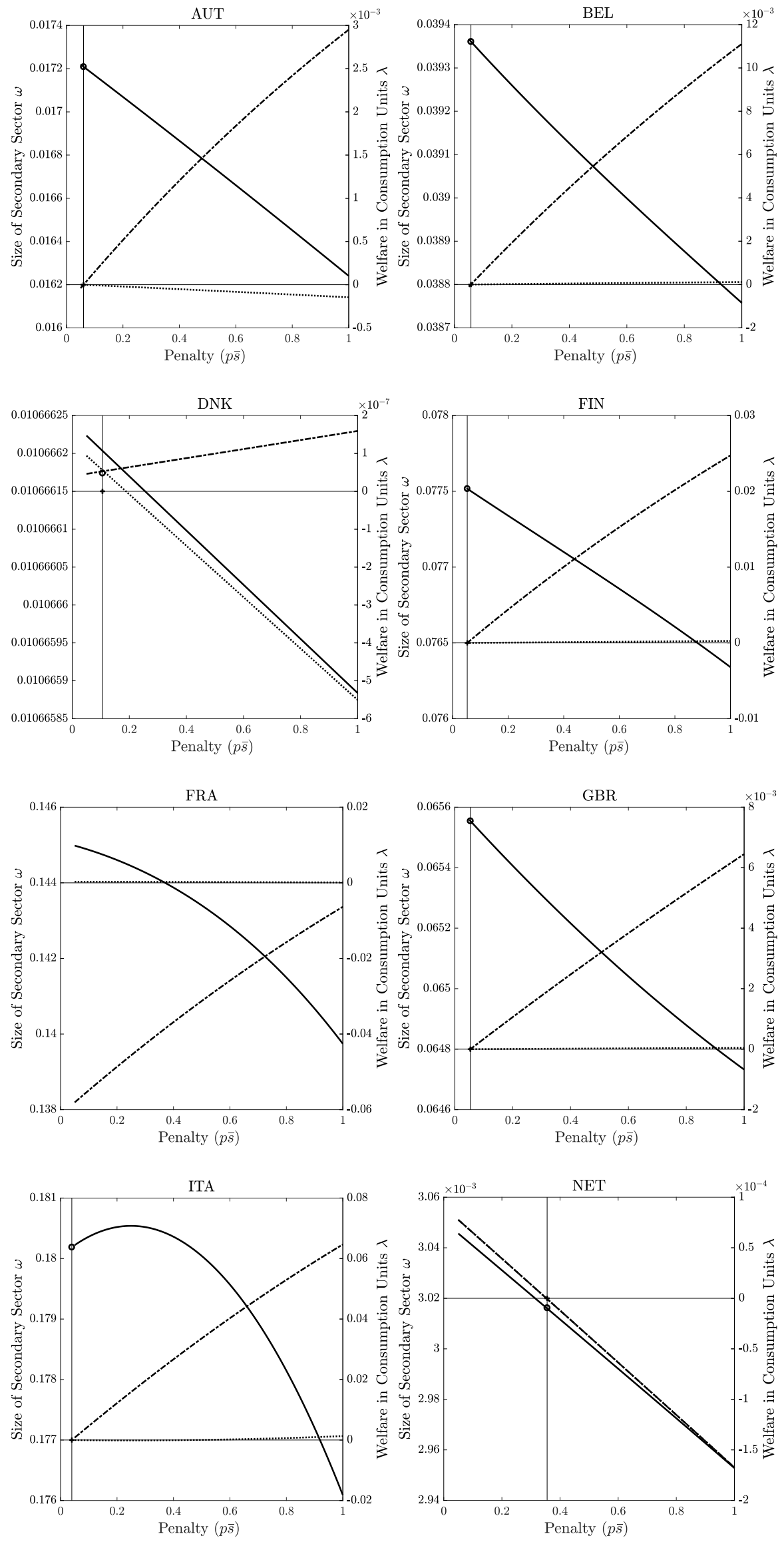
Figure A6: Optimal penalty - employment and welfare (cont.)
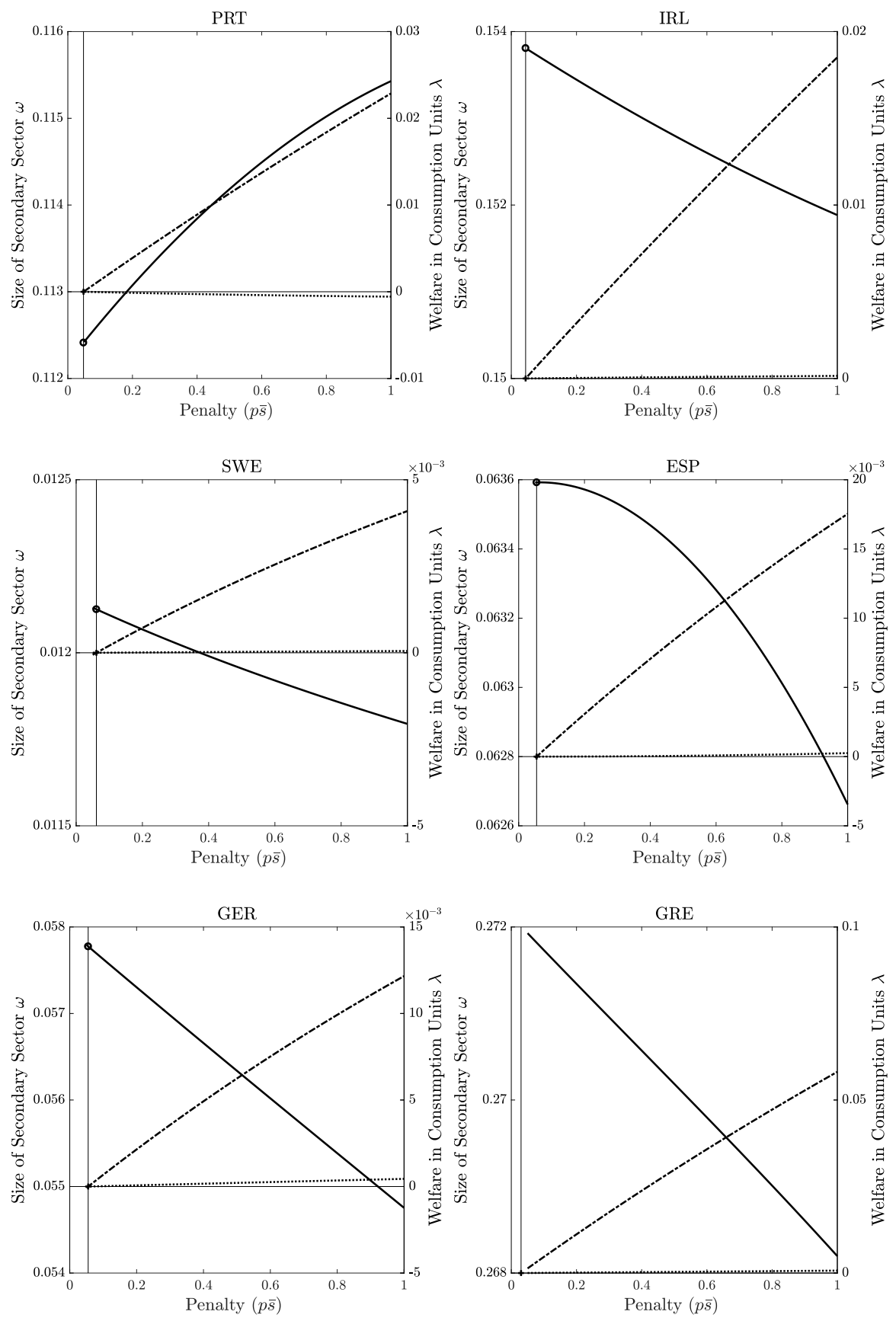
Figure A7: Transitions: avoidable and unavoidable tax mix
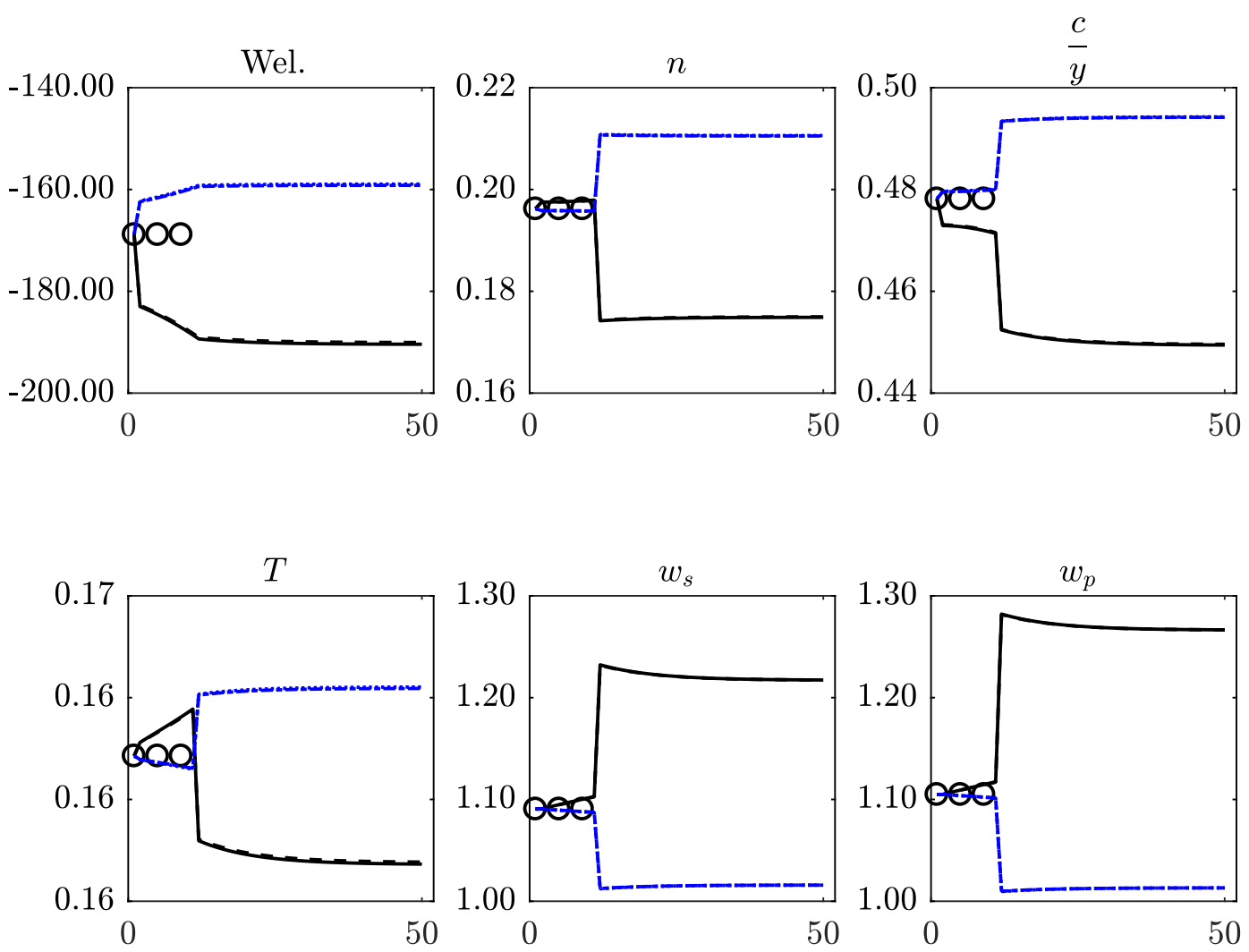

(a) Austria
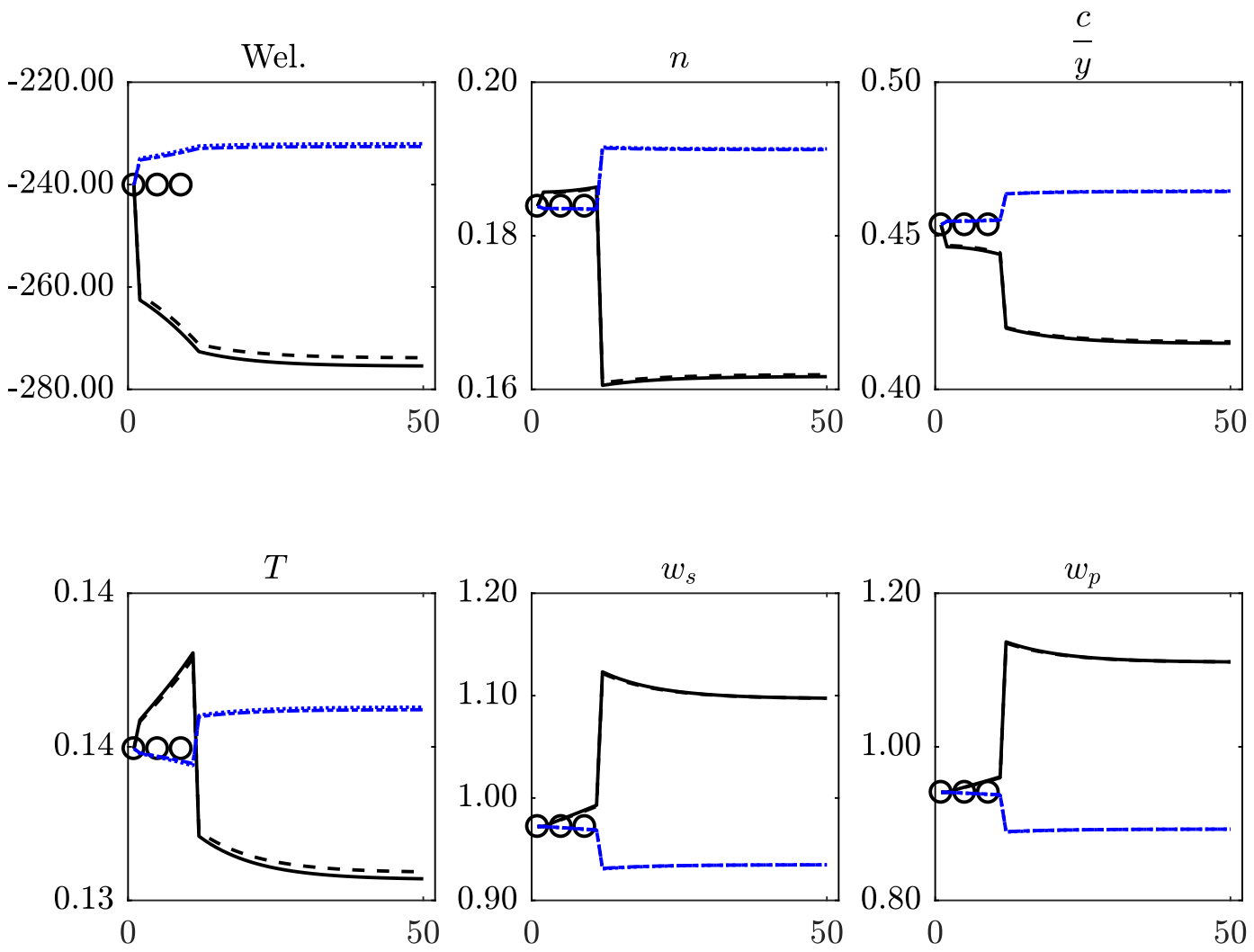

(b) Belgium 
Figure A7: Transitions: avoidable and unavoidable tax mix
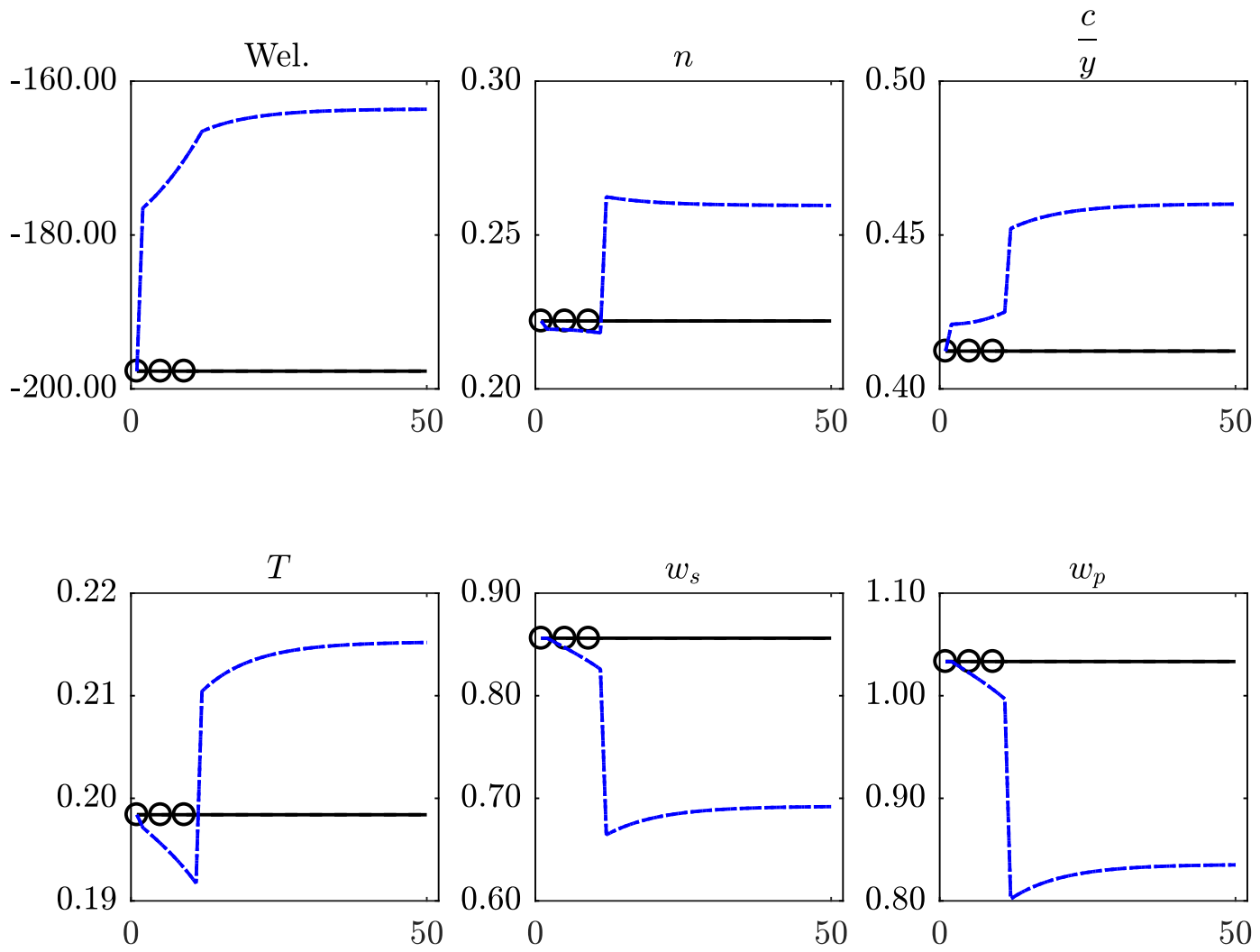

(c) Denmark
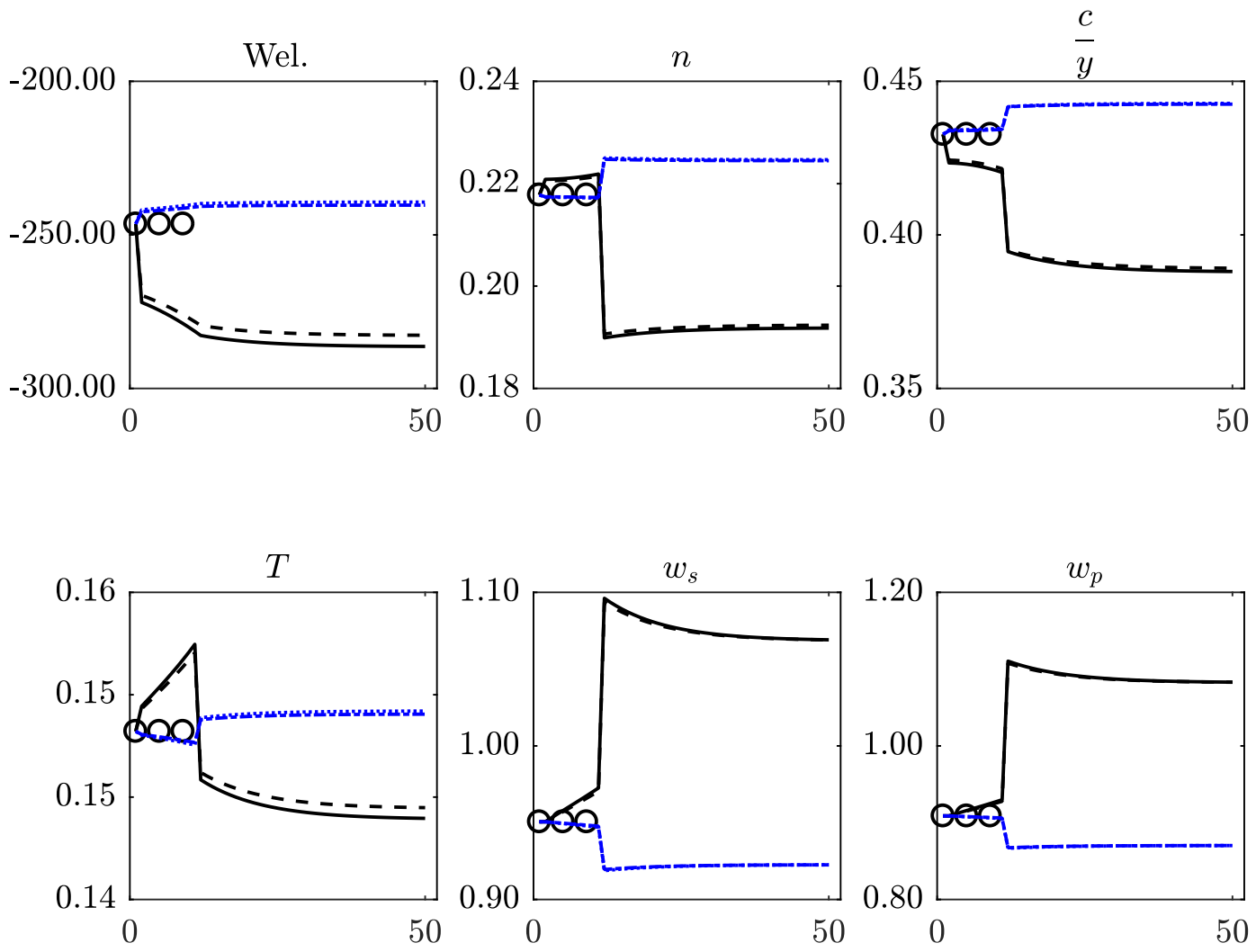

(d) Finland 
Figure A7: Transitions: avoidable and unavoidable tax mix
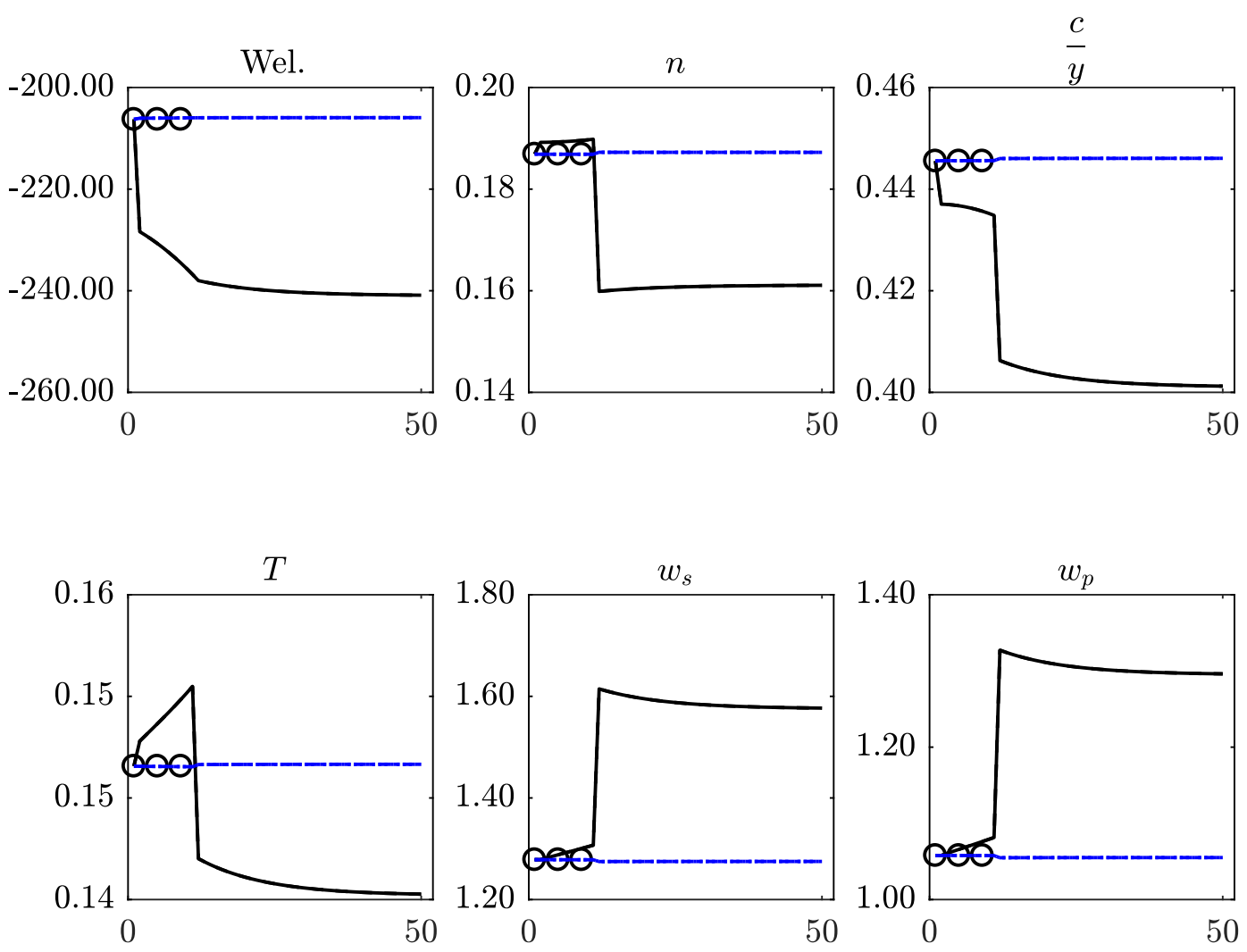

(e) France
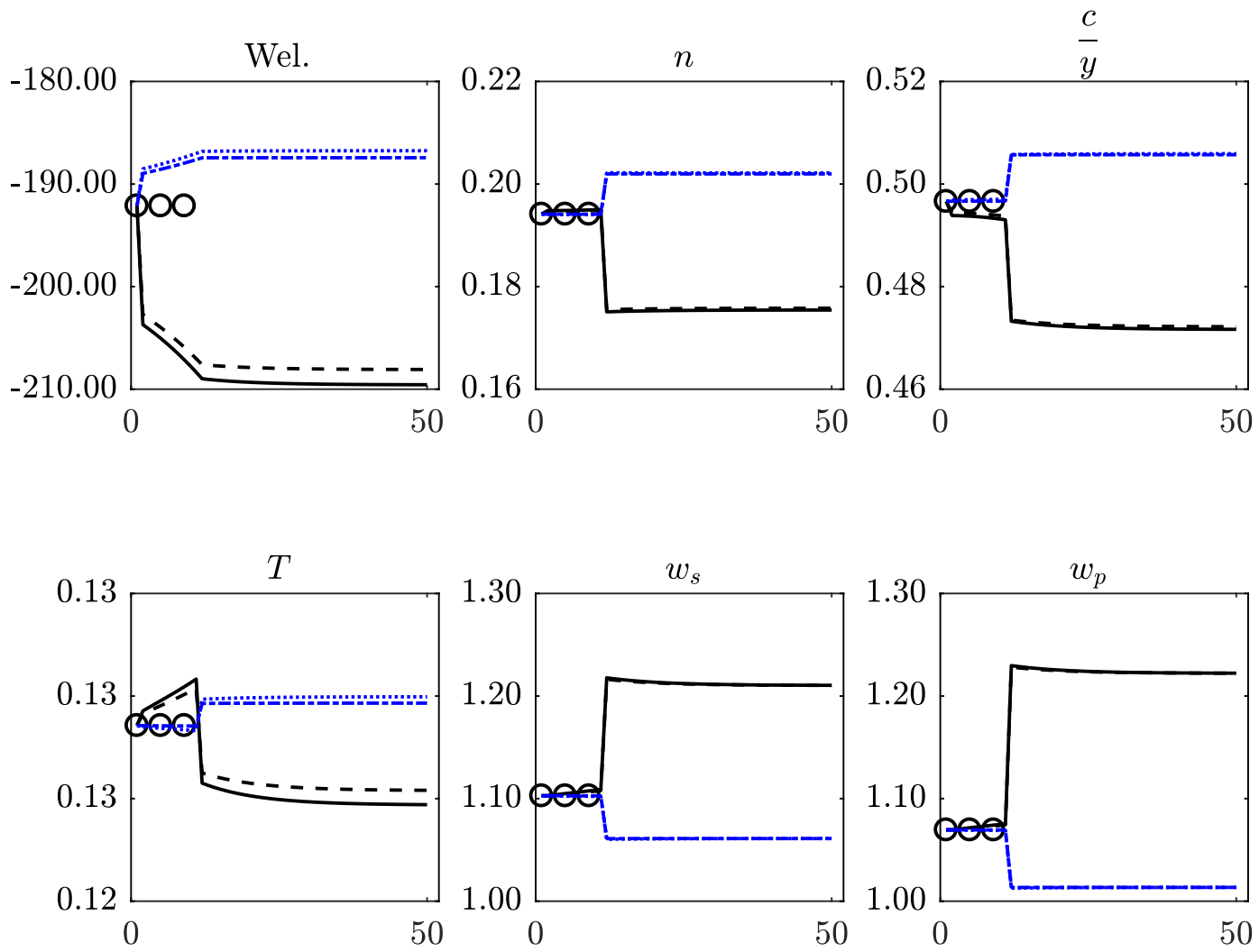

(f) Germany 
Figure A7: Transitions: avoidable and unavoidable tax mix
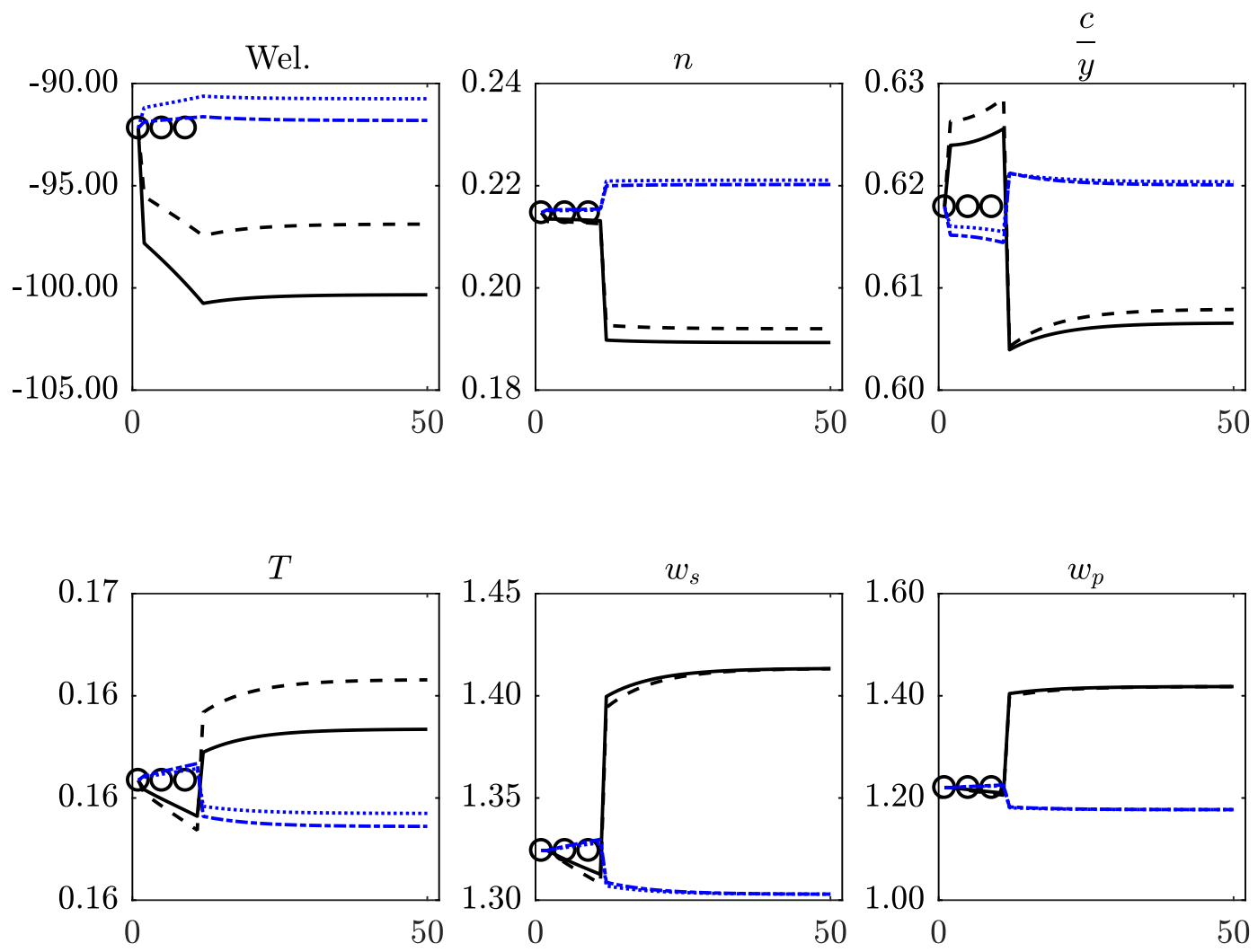

(g) Greece
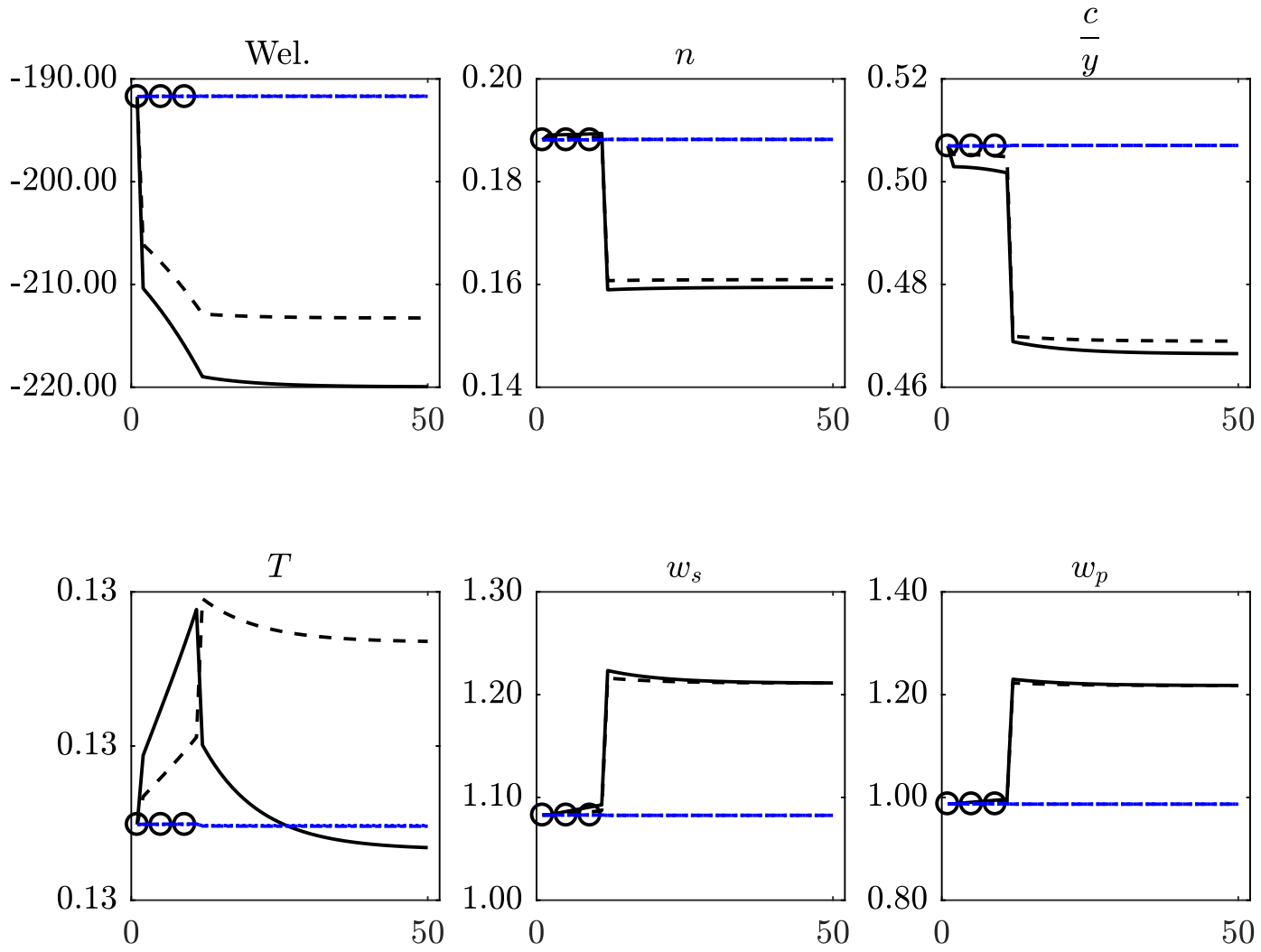

(h) Italy 
Figure A7: Transitions: avoidable and unavoidable tax mix
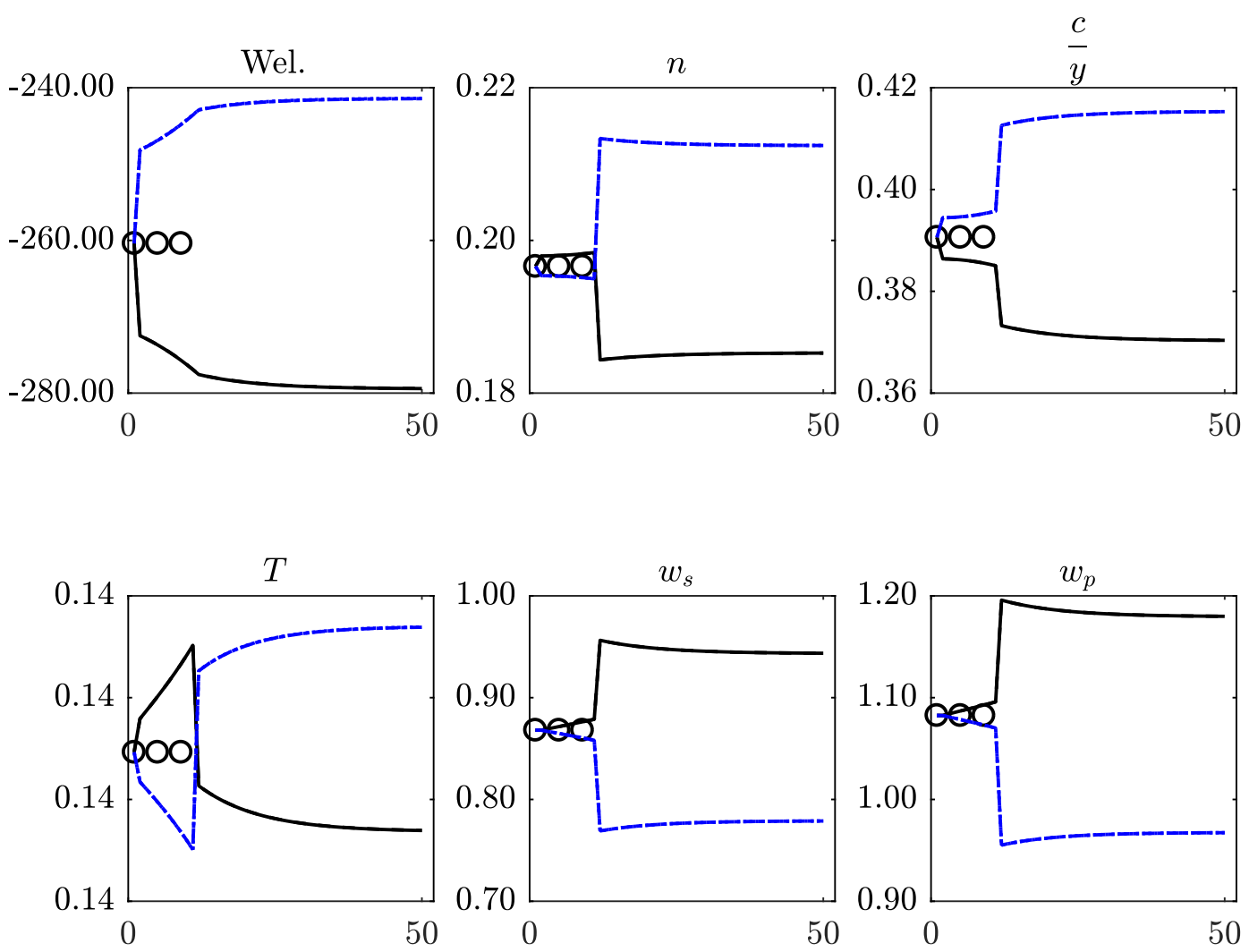

(i) Netherlands
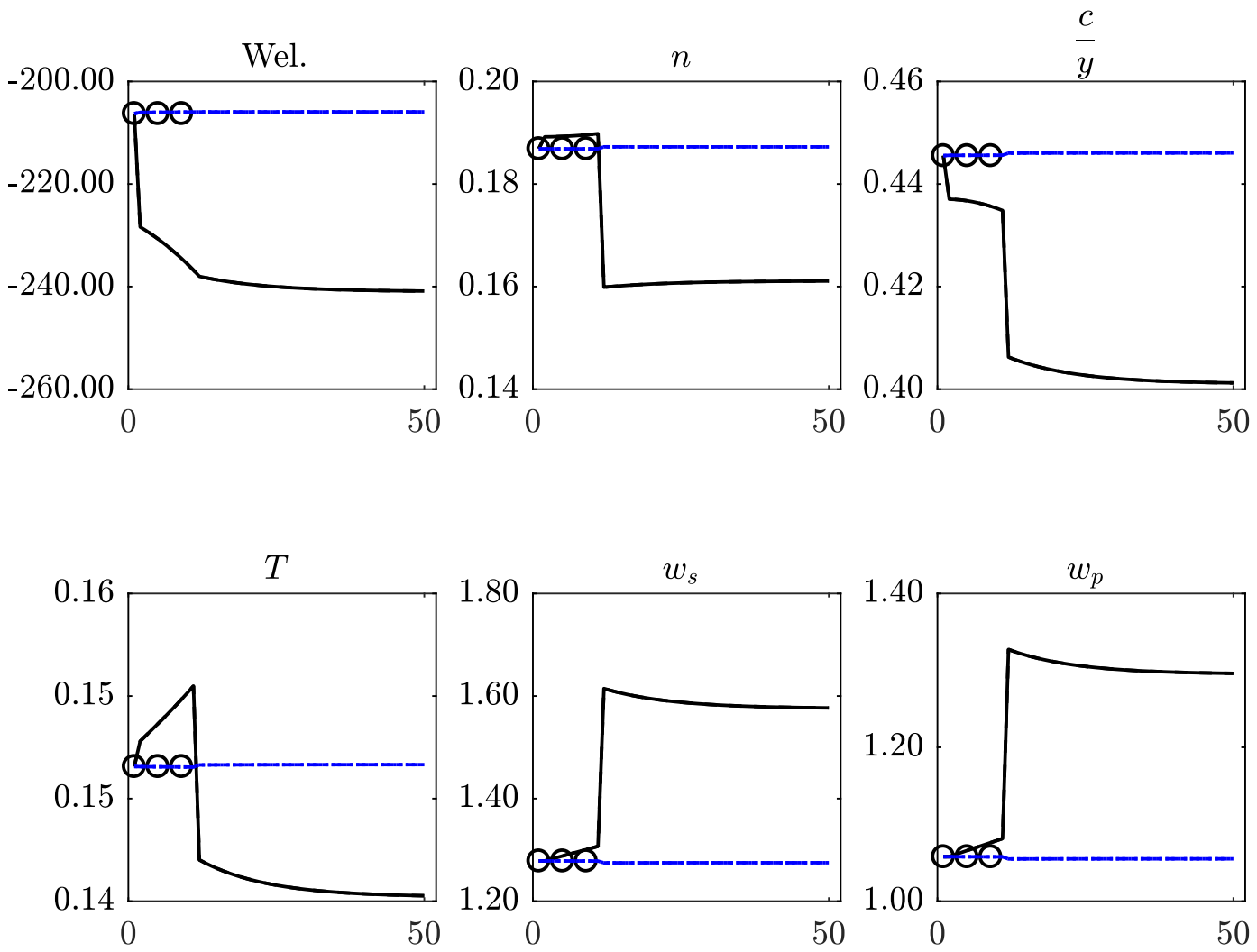

(j) UK 
Figure A7: Transitions: avoidable and unavoidable tax mix
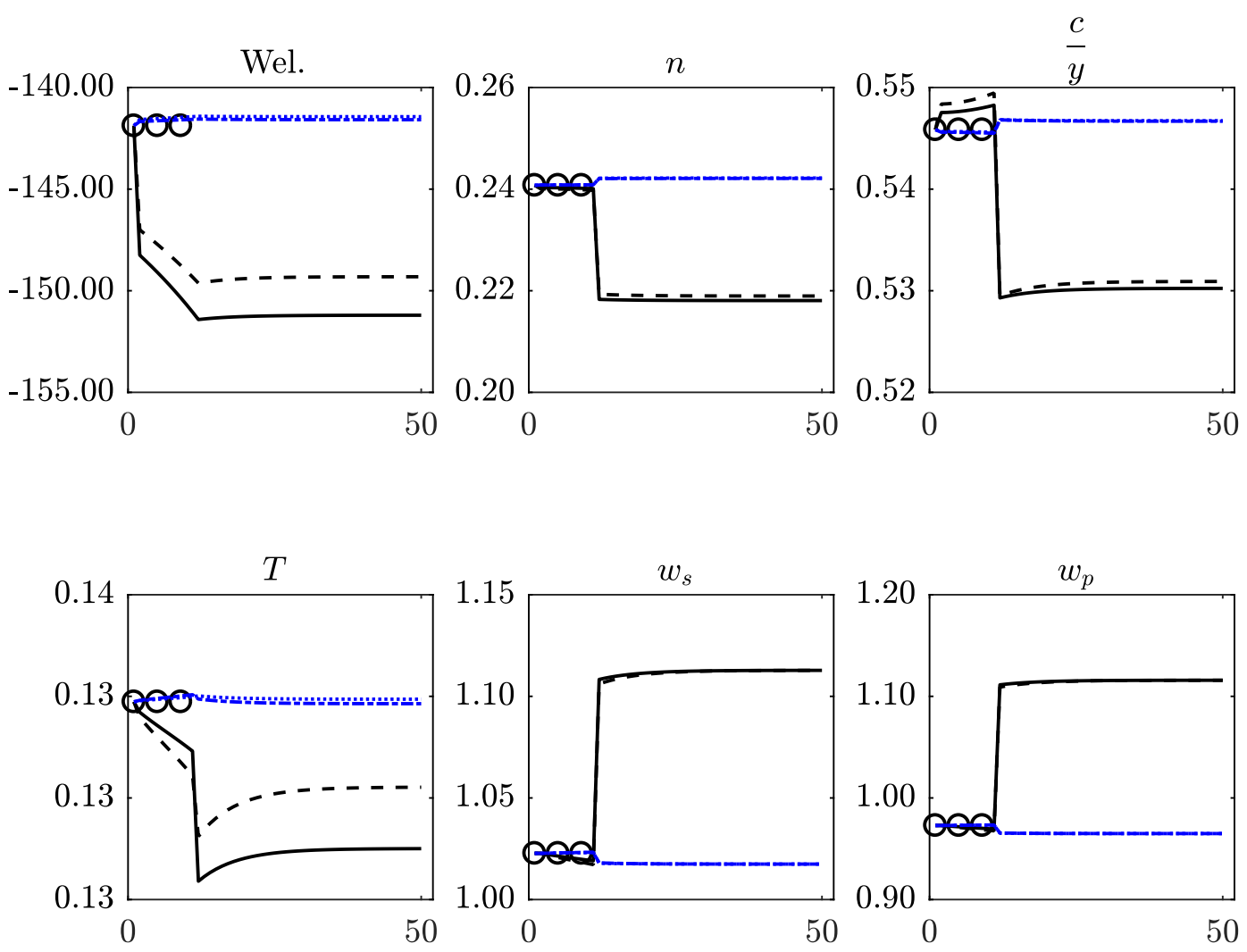

(k) Portugal
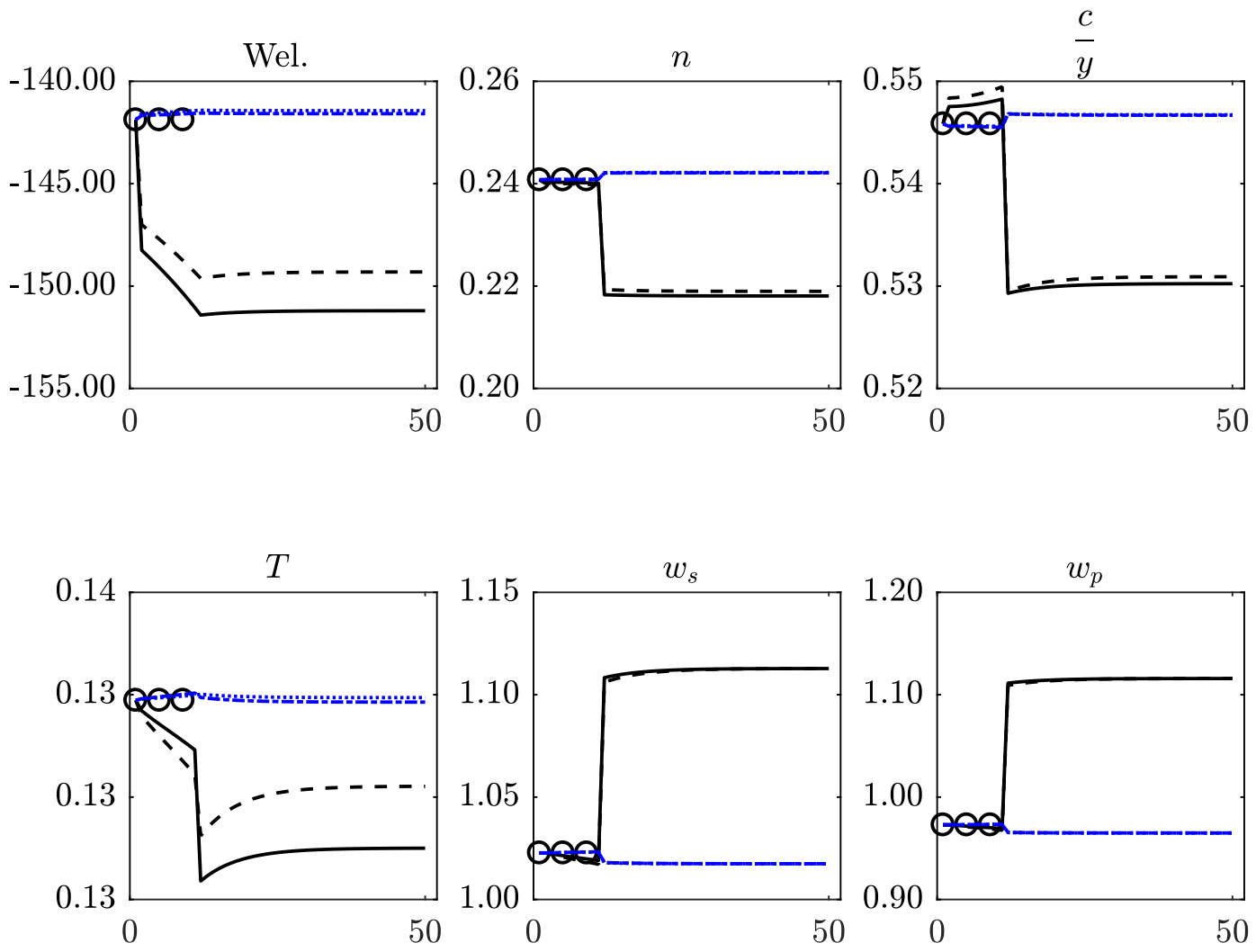

(1) Ireland 
Figure A7: Transitions: avoidable and unavoidable tax mix
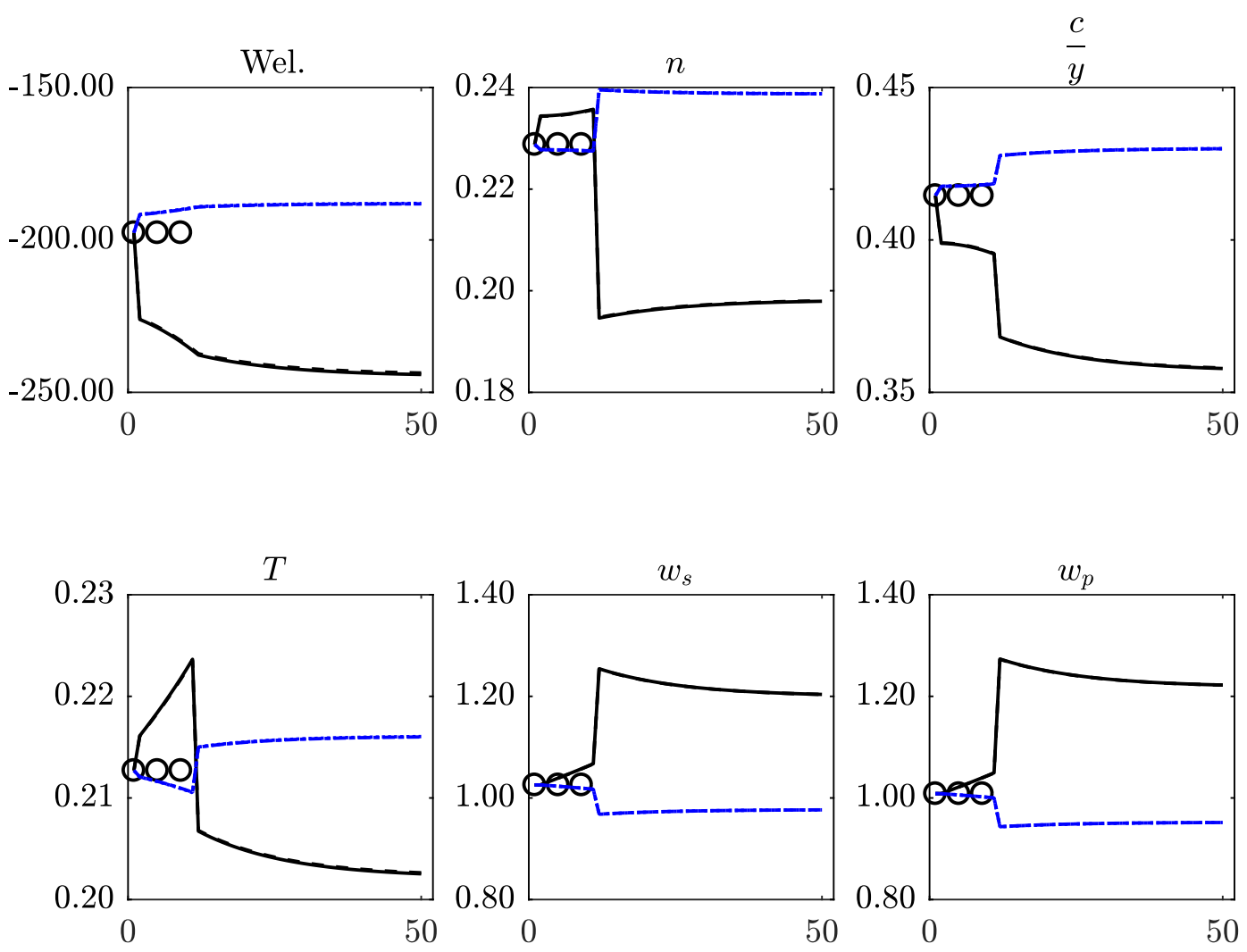

(m) Sweden
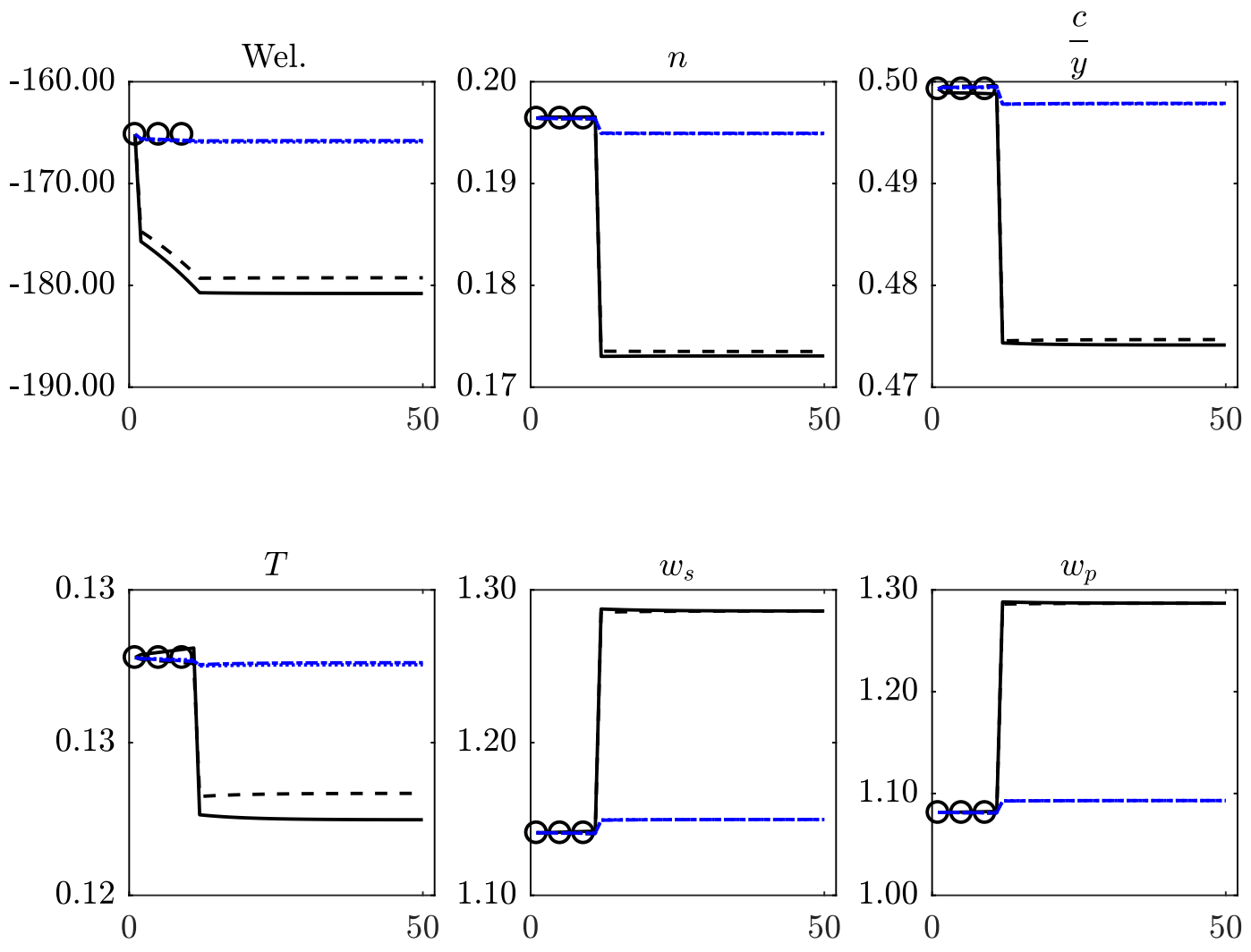

(n) Spain 
Figure A8: Transitions Penalty
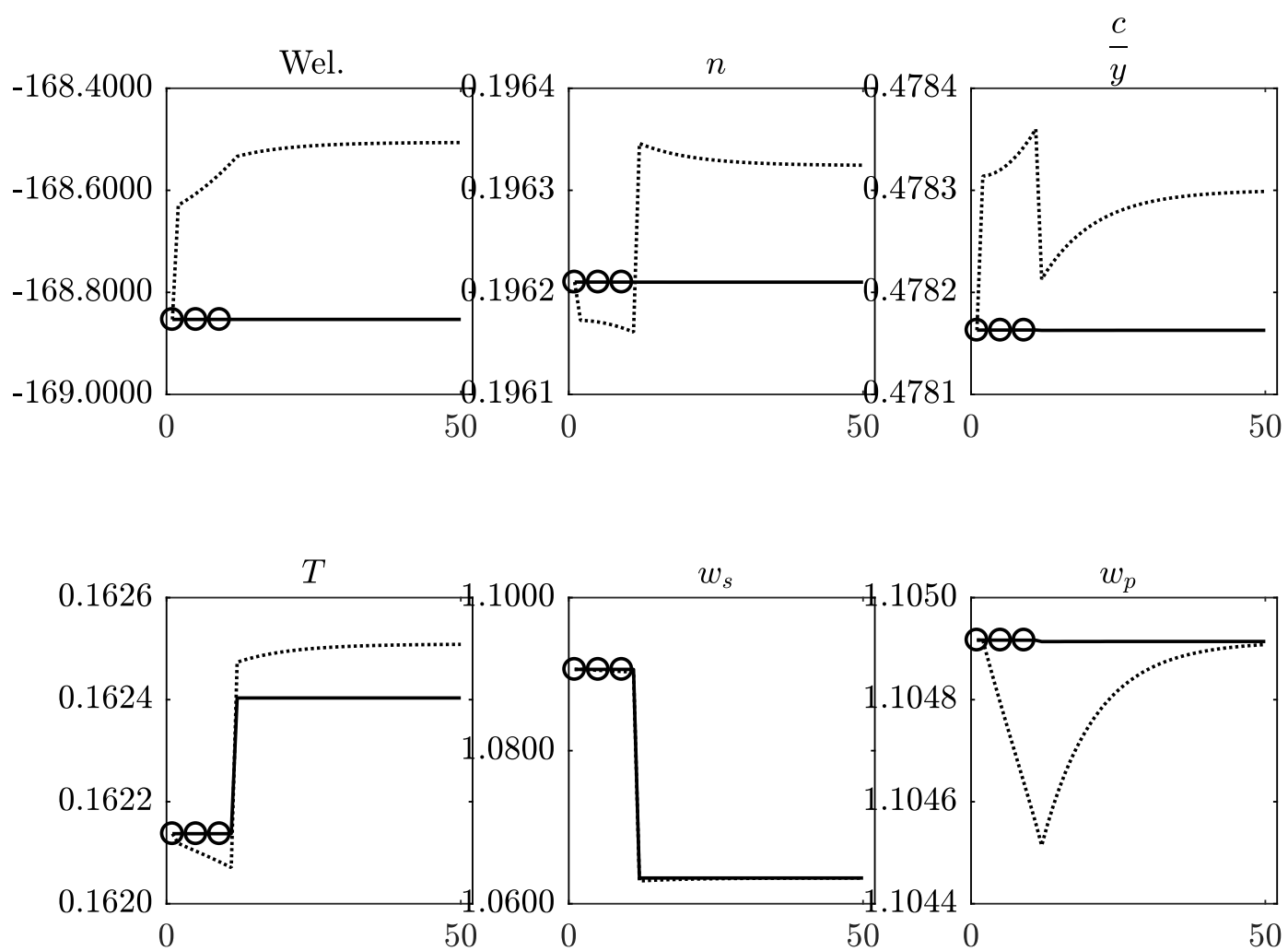

(a) Austria
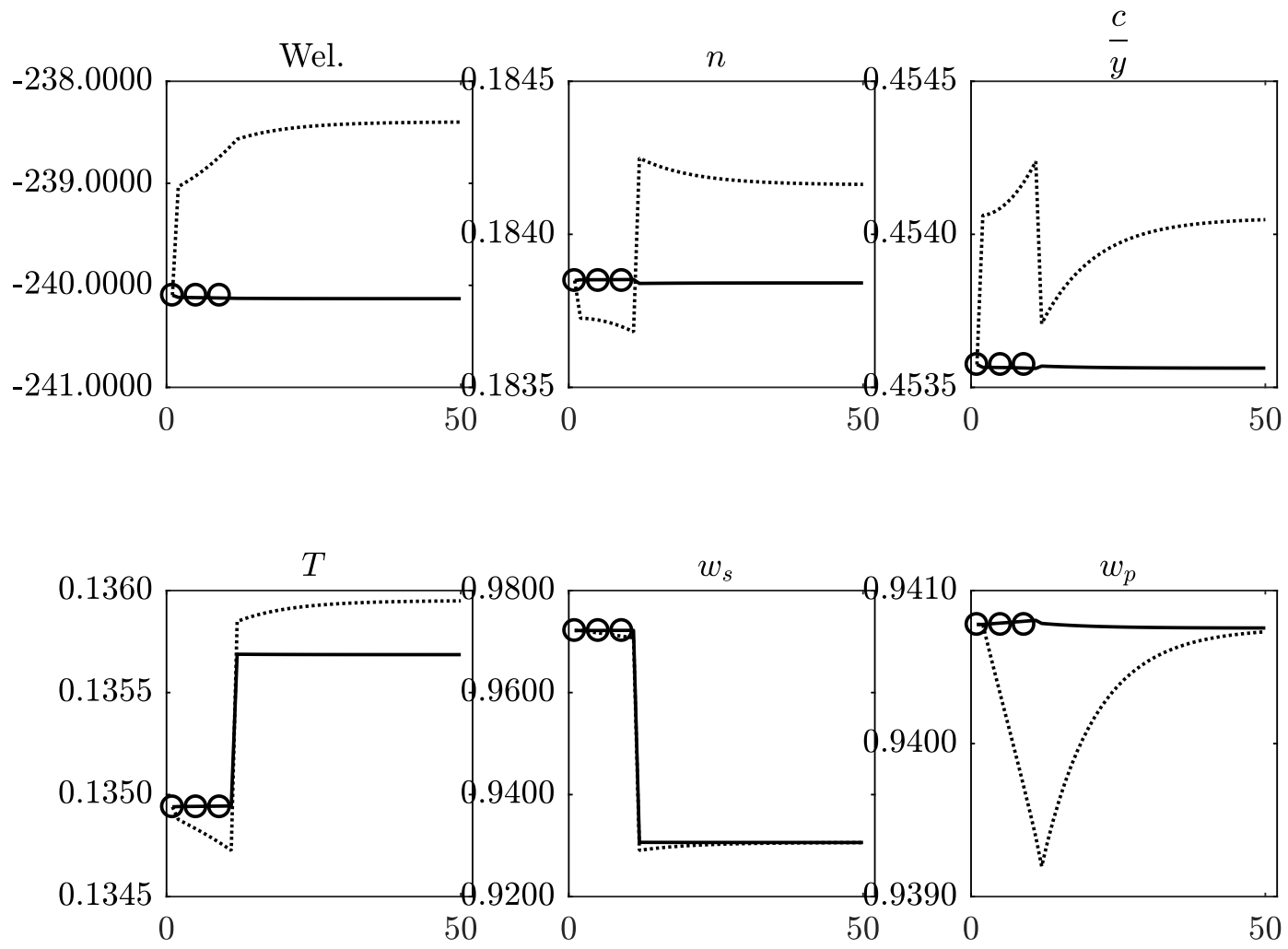

(b) Belgium 
Figure A9: Transitions: penalty
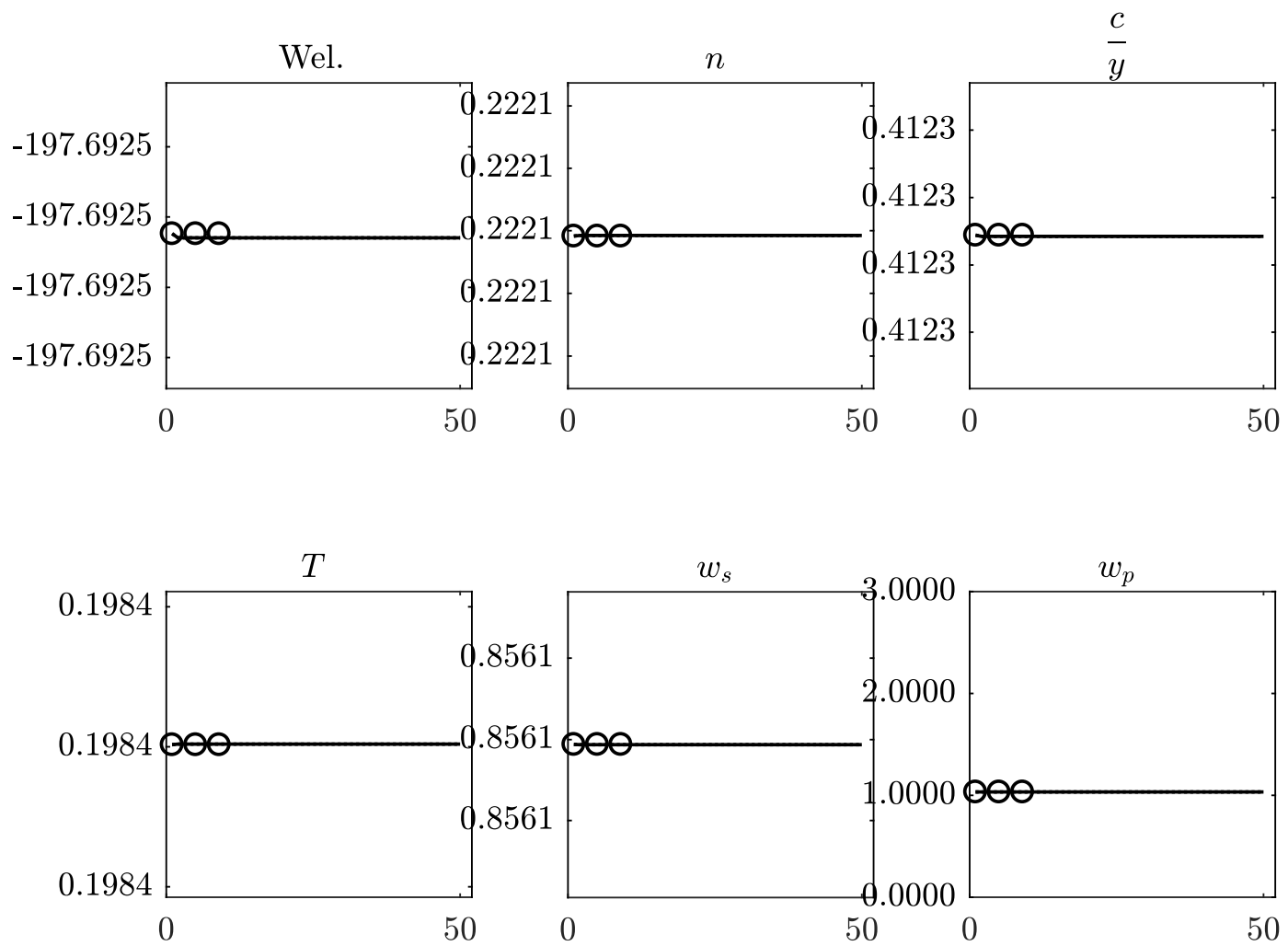

(a) Denmark
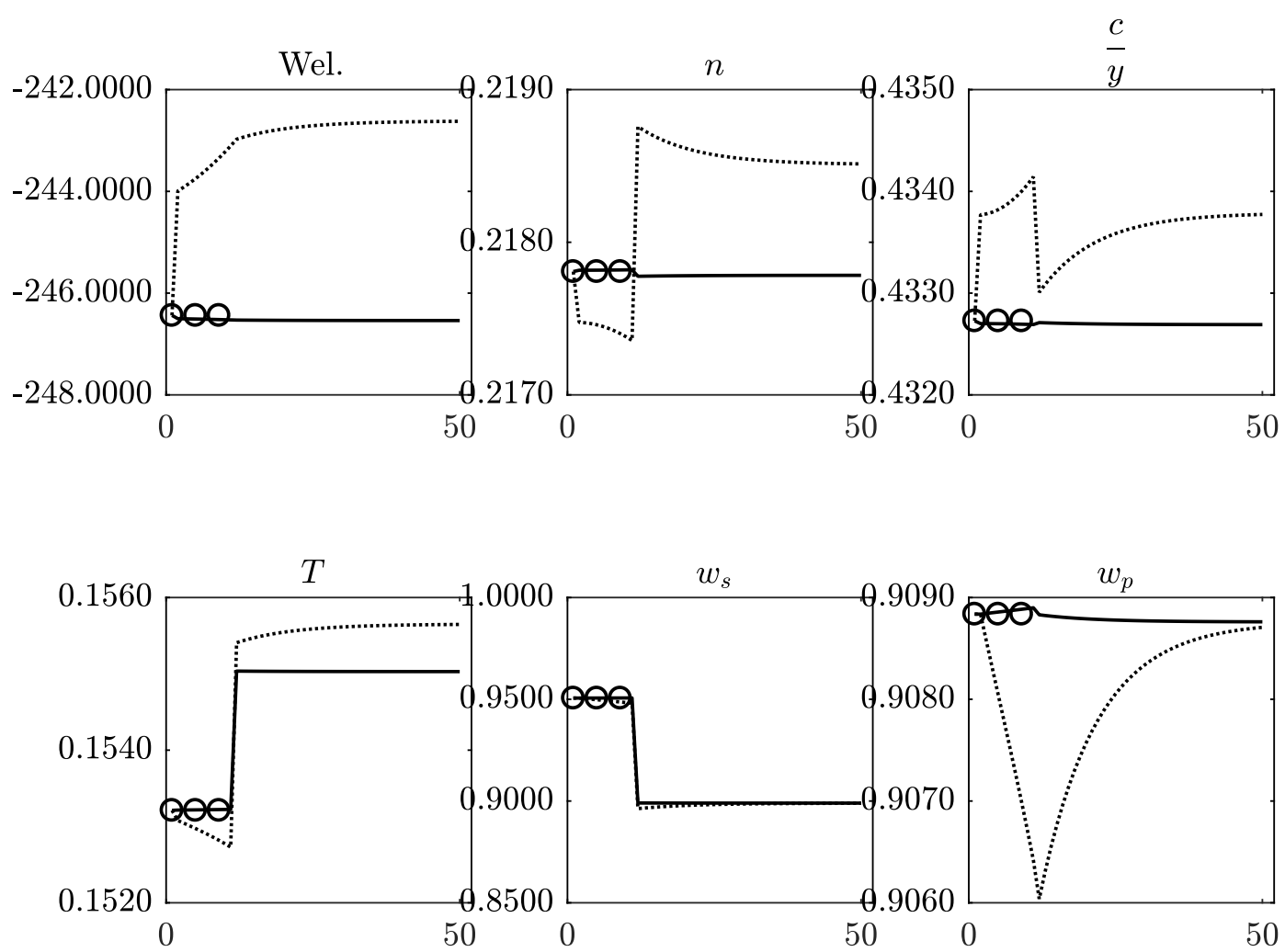

(b) Finland 
Figure A10: Transitions: penalty
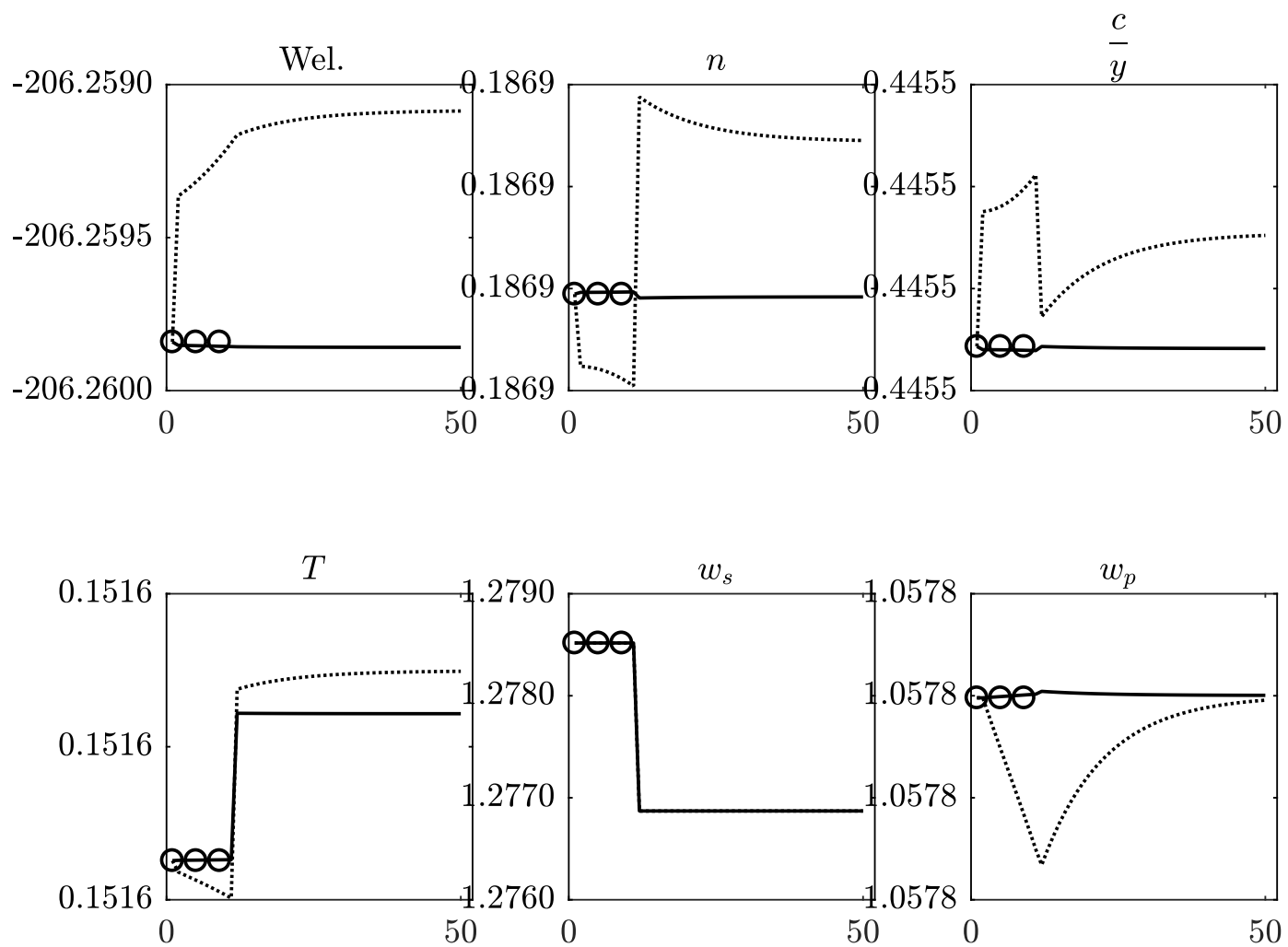

(a) France
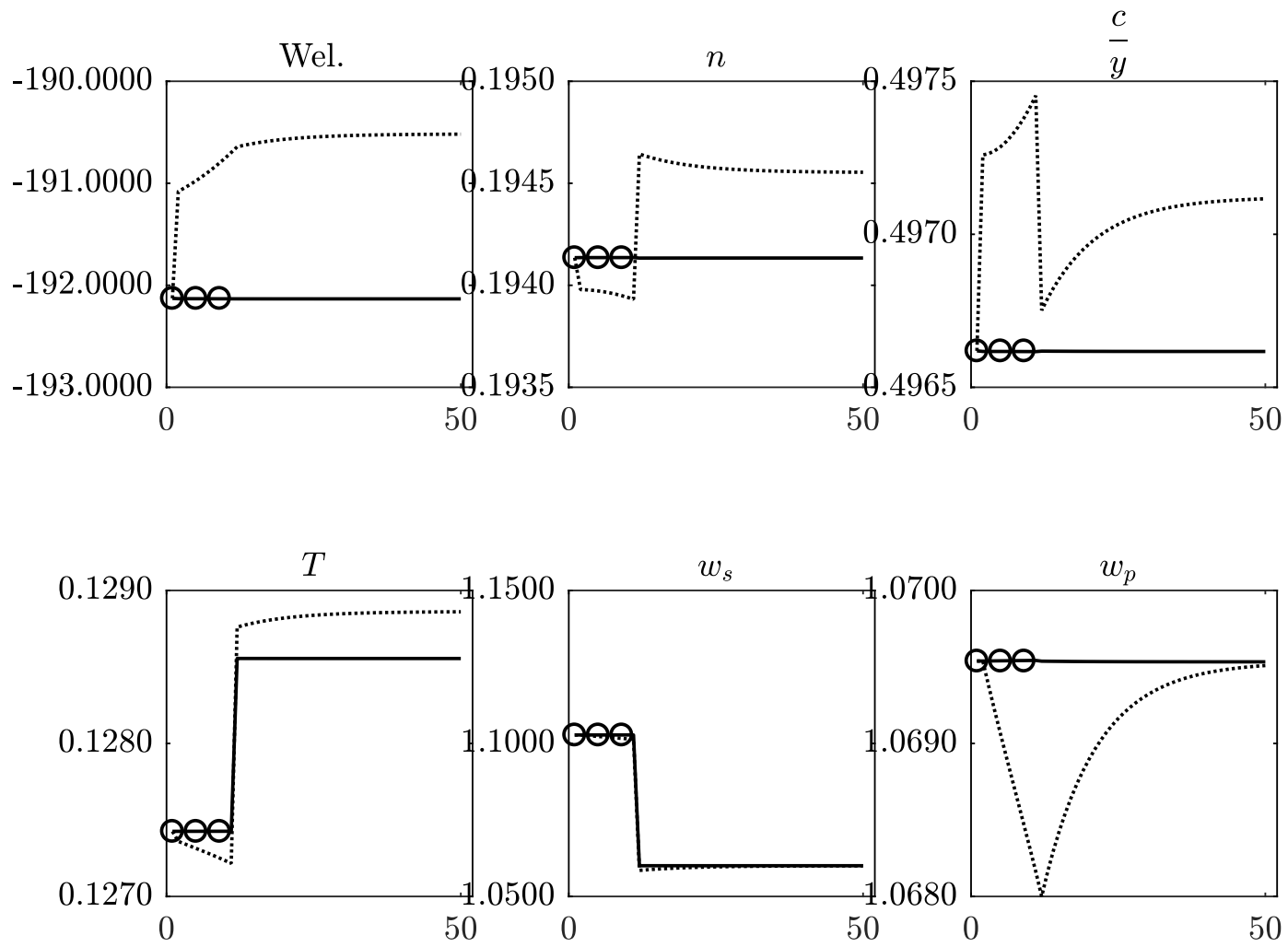

(b) Germany 
Figure A11: Transitions: penalty
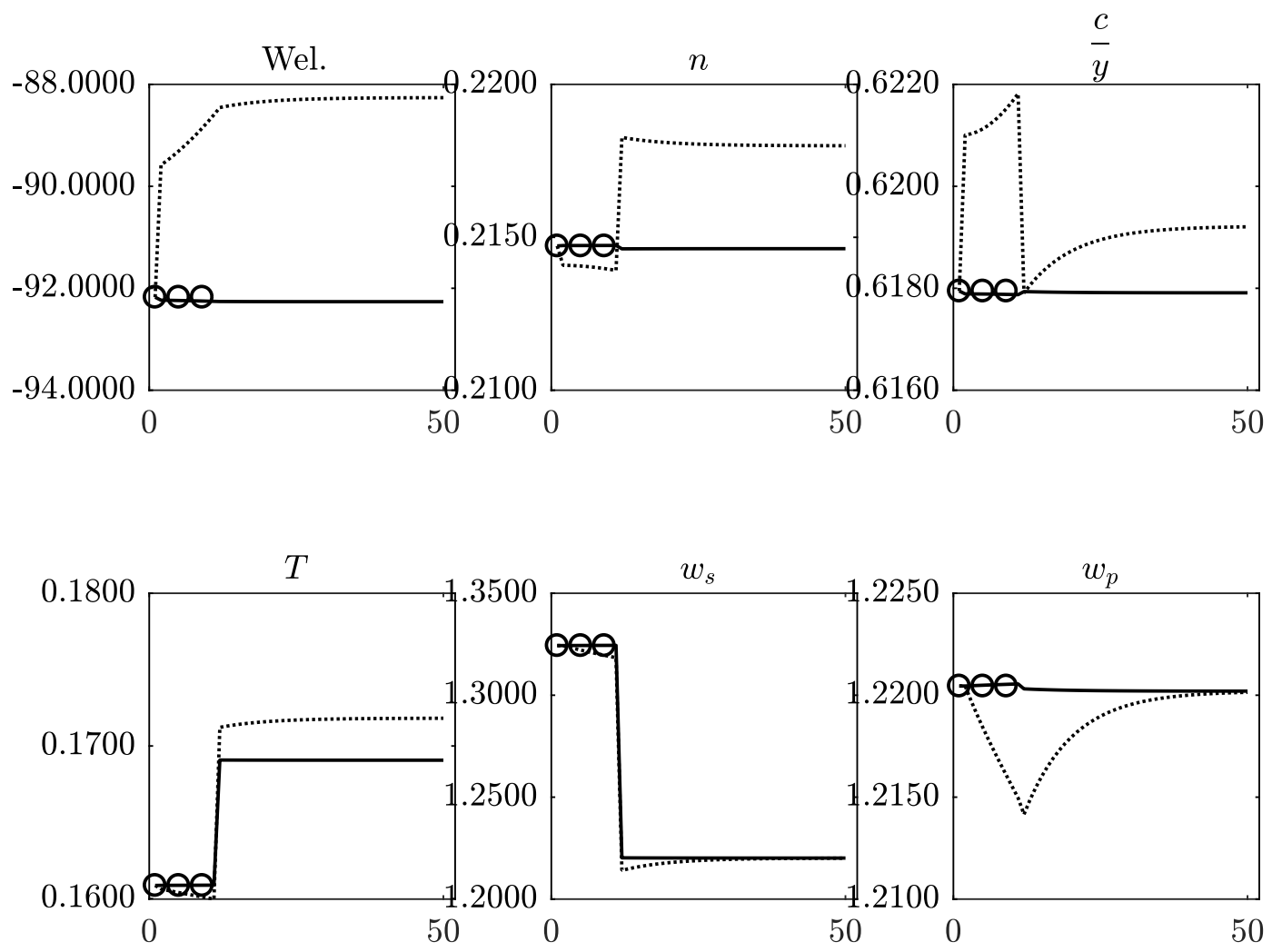

(a) Greece
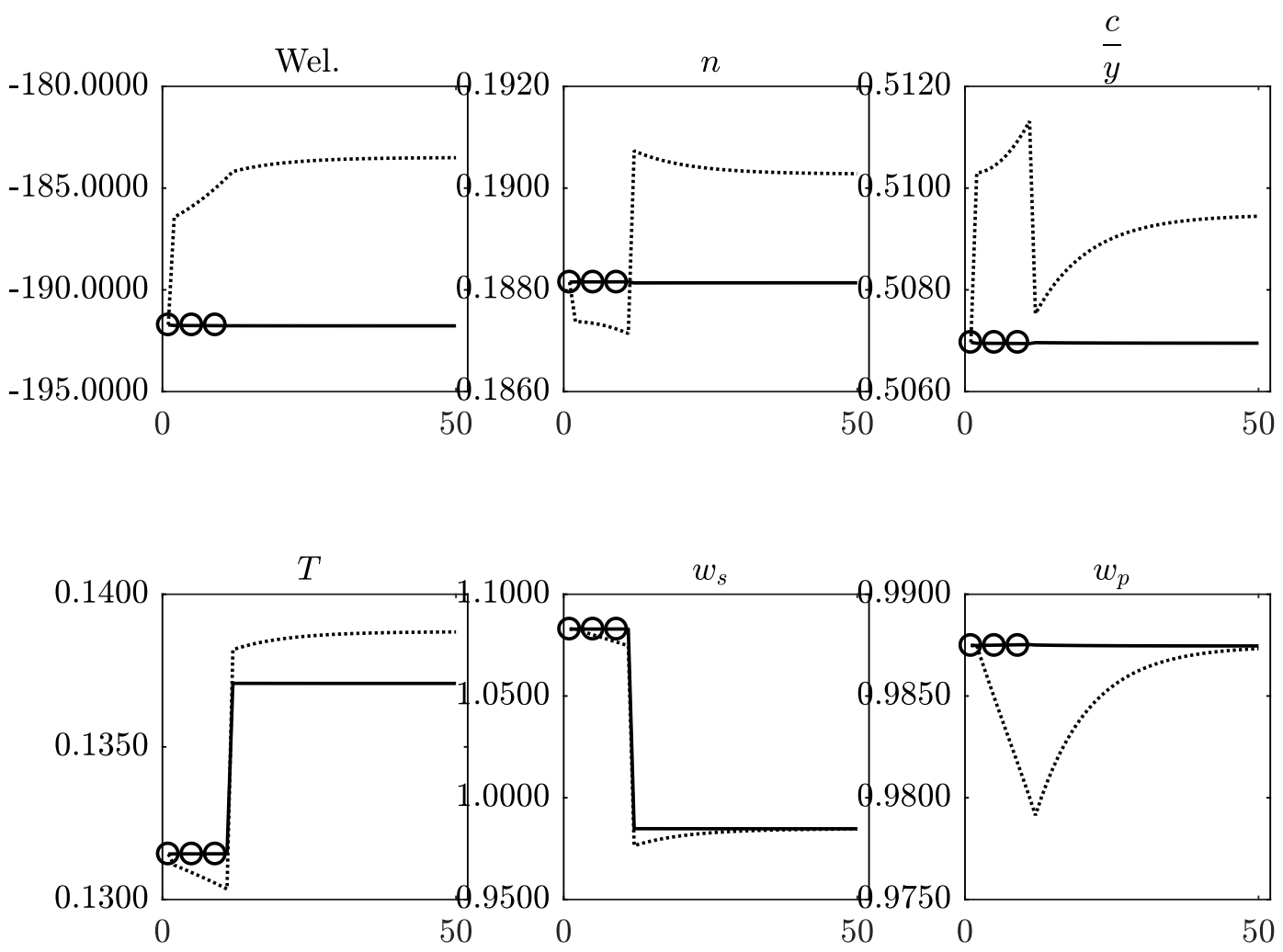

(b) Italy 
Figure A12: Transitions: penalty
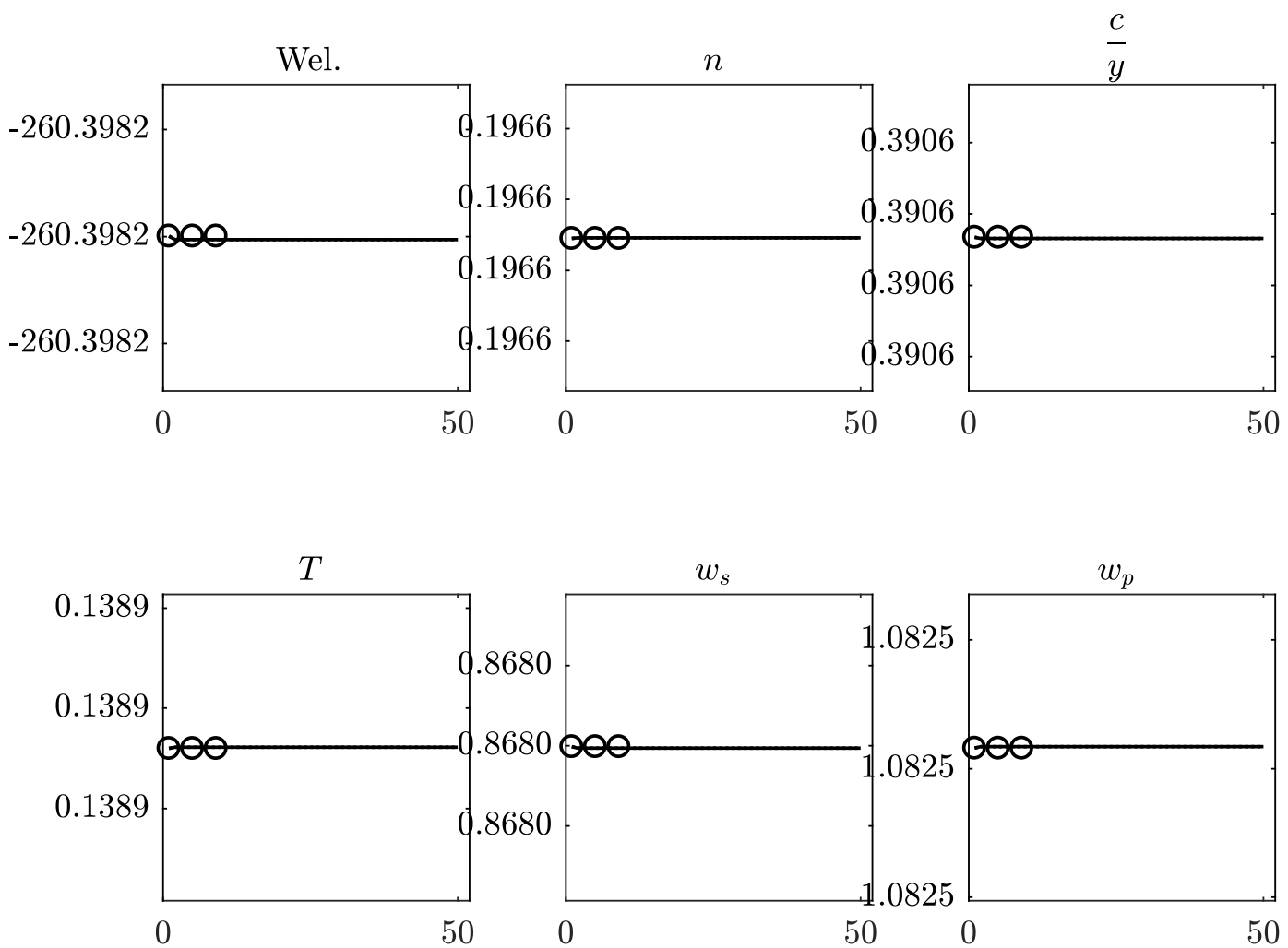

(a) Netherlands
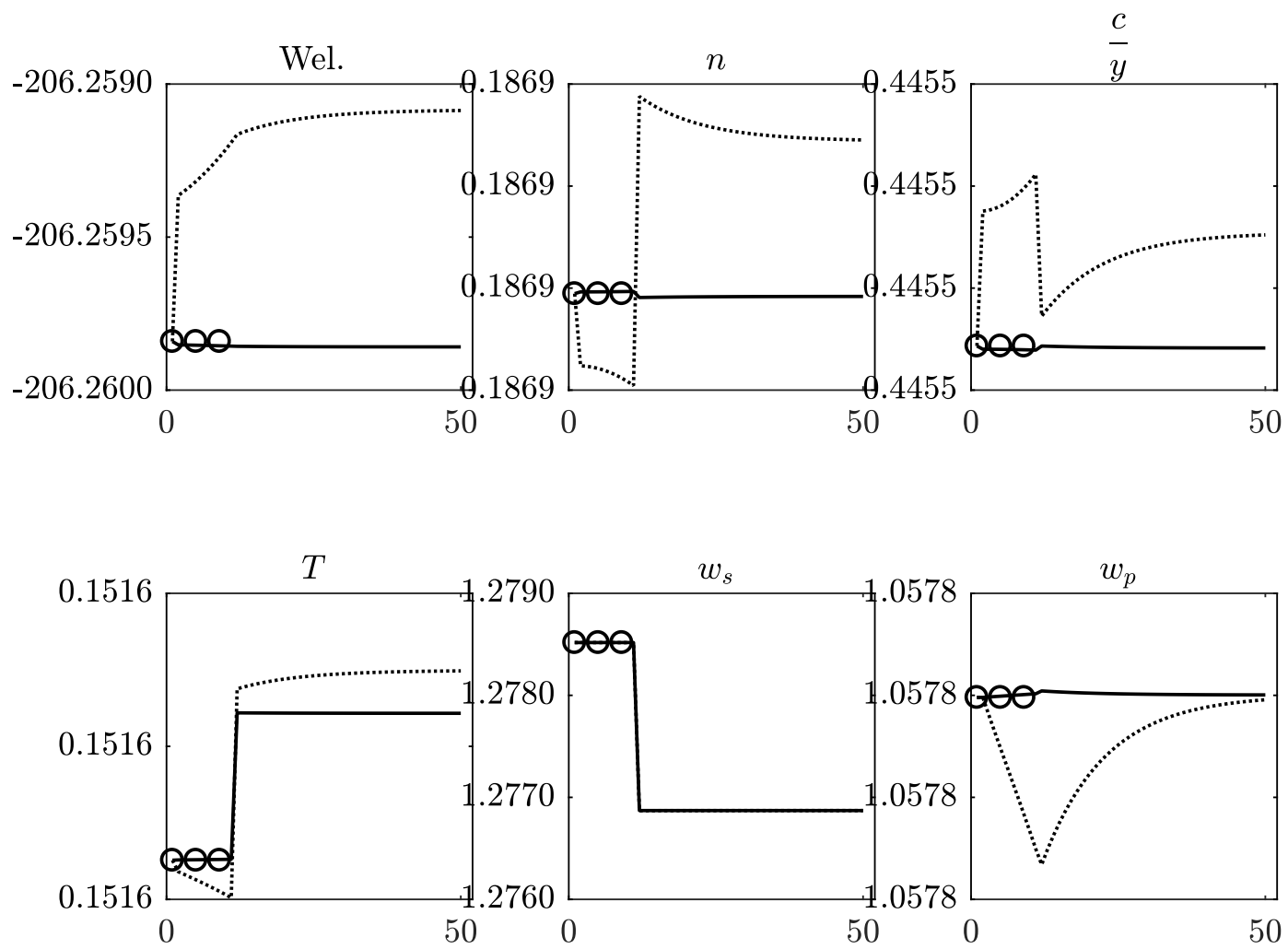

(b) UK 
Figure A12: Transitions: penalty
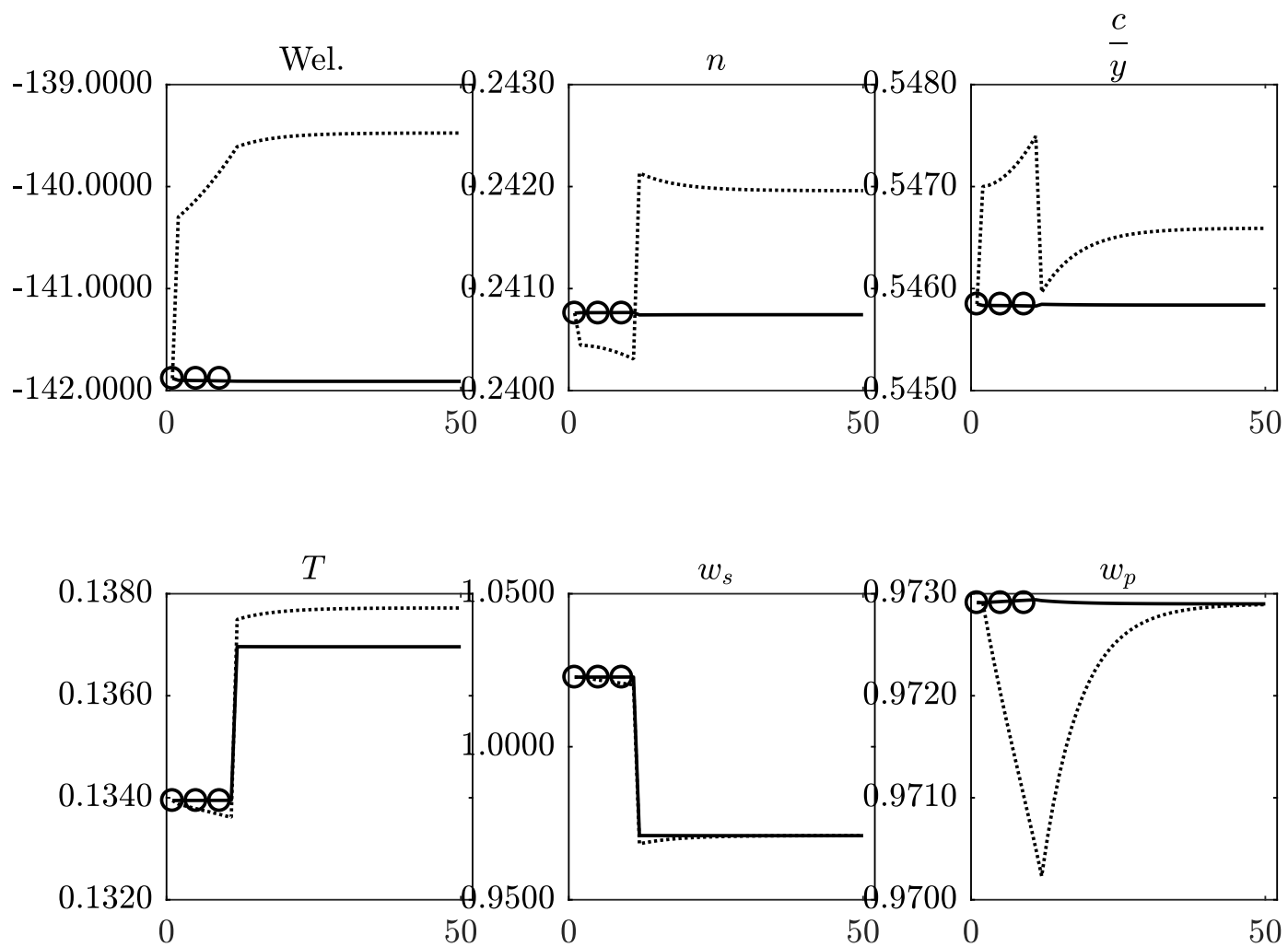

(c) Portugal
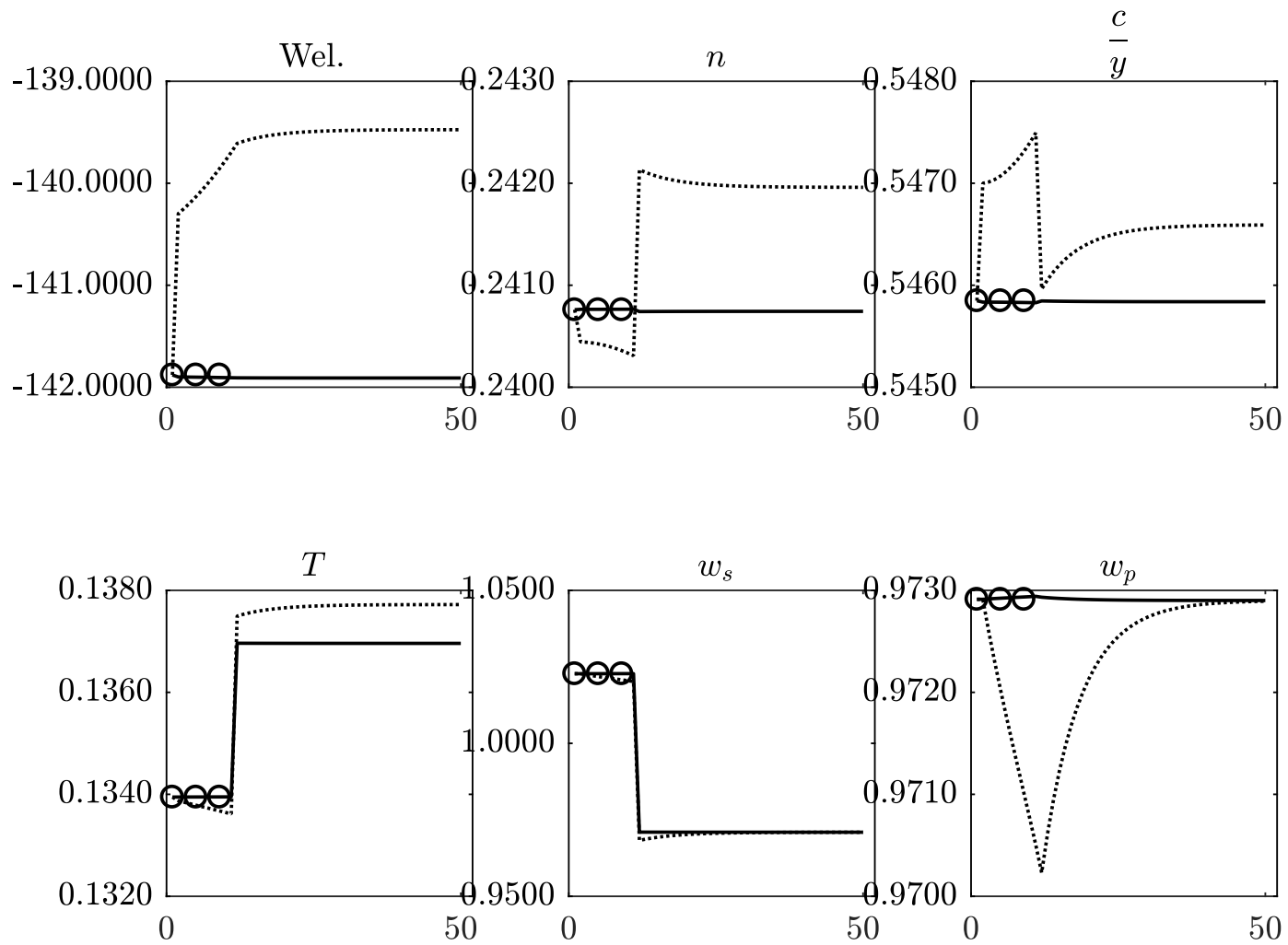

(d) Ireland 
Figure A12: Transitions: penalty
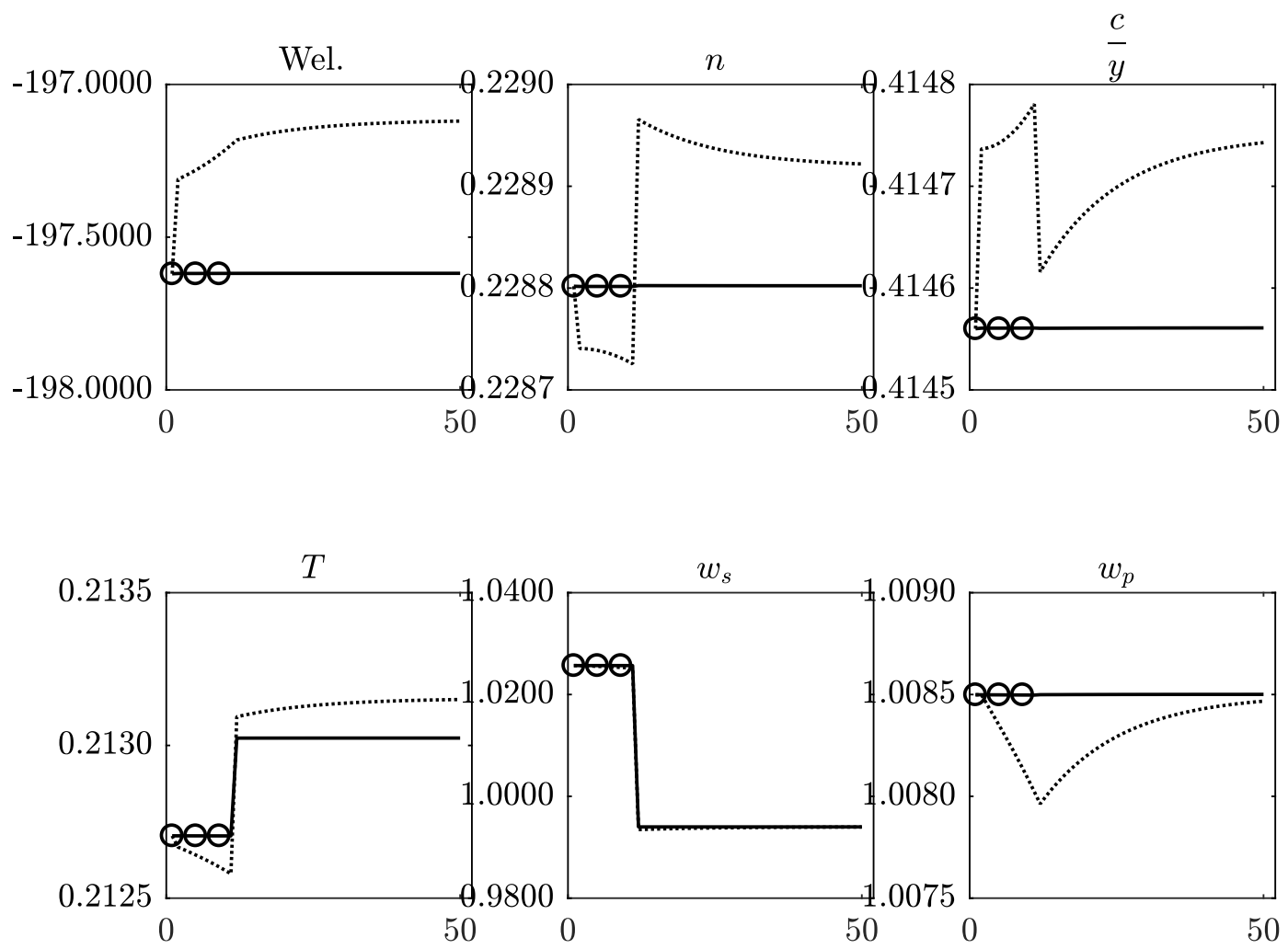

(e) Sweden
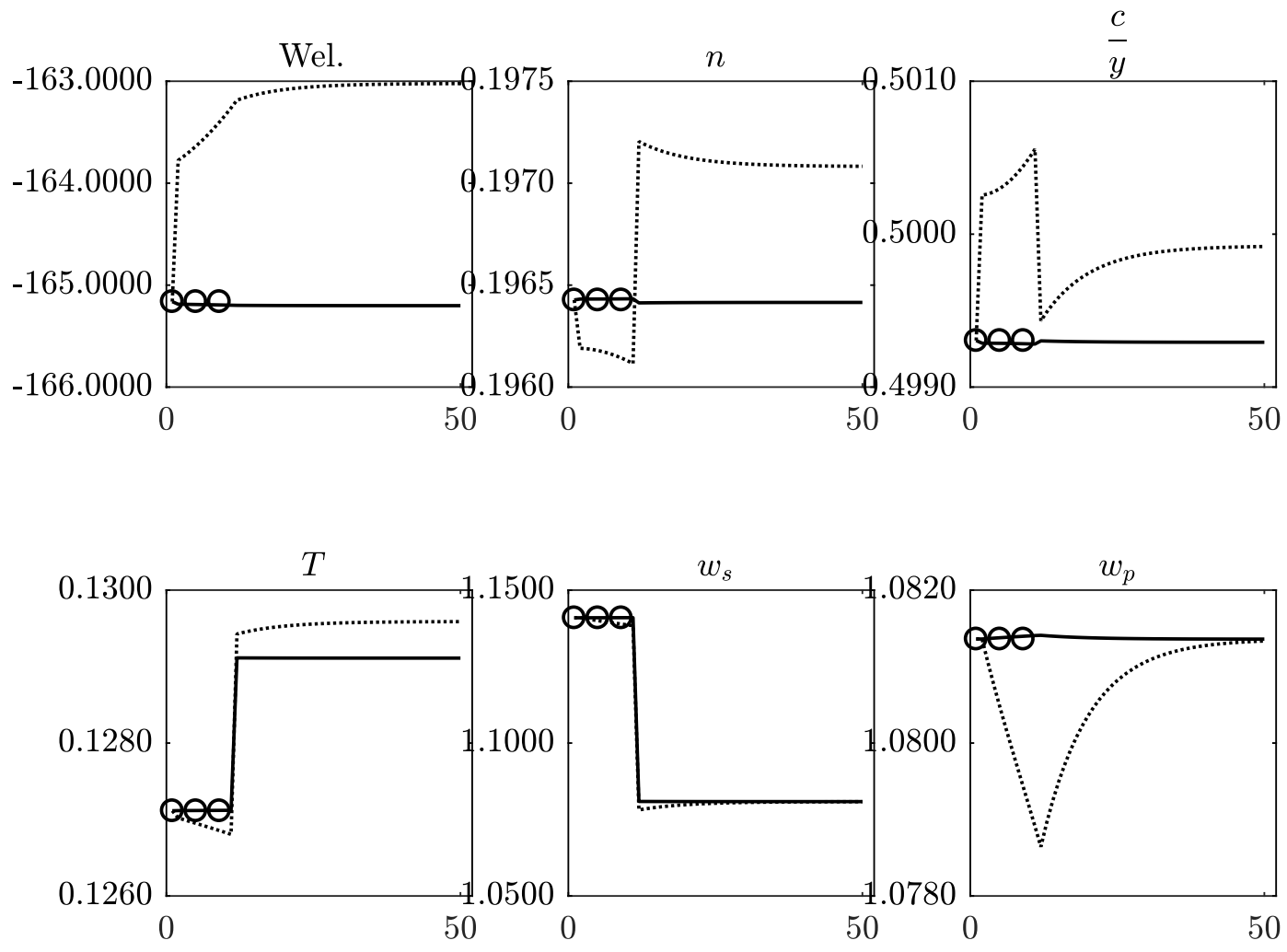

(f) Spain 